http://dx.doi.org/10.11646/zootaxa.3652.1.4

http://zoobank.org/urn:lsid:zoobank.org:pub:10861BBC-FDF6-4520-837C-D4E38AB324D3

\title{
Phylogenetic relationships of Culex (Culex) species (Diptera, Culicidae) from Argentina based on morphological characters
}

\author{
MAGDALENA LAURITO ${ }^{1} \&$ WALTER R. ALMIRÓN \\ Instituto de Investigaciones Biológicas y Tecnológicas (IIByT-CONICET). Centro de Investigaciones Entomológicas de Córdoba, Fac- \\ ultad de Ciencias Exactas, Físicas y Naturales, Universidad Nacional de Córdoba, ARGENTINA \\ ${ }^{1}$ Corresponding author. E-mail: mlaurito@ conicet.gov.ar
}

\begin{abstract}
The purpose of this study was for the first time to establish phylogenetic hypotheses among Culex (Culex) species from Argentina, and to evaluate the relationships of this subgenus with subgenera Phenacomyia and Phytotelmatomyia. We employed maximum parsimony to analyse morphological characters derived from the morphology of the adult, pupal and larval stages. More than 30 figures, including photographs, illustrating 87 characters are provided. The cladistic analysis of 61 terminal taxa and 95 characters was undertaken, under implied weighting method, with a range of $K$ values from 6 to 9. Three unstable taxa were detected therefore a reduced strict consensus tree was created. The subgenus $C u l e x$ appears polyphyletic relative to subgenus Oculeomyia. The internal classification of subgenus Culex is shown to be chaotic; the Pipiens Group is polyphyletic relative to the Sitiens and Coronator Groups, the latter being polyphyletic with respect to the Pipiens Group. Phylogenetic analysis combining characters provided by morphology and molecular sources are needed to interpret more fully the relationships in the group.
\end{abstract}

Key words: Phylogeny, mosquitoes, cladistic, morphological features

\section{Introduction}

The genus Culex L. comprises species of medical and veterinary importance, including vectors of filarias and arboviruses. Culicini contains 795 species grouped in four genera: Deinocerites Theobald, Galindomyia Stone \& Barreto, Lutzia Theobald and Culex (Harbach 2011a). Culex, with 26 subgenera and seven unplaced species (Harbach 2011a), includes many polymorphic features and exceptional forms (Harbach 2007). Its present subgeneric classification is based on external characters of the adult, especially features of the male genitalia (Harbach 2011b). The cosmopolitan subgenus Culex comprises 198 species (Harbach 2011a) in six species groups; the Neotropical species are in the Coronator and Pipiens Groups (Harbach 2011b). The infrasubgeneric categories are based on superficial similarities that may not reflect natural relationships (Harbach 2011b). Achieving an accurate species identification when using only morphological features of the females is a difficult task because most character states are either polymorphic or overlap among species. Characteristics of the larval stage can be useful to identify species; however, overlapping character states and absence of differences may prevent separation of some species. In most Culex (Culex) species, characters of male genitalia allow accurate specific identification. Various anatomical features support the monophyly of Culicidae, Culicinae and Culicini (Harbach \& Kitching 1998). Belkin (1962) indicated that the natural affinities among the subgenera of Culex were obscure and surmised that Lutzia is an ancient and derived group that appears to have a strong affinity with the subgenus Culex. The subgenus Culex would be one of the 'most primitive' groups of the genus Culex, and Lutzia the sister to Culex (Culex) according to Mallampali (1995) and Miller et al. (1996). The relationships recovered by Navarro \& Liria (2000) indicated that Lutzia is the 'most primitive' clade of Culicini and subgenus Phenacomyia Harbach \& Peyton was placed as the sister group to subgenus Culex. St. John (2007) showed the genus Lutzia as the sister to the clade formed by Culex, and the subgenera Phenacomyia and Culex as the 'most primitive' of the genus. Rossi \& Harbach (2008) described the subgenus Phytotelmatomyia as a monophyletic group, interposed between species of the 
subgenera Phenacomyia and Culex. Demari-Silva et al. (2011) recovered Lutzia as a member of the genus Culex, and Phenacomyia within subgenus Culex. Vesgueiro et al. (2011) recovered Lutzia and Phenacomyia within subgenus Culex, and Harbach et al. (2012) recovered Deinocerites and Galindomyia within the genus Culex, and suggested that the subgenus Culex would be monophyletic if $C x$. duttoni, $C x$. apicinus and the Atriceps Group were excluded. Based on molecular and morphological evidence the genus Culex, like others in Culicidae, is para- or polyphyletic (Miller et al. 1996; Harbach \& Kitching 1998; Isoe 2000; St. John 2007; Demari-Silva et al. 2011; Vesgueiro et al. 2011 and Harbach et al. 2012).

The purpose of this study was to establish phylogenetic hypotheses among species of the Culex (Culex) from Argentina and to assess the relationship of this subgenus to Phenacomyia and Phytotelmatomyia.

\section{Material and methods}

Material examined: preparation and terminology. The specimens studied belong to the following entomological collections: Centro de Investigaciones Entomológicas (Córdoba), the Administración Nacional de Laboratorios e Instituto de Salud 'Dr. Carlos G. Malbrán' (Buenos Aires), Centro de Estudios Parasitológicos y de Vectores (La Plata), Fundación e Instituto Miguel Lillo (San Miguel de Tucumán), Departamento de Epidemiología, Faculdade de Saúde Pública (São Paulo) and National Museum of Natural History (Washington). Females and males analyzed in this paper were derived from individually reared fourth-instar larvae. Specific identification was based on male genitalia; only females and larvae associated with males reared from the same habitat (individual collection) were used in this work. The material includes pin-mounted adults, and pupal and larval exuviae and male genitalia mounted on microscope slides in Canada balsam. Morphological terminology follows Harbach (2011a) except for the siphon index, which is calculated measuring the siphon at base (Harbach $e t$ al. 1984).

Taxa. The species analyzed in the present study are listed in Table 1. Ingroup taxa comprise 57 species of Culex (Culex), 26 species of which occur in Argentina. The other 27 include species that occur elsewhere in South America and four species of the Sitiens Group: two of the Old World Sitiens Subgroup, $C x$. sitiens and $C x$. annulirostris, and two species of the Vishnui Subgroup, Cx. vishnui and Cx. tritaeniorhynchus. Outgroup taxa include species of the subgenera Phenacomyia, Phytotelmatomyia and Oculeomyia Theobald, and the genus Lutzia. We examined between one to 13 specimens of each life stage for each species. The specimens of some species were unavailable and their characters were coded from the literature. The life stages of several species are unknown.

TABLE 1. List of the species examined during the phylogenetic analysis. An asterisk (*) following the species indicates those that are distributed in Argentina. The authorship and the species are provided. $\mathrm{CG}=\mathrm{Coronator}$ Group; PG = Pipiens Group; SG = Sitiens Group.

\begin{tabular}{llll}
\hline Genus & Subgenus & Species & Species Group \\
\hline Lutzia & Lutzia & bigoti (Bellardi) & \\
Culex & Oculeomyia & bitaeniorhynchus Giles & \\
& Phenacomyia & corniger Theobald & \\
& Phytotelmatomyia & renatoi Lane \& Ramalho & PG \\
& Culex & abnormalis Lane & PG \\
& acharistus Root* & PG \\
& alani Forattini & PG \\
& ameliae Casal* & SG \\
& annulirostris Skuse & PG \\
& apicinus Philippi $*$ & PG \\
& archegus Dyar & PG \\
& articularis Philippi* & PG \\
& bickleyi Forattini & PG \\
\hline
\end{tabular}


TABLE 1. (Continued)

\begin{tabular}{|c|c|c|c|}
\hline Genus & Subgenus & Species & Species Group \\
\hline & & bonneae Dyar \& Knab & $\mathrm{PG}$ \\
\hline & & brethesi Dyar * & PG \\
\hline & & brevispinosus Bonne-Wesper \& Bonne & PG \\
\hline & & camposi Dyar & CG \\
\hline & & carcinoxenus de Oliveira Castro & PG \\
\hline & & chidesteri Dyar* & PG \\
\hline & & chitae Duret & PG \\
\hline & & coronator Dyar \& Knab* & CG \\
\hline & & covagarciai Forattini & CG \\
\hline & & curvibrachius Angulo \& Olivares & PG \\
\hline & & cuyanus Duret* & PG \\
\hline & & declarator Dyar \& Knab & PG \\
\hline & & diplophyllum Dyar & PG \\
\hline & & dolosus (Lynch Arribálzaga)* & PG \\
\hline & & eduardoi Casal \& García* & PG \\
\hline & & fernandezi Casal, García \& Cavalieri* & PG \\
\hline & & foliaceus Lane & PG \\
\hline & & guayasi Levi-Castillo & PG \\
\hline & & habilitator Dyar \& Knab & PG \\
\hline & & inflictus Theobald & PG \\
\hline & & interfor Dyar* & PG \\
\hline & & lahillei Bachmann \& Casal* & PG \\
\hline & & levicastilloi Lane* & PG \\
\hline & & lygrus Root & PG \\
\hline & & maracayensis Evans & PG \\
\hline & & mauesensis Lane & PG \\
\hline & & maxi Dyar* & PG \\
\hline & & mollis Dyar \& Knab* & PG \\
\hline & & nigripalpus Theobald & PG \\
\hline & & ousqua Dyar & CG \\
\hline & & paramaxi Duret & PG \\
\hline & & pipiens L.* & PG \\
\hline & & plicatus Angulo \& Olivares & PG \\
\hline & & quinquefasciatus Say* & PG \\
\hline & & quitensis Levi-Castillo & PG \\
\hline & & riojanus Duret* & PG \\
\hline & & saltanensis Dyar* & PG \\
\hline & & scheuberi Carpintero \& Leguizamón* & PG \\
\hline & & sitiens Wiedemann & SG \\
\hline & & spinosus Lutz* & PG \\
\hline & & surinamensis Dyar & PG \\
\hline & & tatoi Casal \& García* & PG \\
\hline & & thriambus Dyar & PG \\
\hline & & tritaeniorhynchus Giles & SG \\
\hline & & usquatissimus Dyar* & CG \\
\hline & & usquatus Dyar* & CG \\
\hline & & vishnui Theobald & SG \\
\hline
\end{tabular}


Morphological characters: selection, coding and description. The selection of characters was based on an exhaustive assessment of the morphology of all life stages (except the egg), without conjecture on their phylogenetic informativeness. As many characters as possible were included: some used by Darsie (1985), Forattini (2002), Harbach \& Kitching (1998), Harbach \& Peyton (1992), Rossi \& Harbach (2008) and other features based on our observations.

Autapomorphic characters were excluded from the analysis. Polymorphic characters were coded as 01,02 and 12 (Table 2). Characters that could not be scored because of the absence of homologous structures ('dependent characters') are indicated with a dash '-', e.g. the absence of pale scaling on the maxillary palpus (character 42) of Cx. apicinus which is absent in this taxon. Missing data were coded with a question mark '?'. These kinds of states were numerous due to several life stages of some species being unknown. The states of continuous characters were scored by clear gaps in the observed counts or measurements (e.g. character 12) or by reference to observed intraspecific variation (e.g. character 54).

Data for 95 binary or multistate characters were coded for 61 species from fourth-instar larva (28), pupa (10), adults (31) and male genitalia (26), treated as unordered. The data matrix was prepared using Mesquite ver. 2.75 (Maddison \& Maddison 2010). Most character states are illustrated in the current study. References are given for illustrations of characters that are not illustrated herein.

\section{Fourth-instar larva.}

0. Antenna, length relative to length of head capsule: $(0) \leq 0.35$; (1) $>0.35$ to $\leq 0.60$ (Fig. 1A); (2) $>0.60$ to $\leq$ 1.00 (Fig. 1B); (3) > 1.00 times (Fig. 1C). This ratio is obtained by dividing antennal length by the length of the head measured from the anterior margin of the median labral plate to the posterior margin of the dorsal apotome.

1. Seta 1-A, insertion: (0) near mid-length of antenna (about 0.50 from base, Fig. 1A); (1) on distal third of antenna, Fig. 1B-F).

2. Seta 1-A, branches: (0) 1-5; (1) > 5 (Fig. 1A-F). In most Neotropical species of subgenus Culex, seta 1-A has more than 5 branches.

3. Seta 1-A, length relative to the length of the antenna: (0) $<0.50$ (Fig. 1E); (1) $\geq 0.50$ (Fig. 1C). This ratio is obtained by dividing the length of the medial branches of seta 1-A by the length of the antenna.

4. Seta 1-C, branches: (0) filamentous (Fig. 1D); (1) aciculate (Fig. 1E); (2) spiniform (Fig. 1B); (3) flat (see Harbach 1988).

5. Seta 2-C: (0) absent (Fig. 1C); (1) present (Fig. 1E).

6. Seta 4-C, branches: (0) simple (Fig. 2A); (1) aciculate (Fig. 2B).

7. Seta 8-C, insertion relative to seta 9-C: (0) anterior (Fig. 1B); (1) posterior (Fig. 1C-F); (2) on same level (Fig. 1A). Note that relative setal positions are more or less constant during development, and the importance of this phenomenon in recognizing phylogenetic relationships is well established in Reinert et al. $(2004,2008$, and 2009) and Harbach et al. (2012).

8. Seta 14-C, insertion relative to seta 13-C: (0) anterior (Fig. 1B,E); (1) posterior (Fig. 1D,F); (2) on same level (Fig. 2A,C).

9. Seta 16-C: (0) absent (Fig. 3A); (1) present (Fig. 3B).

10. Seta 3-P, length relative to seta 1-P: (0) shorter (see Harbach \& Peyton 1992); (1) equal (Figs. 4A, 5A); (2) longer.

11. Seta 3-P, development: (0) single (Fig. 4A); (1) double (Fig. 5A); (2) three or more branches. When the seta 3$\mathrm{P}$ is single or double-branched there is no variability, whereas, if it has more branches, the number can vary from three to more than three, even within the same species.

12. Seta 4-P, length relative to seta 1-P: $(0)<0.50$ (see Rossi \& Harbach 2008); (1) $\geq 0.50$ to $\leq 0.75 ;(2)>0.75$ to $\leq 1$; (3) $>1.00$. According to Rossi \& Harbach (2008), in the subgenera Phenacomyia and Phytotelmatomyia, seta 4-P is about 0.35 the length of seta 1-P and about 0.65 in subgenus Culex. The length of this seta could have been scored as shorter, equal or longer than seta 1-P but based on the observed variability of the analyzed species and in an attempt to set up clear gaps, the given ranges were established.

13. Seta 4-P, development: (0) single; (1) double (Fig. 4A); (2) three or more branches (Fig. 5A).

14. Seta 7-P, development: (0) single; (1) double (Fig. 4A); (2) triple; (3) four or more branches (Fig. 5A).

15. Setae 8-P, development: (0) single; (1) double (Fig. 4A); (2) triple (Fig. 5A).

16. Seta 7-II, length relative to seta 7-I: (0) shorter (Fig. 4A); (1) equal.

17. Seta 4-VIII, development: (0) single (Fig. 5B); (1) multiple (Fig. 4B). 
A
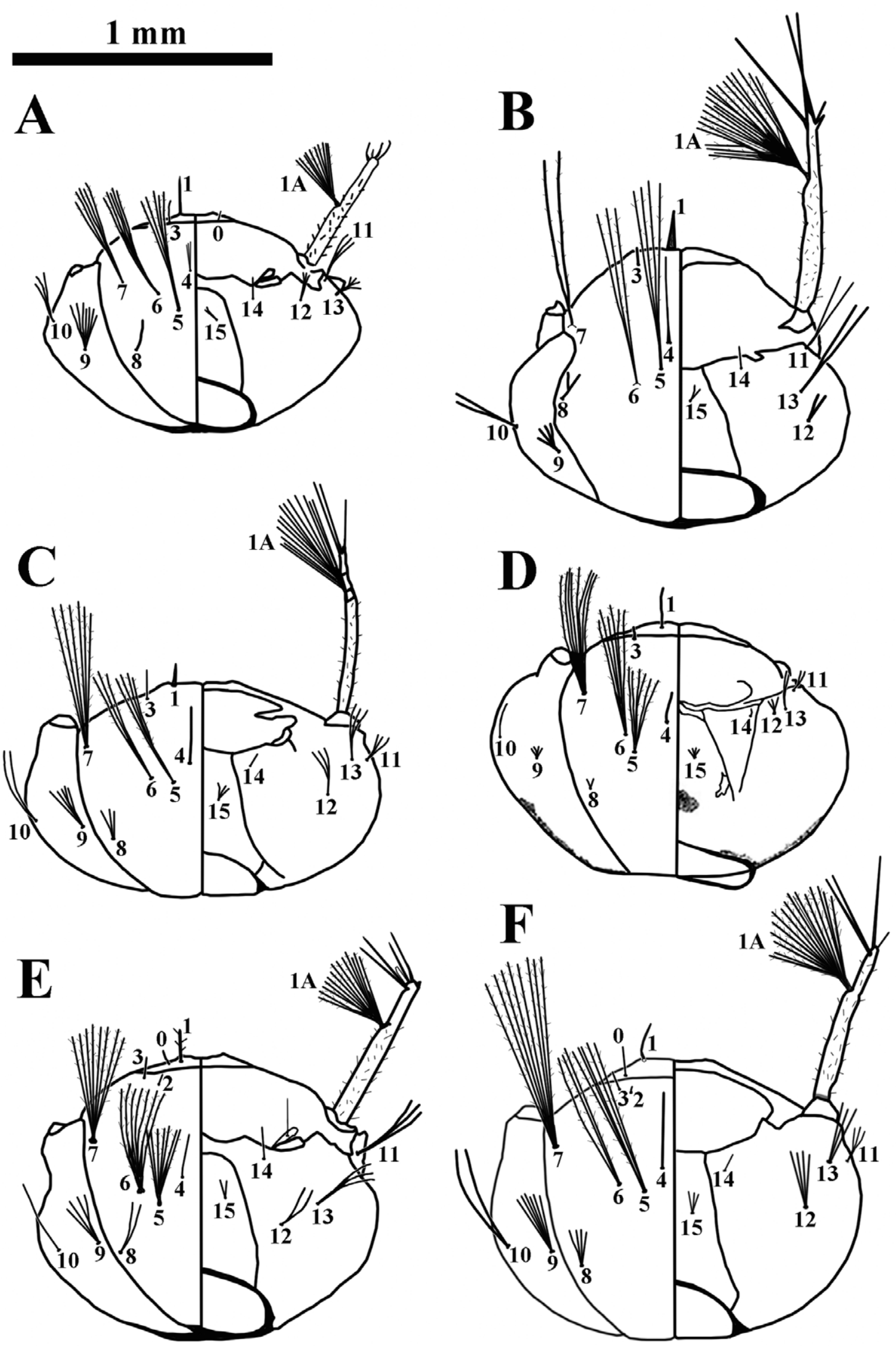

FIGURE 1. Chaetotaxy of heads of mosquito larvae in dorsal aspect (left) and ventral aspect (right). A: Culex (Culex) acharistus Root; B: Culex (Culex) ameliae Casal; C: Culex (Culex) lahillei Bachmann \& Casal; D: Culex (Culex) saltanensis Dyar; E: Culex (Culex) apicinus Dyar \& Knab; F: Culex (Culex) articularis Philippi. A = antenna; 0-15 = head setae. 

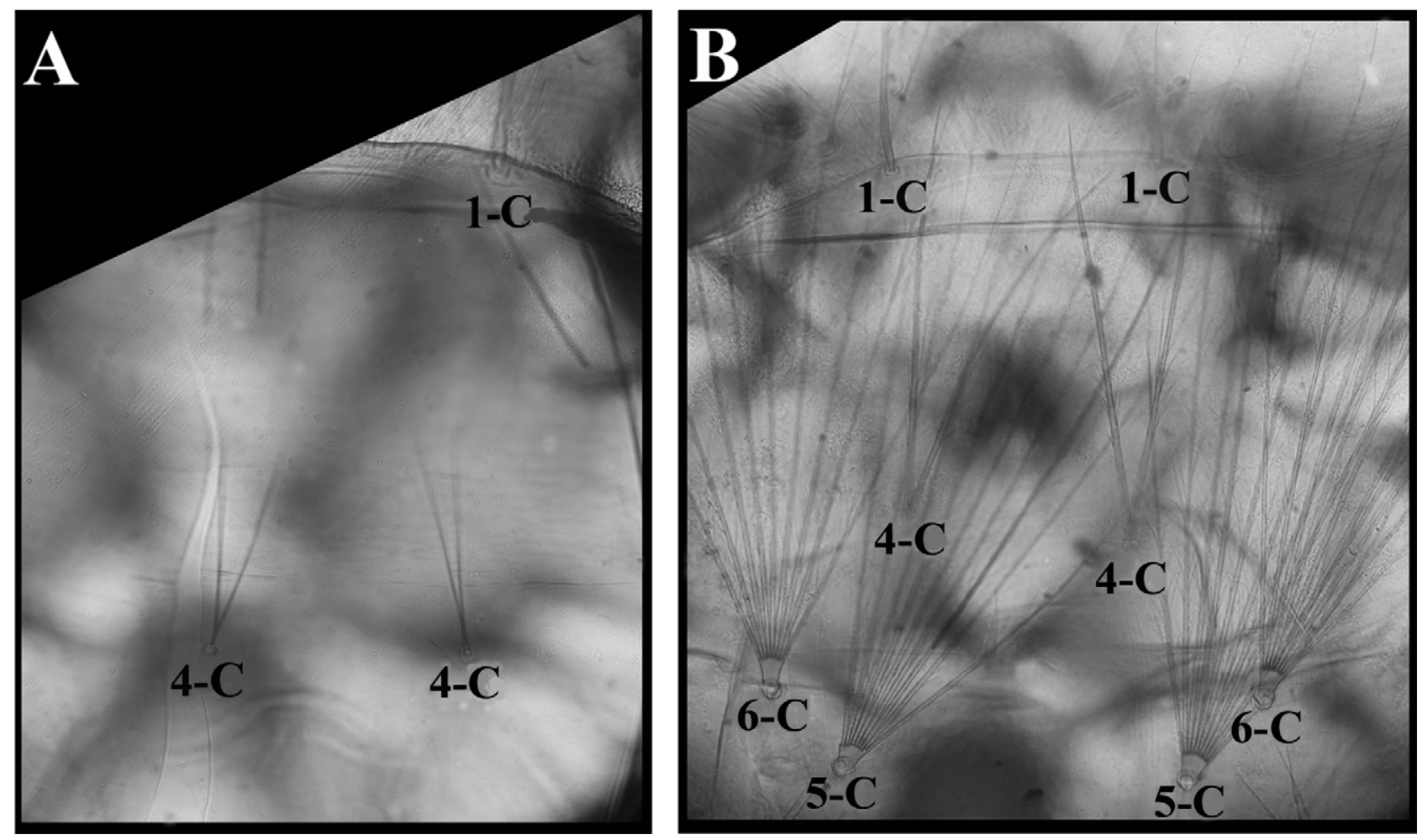

FIGURE 2. Dorsal aspect of heads of fourth-instar larvae of Culex (Culex). A: Culex (Culex) acharistus Root; B: Culex (Culex) fernandezi Casal, García \& Cavalieri. 1,4-6C = head setae.

18. Seta 4-VIII, position: (0) midway between the siphon base and the dorsal margin of segment X; (1) closer to the dorsal margin of segment $\mathrm{X}$ (Fig. 4B).

19. Comb scales, shape: (0) spine-like (Fig. 6A); (1) evenly fringed (Fig. 6B); (2) both.

20. Seta 2-X, development: (0) single; (1) double (Fig. 4B); (2) triple; (3) four or more branches (Fig. 5B). When the seta $2-\mathrm{X}$ is single, double- or triple-branched there is no variability, whereas, if it has more branches, the number can vary between four and seven even within the same species.

21. Saddle, denticles on posterior margin: (0) absent (Fig. 5B); (1) present (Fig. 4B).

22. Siphon, pigmentation: (0) yellowish to tan (Fig. 7A); (1) brown (Fig. 7B). The strong pigmentation of the siphon and head of some species like $C x$. apicinus, $C x$. acharistus and $C x$. articularis is clear when compared with other species such as $C x$. pipiens and $C x$. maxi, among others.

23. Siphon, distal surface: (0) smooth (Fig. 7B); (1) spiculate (Fig. 7A).

24. Siphon, subapical spines: (0) absent (Fig. 7B); (1) present (Fig. 8A,B).

25. Siphon, subapical spines (if present): (0) anteriorly (Fig. 8A); (1) anteriorly and posteriorly (Fig. 8B).

26. Seta 1-S, number of elements inserted beside the pecten spines: (0) none (Fig. 4B); (1) one; (2) two or more (Fig. 5B). When there are no elements of seta 1-S between the pecten spines, or at least there is one, the state is constant in the species. On the contrary, when the number of elements exceeds one, the number could vary between 2 and 4 in the same species.

27. Seta 1-S, length of the most basal element relative to the siphon width: (0) shorter (Fig. 5B); (1) equal or longer (Fig. 4B). 


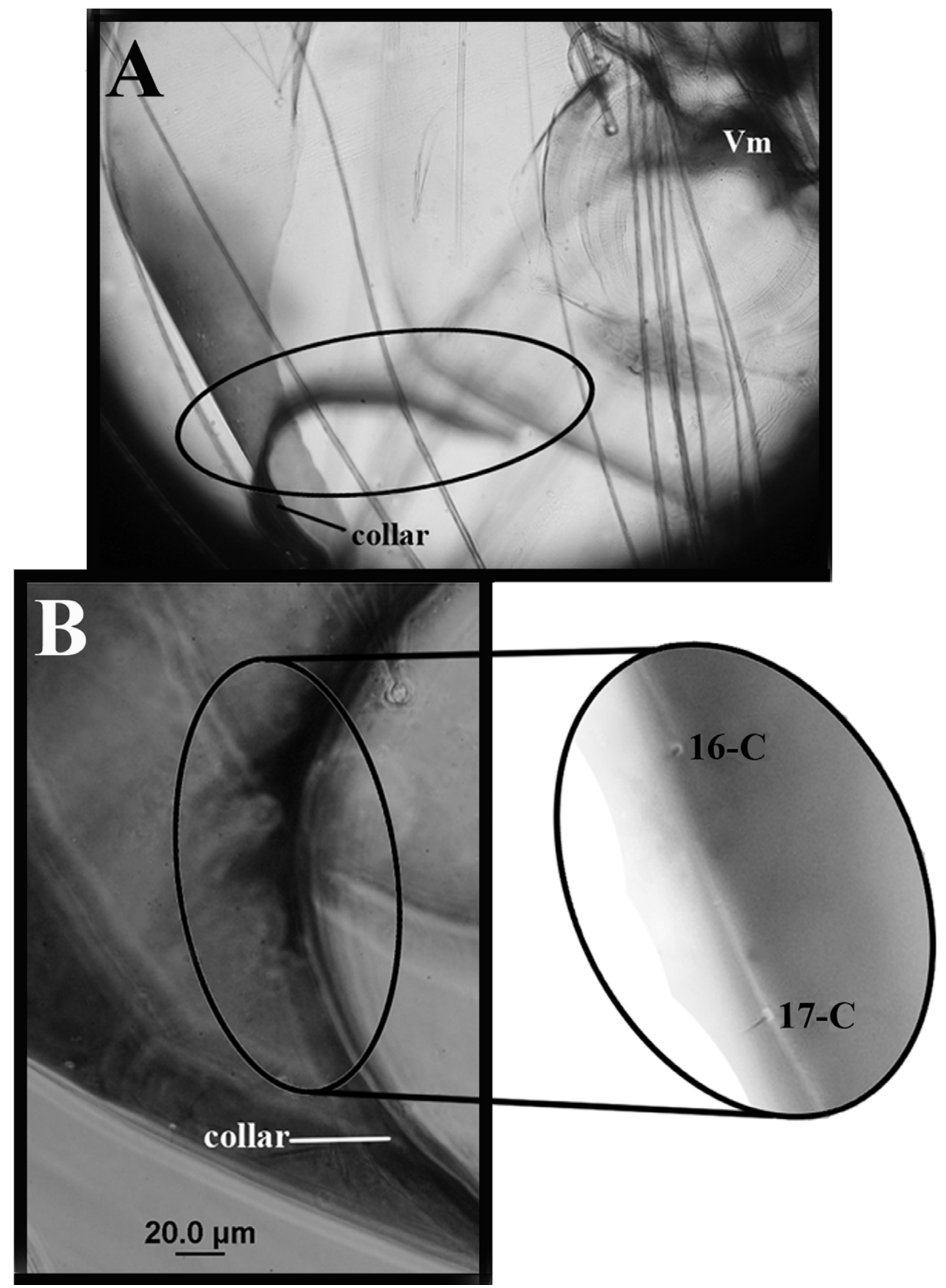

FIGURE 3. Seta 16 of head of fourth-instar larvae of Culex (Culex). A: Culex (Culex) brethesi Dyar; B: Culex (Culex) cuyanus Duret. Vm = ventromentum; $16,17-\mathrm{C}=$ head setae. 


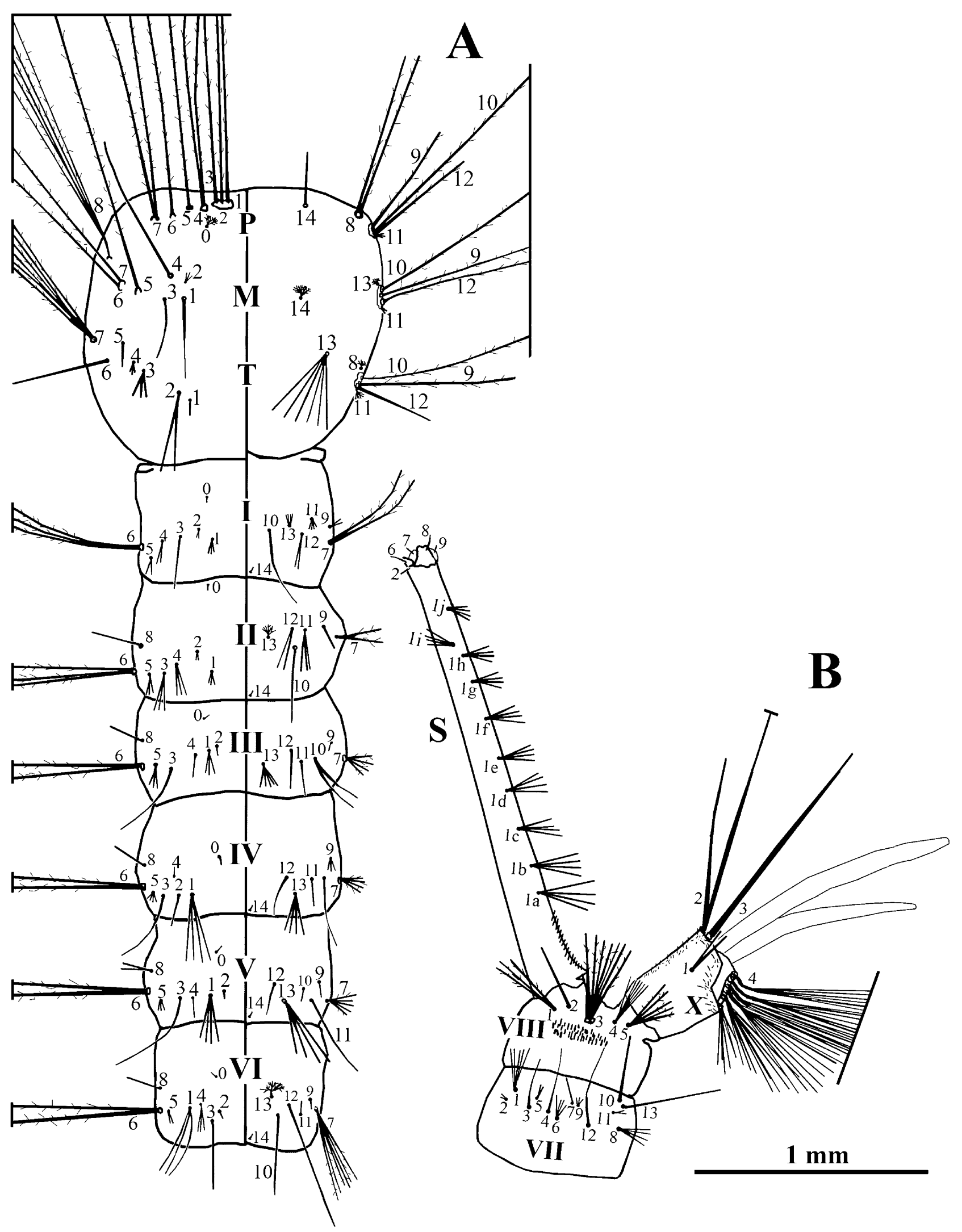

FIGURE 4. Larva of Culex (Culex) ameliae Casal. A: thorax and abdominal segments I-VI; B: abdominal segments VII,VIII,X and siphon. $\mathrm{M}=$ mesothorax; $\mathrm{P}=$ prothorax; $\mathrm{S}=$ siphon; $\mathrm{T}=$ metathorax; $\mathrm{I}-\mathrm{VIII}, \mathrm{X}=$ abdominal segments. The positions shown in the figure may not be accurate due to having been drawn from exuviae. 


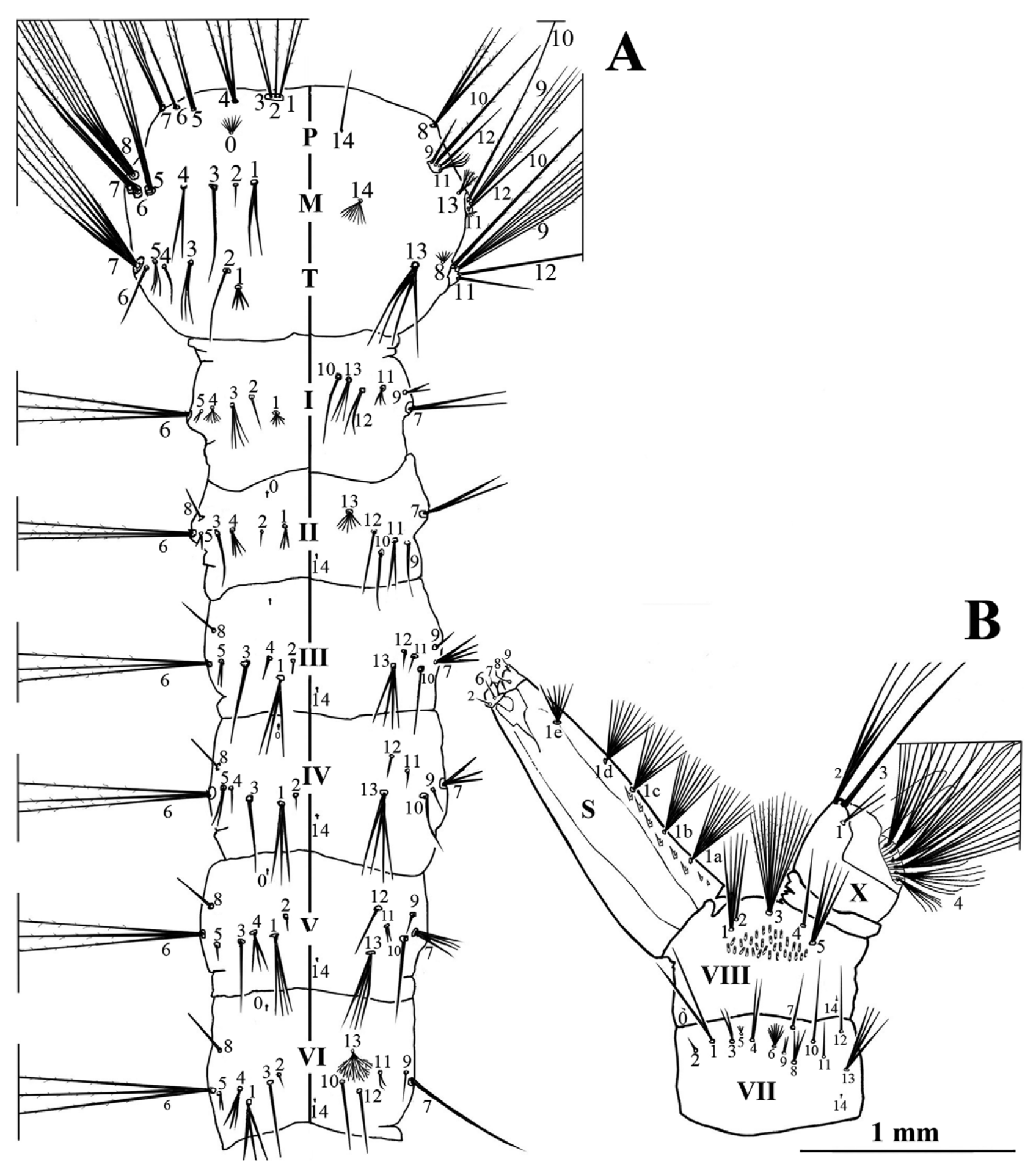

FIGURE 5. Larva of Culex (Culex) apicinus Philippi. A: thorax and abdominal segments I-VI; B: abdominal segments VII,VIII,X and siphon. $\mathrm{M}=$ mesothorax; $\mathrm{P}=$ prothorax; $\mathrm{S}=$ siphon; $\mathrm{T}=$ metathorax; $\mathrm{I}-\mathrm{VIII}, \mathrm{X}=$ abdominal segments. The positions shown in the figure may not be accurate due to having been drawn from exuviae. 

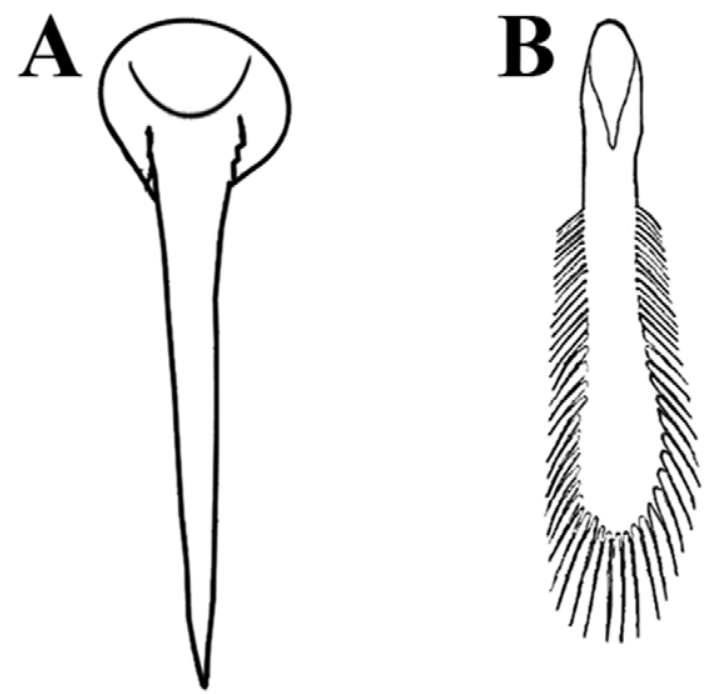

FIGURE 6. Comb scales of segment VIII of fourth-instar larvae. A: Culex (Culex) fernandezi Casal, García \& Cavalieri; B: Culex (Culex) apicinus Philippi.

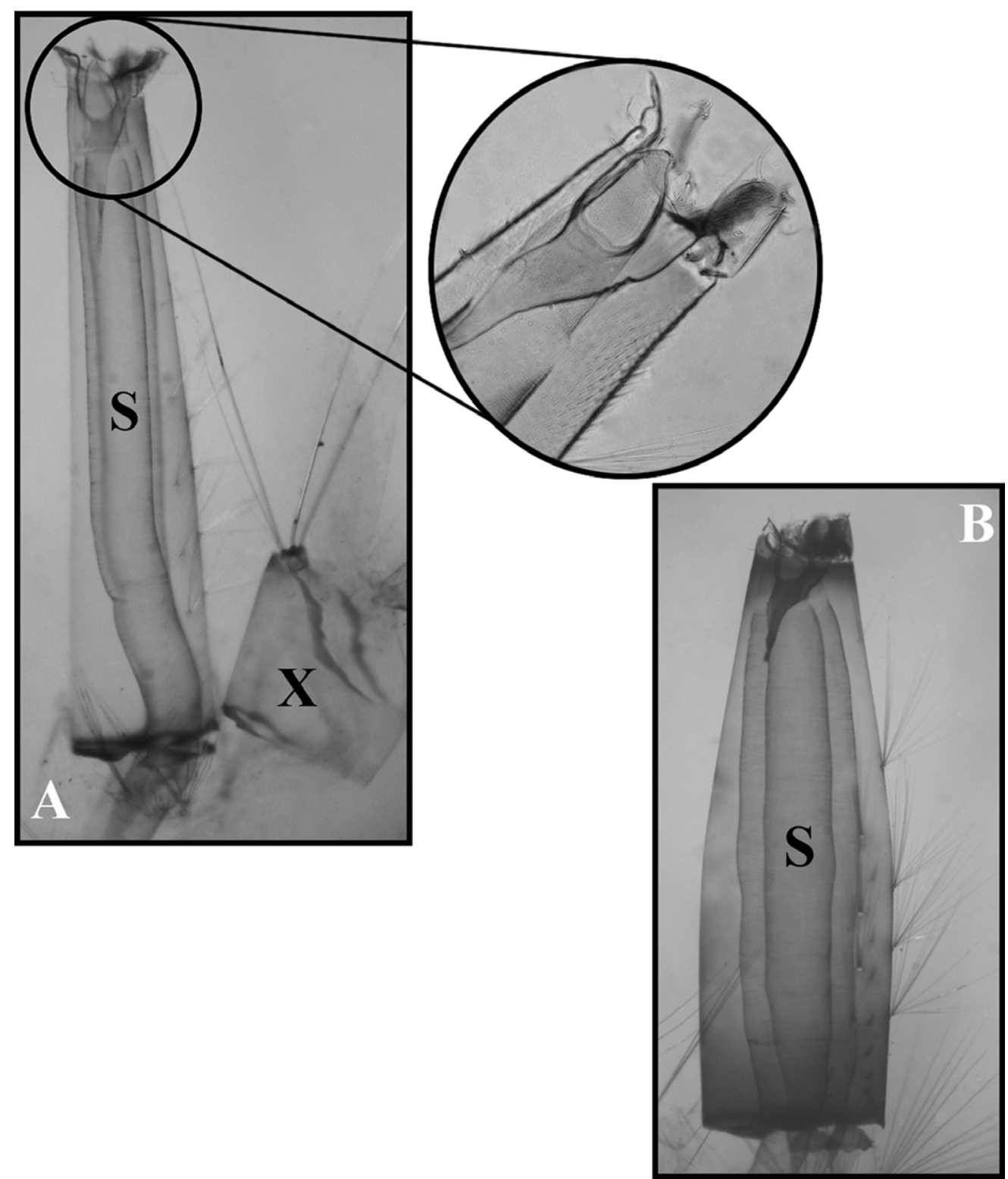

FIGURE 7. Siphon pigmentation of fourth-instar larvae. A: Culex (Culex) saltanensis Dyar; B: Culex (Culex) apicinus Philippi. $\mathrm{S}=$ siphon; $\mathrm{X}=$ abdominal segment $\mathrm{X}$. 


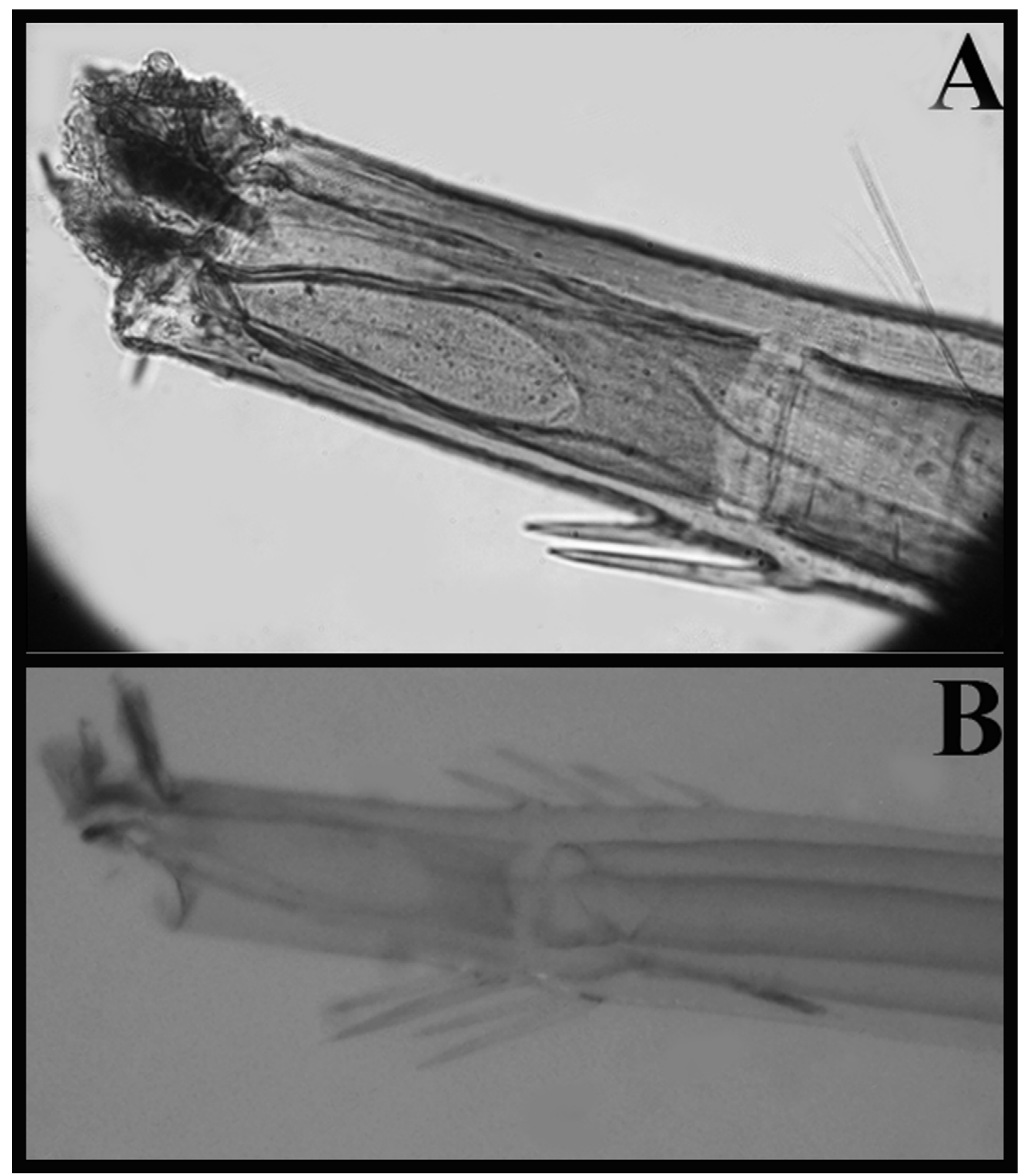

FIGURE 8. Subapical spines of the siphon of fourth-instar larvae. A: Culex (Culex) maxi Dyar; B: Culex (Culex) coronator Dyar \& Knab.

\section{Pupa}

28. Trumpet, shape: (0) flared (length of pinna less than diameter at apex (Fig. 9A); (1) cylindrical (length of pinna equal to longer than diameter at apex) (Fig. 10A).

29. Seta 1-CT, length relative to length of seta 2-CT: (0) shorter (Fig. 10A); (1) longer (Fig. 9A).

30. Seta 10-CT, development: (0) 1-4 branches (Fig. 10B); (1) five or more branches (Fig. 11B).

31. Seta 6-I, length relative to seta 7-I: (0) shorter; (1) equal (Fig. 9B); (2) longer (Fig. 10B).

32. Seta 2-II, insertion relative to seta 3-II: (0) anterior; (1) posterior; (2) about the same level (Figs. 9B, 10B).

33. Seta 6-II, length relative to seta 7-II: (0) equal (Fig. 9B); (1) longer (Fig. 10B).

34. Seta 5-IV, length relative to seta 5-V: (0) shorter (see Laurito et al. 2011); (1) equal (Figs. 9B, 10B); (2) longer (see Rossi et al. 2006).

35. Seta 1-Pa: (0) single (Fig. 10B); (1) double (Fig. 9B). 
36. Seta 2-Pa: (0) absent (see Laurito et al. 2009); (1) present.

37. Seta 2-Pa (if present): (0) single; (1) double.
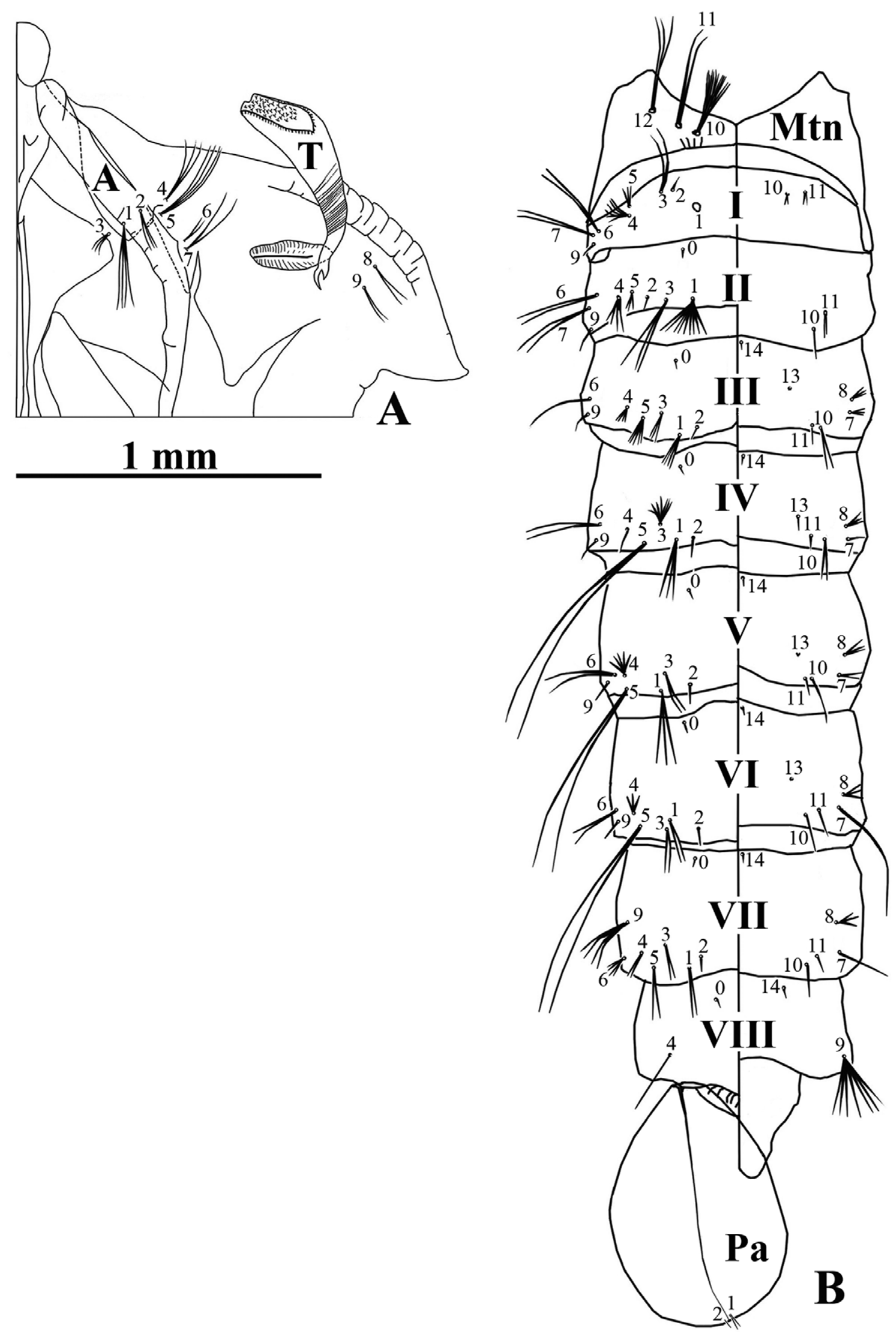

FIGURE 9. Pupa of Culex (Culex) ameliae Casal. A: cephalothorax; B: metanotum and abdomen. Mtn = metanotum; Pa = paddle; $\mathrm{T}$ = trumpet; $\mathrm{I}-\mathrm{VIII}=$ abdominal segments. 

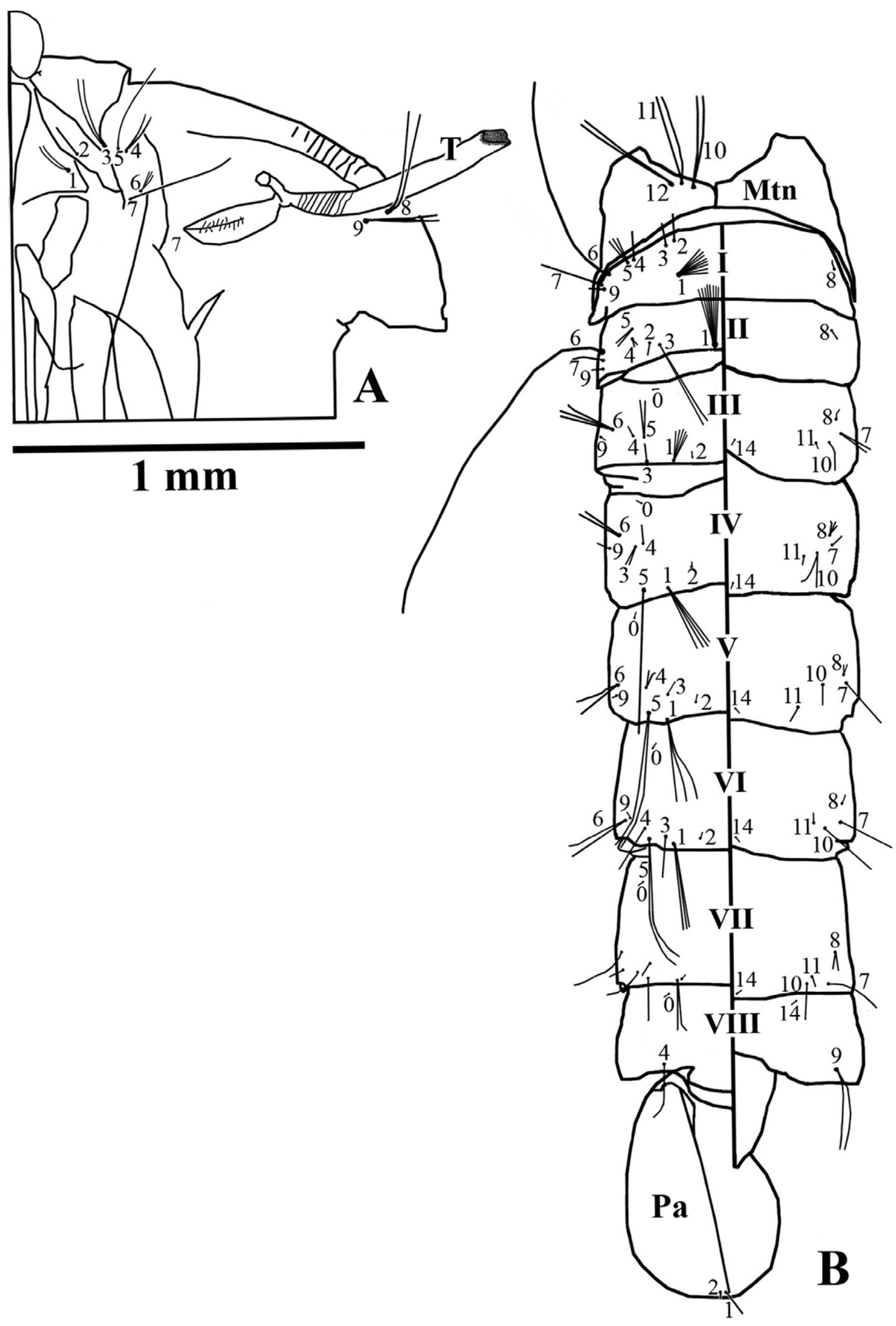

FIGURE 10. Pupa of Culex (Culex) apicinus Philippi. A: cephalothorax; B: metanotum and abdomen. A = antenna; Mtn = metanotum $; \mathrm{Pa}=$ paddle $; \mathrm{T}=$ trumpet $; \mathrm{I}-\mathrm{VIII}=$ abdominal segments. 


\section{Adults (females except where otherwise indicated)}

38. Erect forked scales, colour: (0) brown (Fig. 11A); (1) whitish and brown (Fig. 11B); (2) whitish (Fig. 11C); (3) yellowish.

39. Interocular space (see Harbach \& Kitching 1998): (0) without scales/setae; (1) with scales/setae.

40. Maxillary palpus (male), setal development on palpomeres 4 and 5: (0) weak (Fig. 12A); (1) strong (Fig. 12B). The weak setal developmental pattern is characterized by short, thin, light brown, and scattered setae.

41. Maxillary palpus, pale scaling: (0) absent (Fig. 13A); (1) present (Fig. 13B).

42. Maxillary palpus, pale scaling (if present): (0) forming a ring; (1) in a patch (Fig. 13B); (2) scattered.

43. Proboscis, pale scaling: (0) absent; (1) present (Fig. 14A, B).

44. Proboscis, pale scaling (if present): (0) forming a ring (Fig. 14A); (1) in a patch (Fig. 14B).

45. Scutum, lateral stripe of pale scales, from anterior dorsocentral line to anterior part of supraalar area: (0) absent (Fig. 15A); (1) present (Fig. 15B).

46. Scutellum, scaling: (0) confined to the lobes (Fig. 16A); (1) evenly distributed (Fig. 16B).

47. Scutellum, shape of scales: (0) broad (Fig. 16A); (1) narrow (Fig. 16B).

48. Scutellum, colour of scales: (0) whitish (Fig. 16A,B); (1) brown; (2) golden.

49. Postspiracular scales: (0) absent (Fig. 17A); (1) present (Fig. 17B).

50. Prealar scales: (0) absent (Fig. 17B); (1) present (Fig. 178A).

51. Upper mesepimeral scales: (0) absent; (1) present (Fig. 17A).

52. Lower mesepimeral scales: (0) absent; (1) present (Fig. 17A).

53. Lower mesepimeral setae: (0) absent; (1) present. Lower mesepimeral setae are absent in Sitiens Group species and always present in the Pipiens Group and Lutzia species.

54. Lower mesepimeral setae (if present): (0) 1-5; (1) more than five. One or two, exceptionally three or four, lower mesepimeral setae occur in species of the Pipiens Group and six or more in Lutzia species.

55. Subcosta, junction with costa relative to furcation of $\mathrm{R}_{2+3}$ : (0) proximal (Fig. 18A); (1) distal; (2) same level (Fig. 18B).

56. Media, distance between $M_{3+4}$ and radiomedial (rm) crossvein, relative to length of $M_{3+4}:(0)$ shorter (Fig. 19A); (1) equal; (2) longer (Fig. 19B).

57. Alula, scales: (0) dark (Fig. 20A); (1) pale and dark (Fig. 20B).

58. Forefemur, whitish scaling: (0) absent (Fig. 21A); (1) present (Fig. 21B).

59. Forefemur, whitish scaling (if present): (0) in a patch (Fig. 21B); (1) scattered.

60. Hindfemur, whitish scaling: (0) absent; (1) present (Fig. 22A,B).

61. Hindfemur, whitish scaling (if present): (0) in a patch (Fig. 22A,B); (1) scattered.

62. Hindfemur-tibial joint: (0) dark-scaled (Fig. 22A); (1) pale-scaled (Fig. 22B).

63. Hindtarsomere 1, length relative to hindtibia: (0) shorter; (1) equal; (2) longer.

64. Hindtarsomeres 3 and 4, colour: (0) brown and whitish-scaled (Fig. 22B); (1) entirely golden-scaled; (2) entirely brown-scaled (Fig. 22A).

65. Terga III-VI, basal whitish scales: (0) absent (Fig. 23A); (1) present (Fig. 23B,C).

66. Terga III-VI, basal whitish scales (if present): (0) as a band (Fig. 23B); (1) as a medial patch only (Fig. 23C); (2) as lateral patches only; (3) as medial and lateral patches connected. A 'band' means a continuous and uniform strip of scales across the width of the segment; a 'patch' is a spot of scales at medial and/or lateral position with or without connection of a narrow strip of scales.

67. Terga III-VI, apical whitish scales: (0) absent (Fig. 23B,C); (1) present (Fig. 23A).

68. Sterna III-VI: (0) entirely whitish-scaled (Fig. 24A); (1) whitish-scaled with some scattered brown scales on midline (Fig. 24B); (2) whitish-scaled with some brown scales along posterior border (Fig. 24C); (3) whitishscaled with triangular patches of brown scales; (4) brown-scaled with patches of whitish scales (Fig. 24D). 


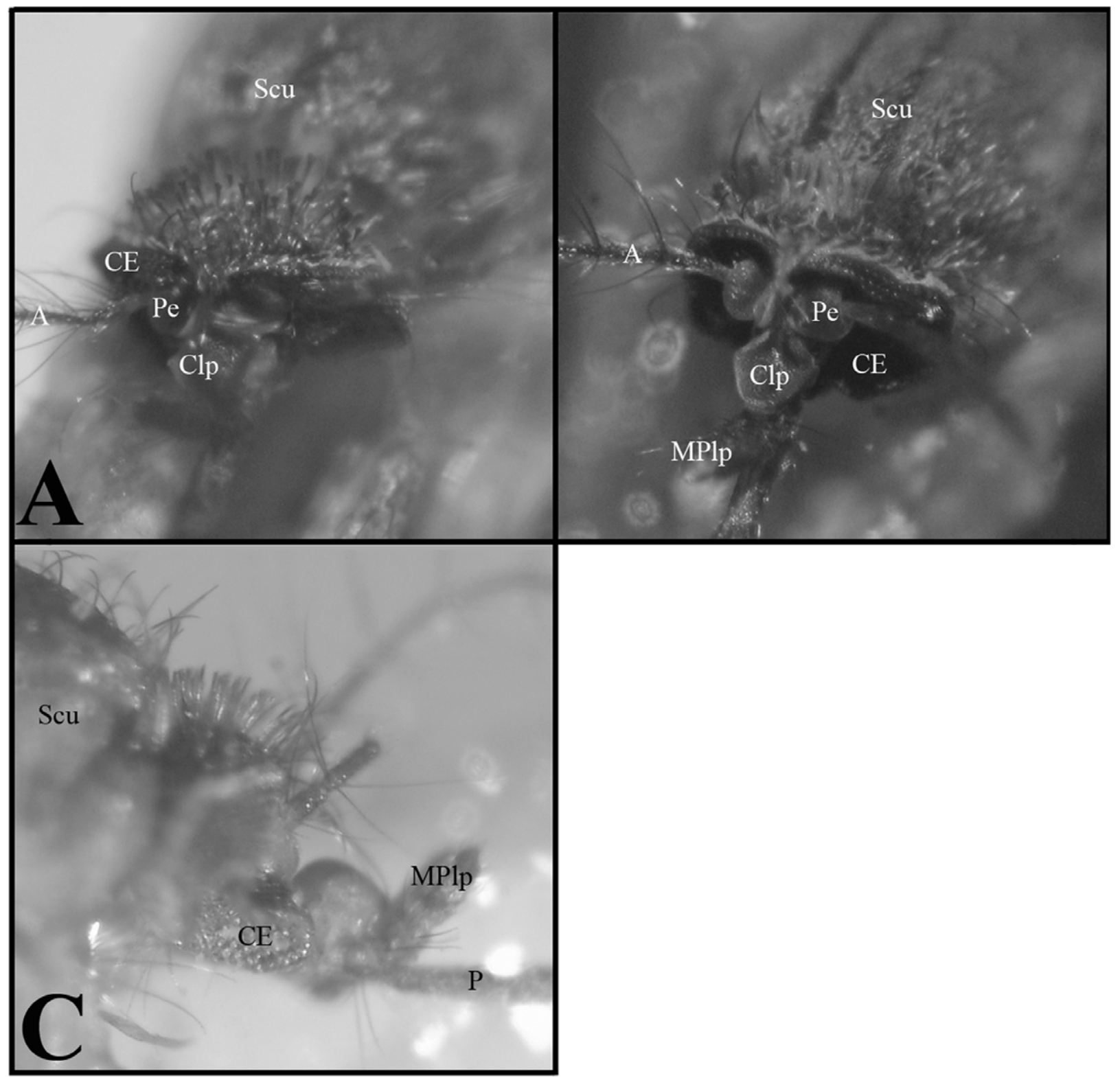

FIGURE 11. Erect forked scales of adult female mosquitoes. A: Culex (Culex) saltanensis Dyar; B: Culex (Culex) quinquefasciatus Say; C: Culex (Culex) coronator Dyar \& Knab. A = antenna; $\mathrm{CE}=$ compound eye; $\mathrm{Clp}=$ clypeus; $\mathrm{MPlp}=$ maxillary palpus; $\mathrm{Pe}=$ pedicel; $\mathrm{Scu}=$ scutum.

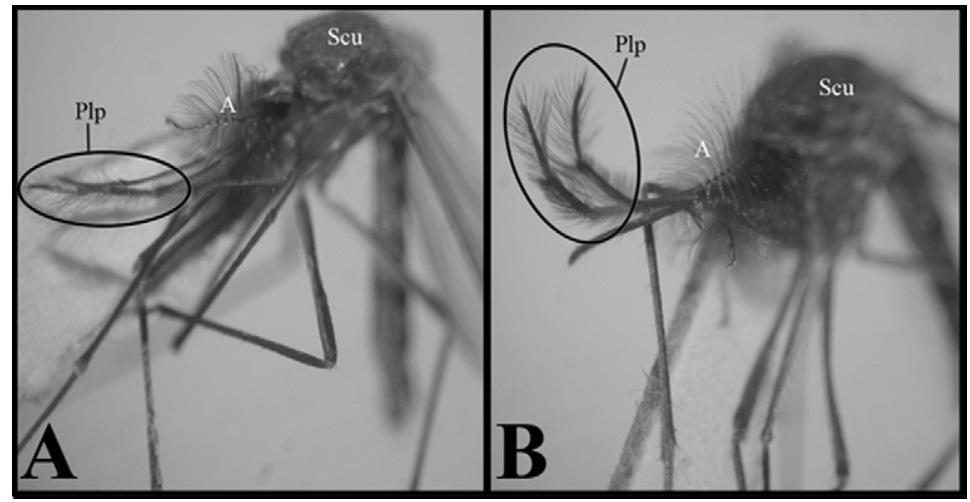

FIGURE 12. Setal development of maxillary palpus of adult male mosquitoes. A: Culex (Culex) quinquefasciatus Say; B: Culex (Culex) brethesi Dyar. A = antenna; $\mathrm{Plp}=$ palpomeres; $\mathrm{Scu}=$ scutum. 


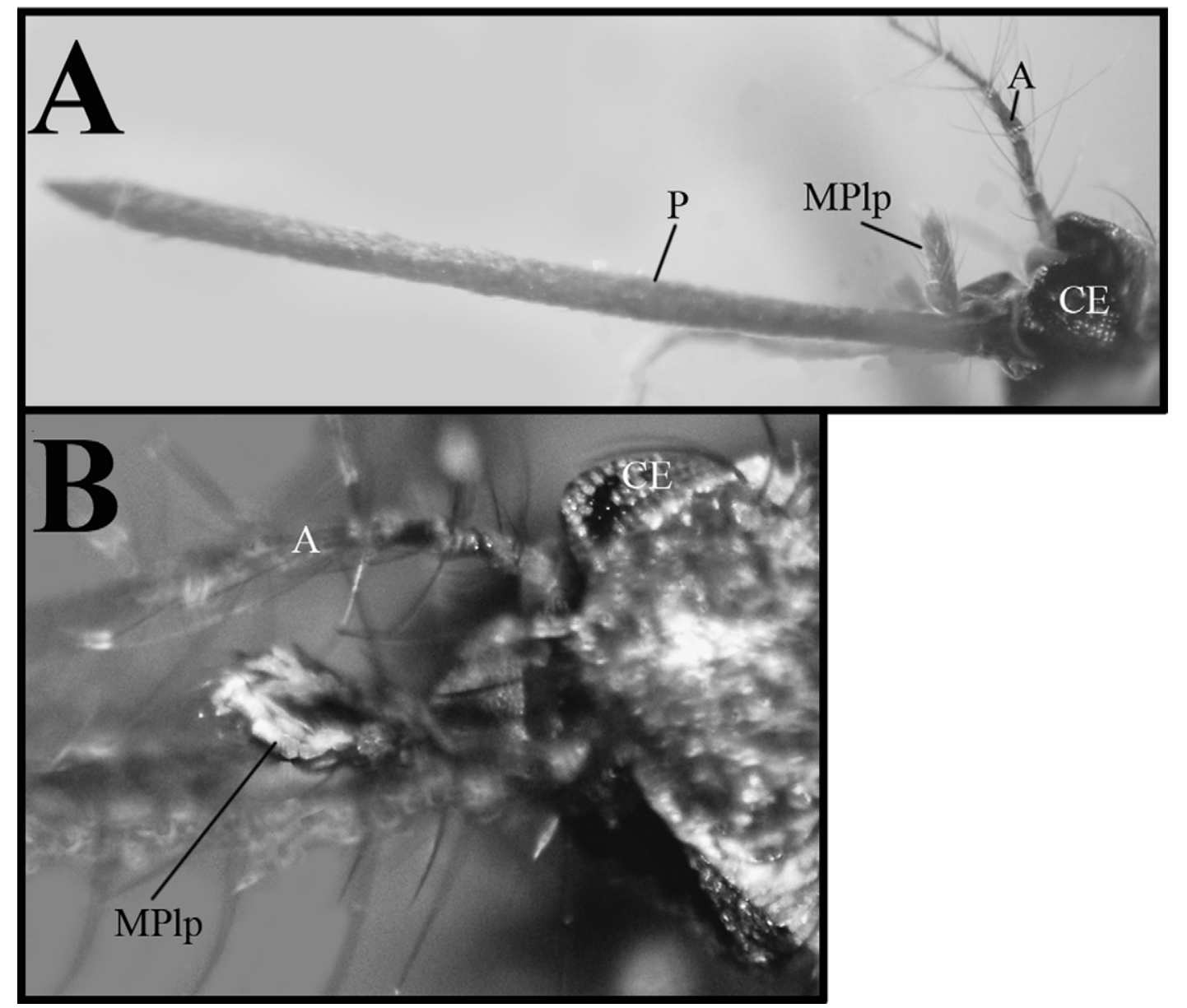

FIGURE 13. Pale scaling of maxillary palpus of adult female mosquitoes. A: Culex (Culex) fernandezi Casal, García \& Cavalieri; B: Culex (Culex) quinquefasciatus Say. A = antenna; $\mathrm{CE}=$ compound eye; $\mathrm{MPlp}=$ maxillary palpus; $\mathrm{P}=$ proboscis.

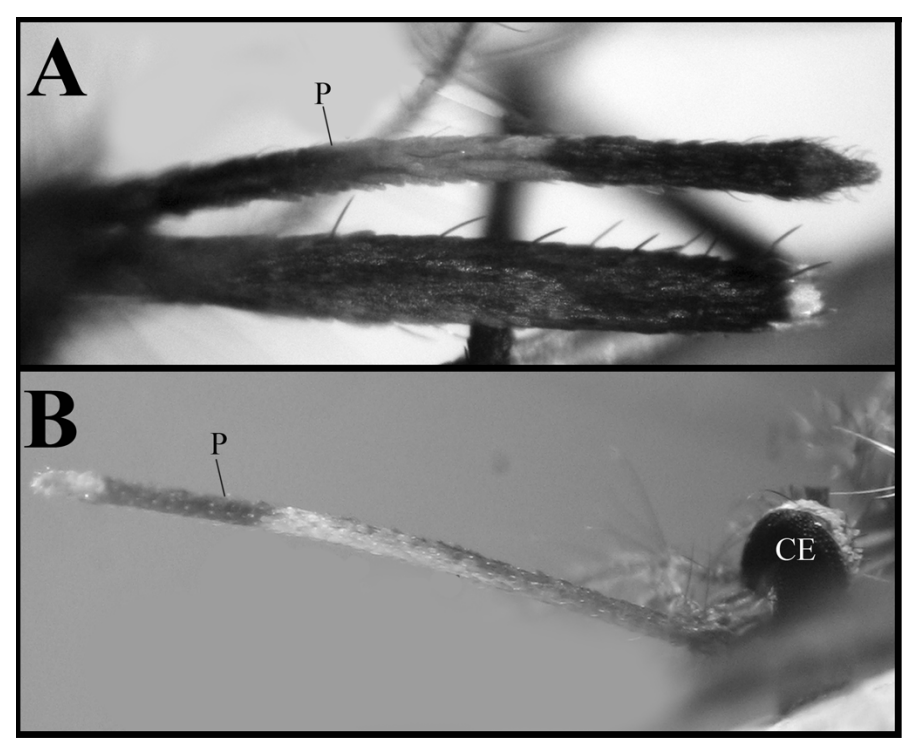

FIGURE 14. Pale scaling of proboscis of adult female mosquitoes. A: Culex (Culex) dolosus (Lynch Arribálzaga); B: Culex (Culex) coronator Dyar \& Knab. $\mathrm{CE}=$ compound eye; $\mathrm{P}=$ proboscis. 


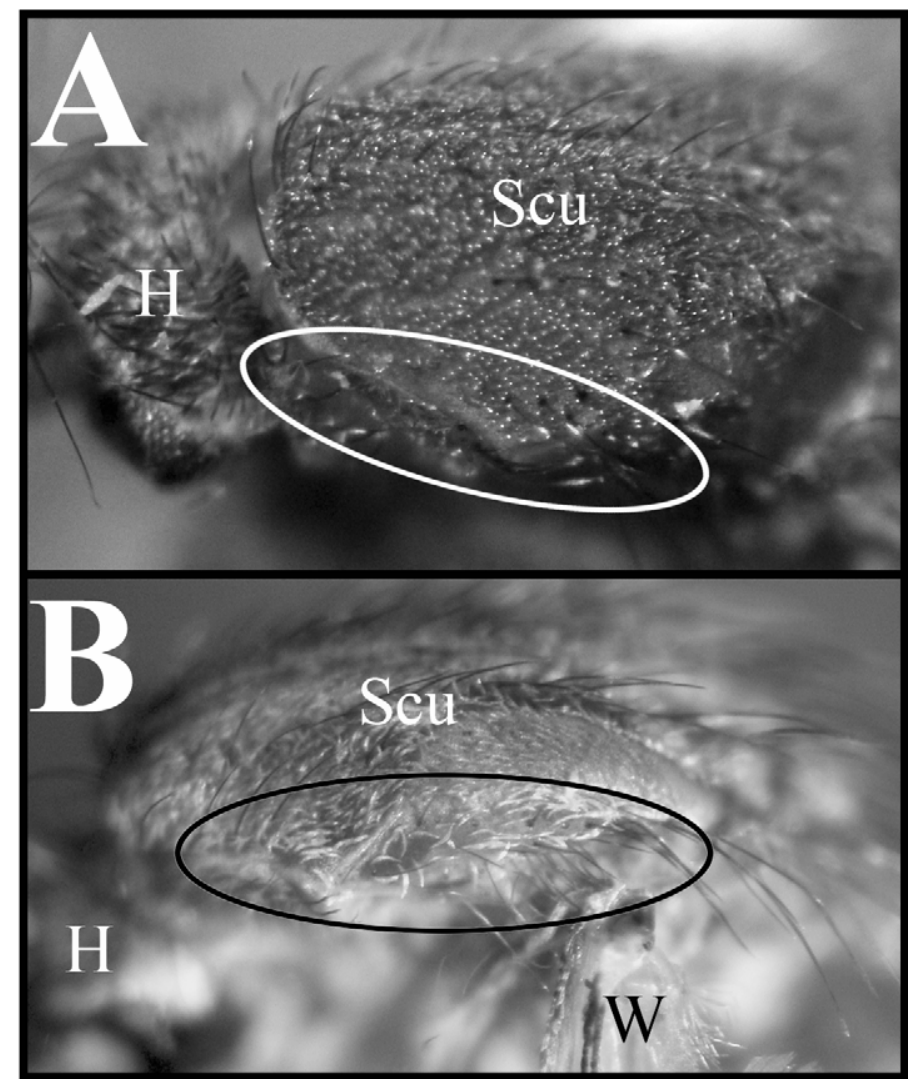

FIGURE 15. Lateral band of pale scales of scutum, from anterior dorsocentral line to anterior part of supraalar area of adult female mosquitoes. A: Culex (Culex) bidens Dyar; B: Culex (Culex) acharistus Root. $\mathrm{H}=$ head; $\mathrm{Scu}=\mathrm{scutum}$; $\mathrm{W}=$ wing.

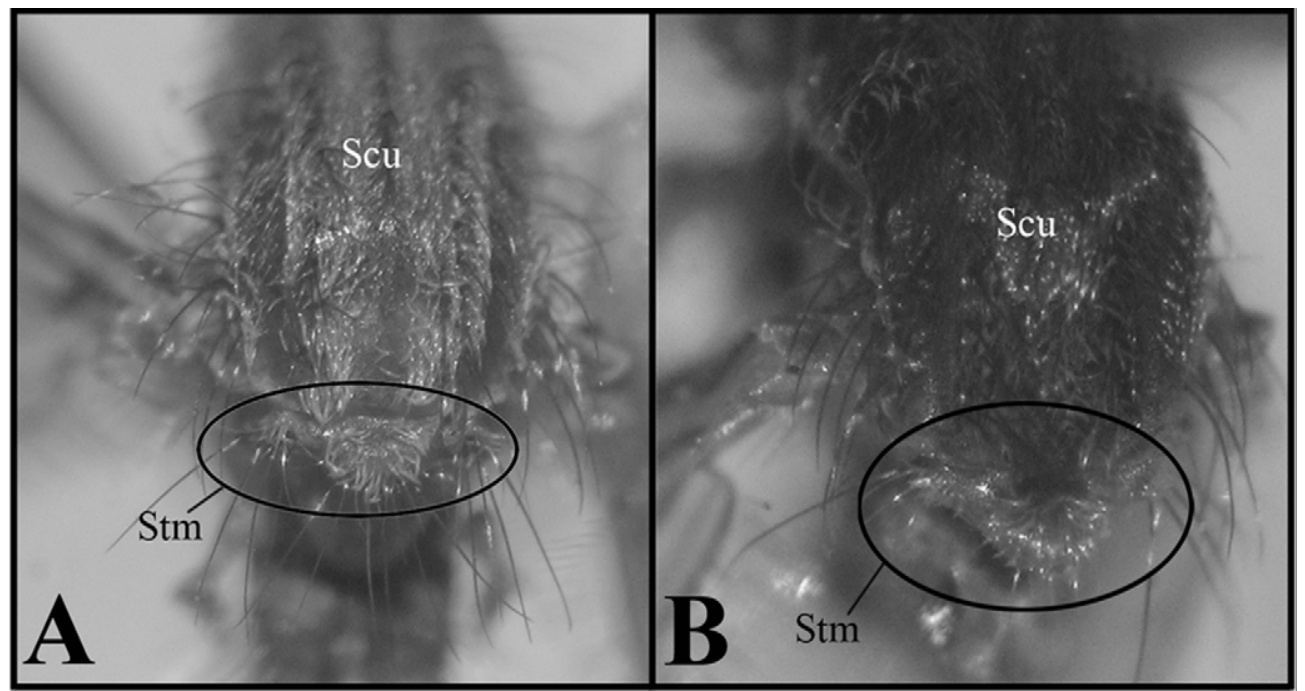

FIGURE 16. Scutellum of adult female mosquitoes. A: Culex (Culex) lahillei Bachmann \& Casal; B: Culex (Culex) coronator Dyar \& Knab. Scu = scutum; Stm = scutellum. 


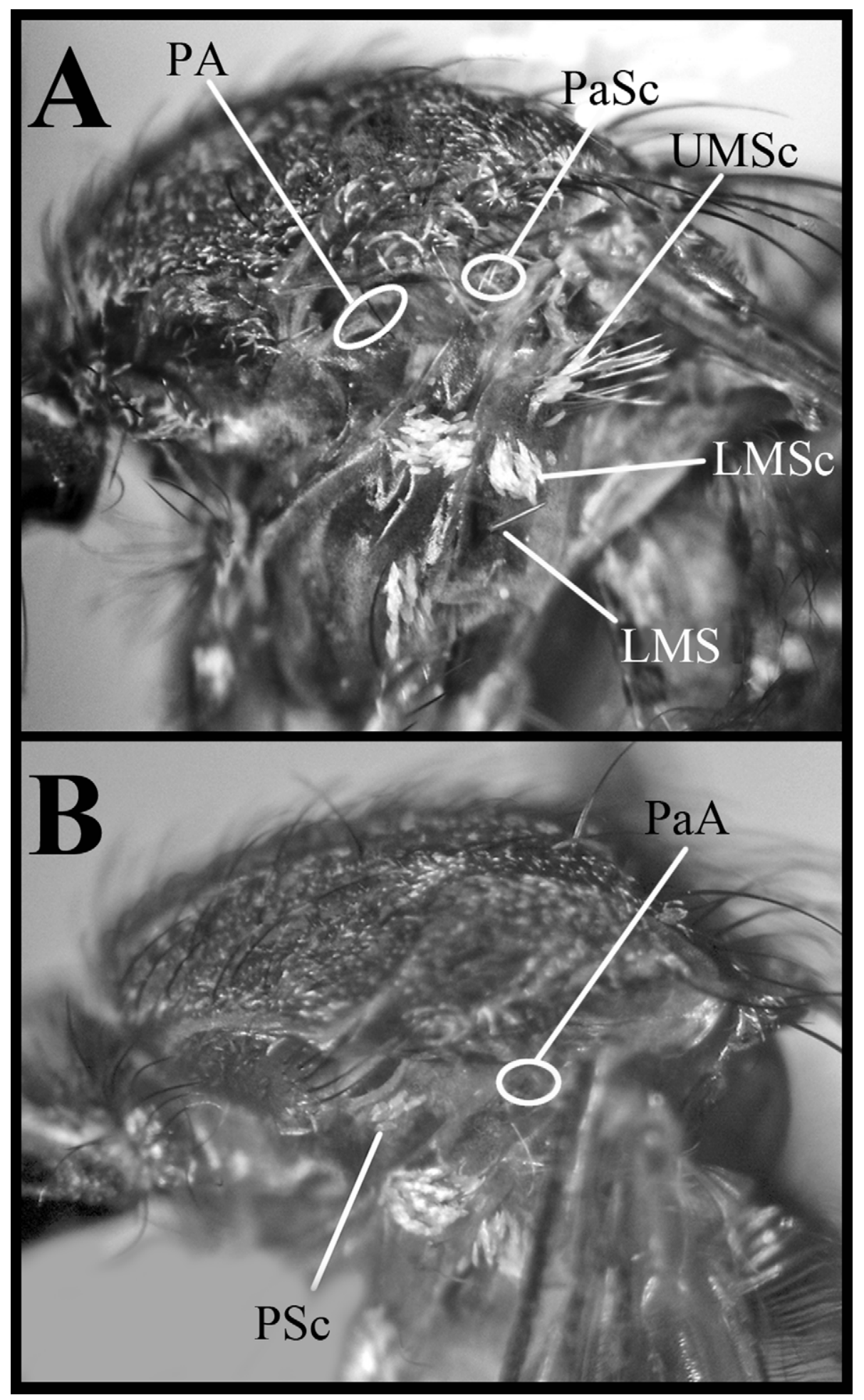

FIGURE 17. Pleural scales and setae of adult female mosquitoes. A: Culex (Culex) ameliae Casal; B: Culex (Culex) fernandezi Casal, García \& Cavalieri. LMSc = lower mesepimeral scales; LMS = lower mesepimeral setae; PA = postspiracular area; PaA $=$ prealar area PaSc $=$ prealar scales; PSc $=$ postspiracular scales; UMSc $=$ upper mesepimeral scales. 


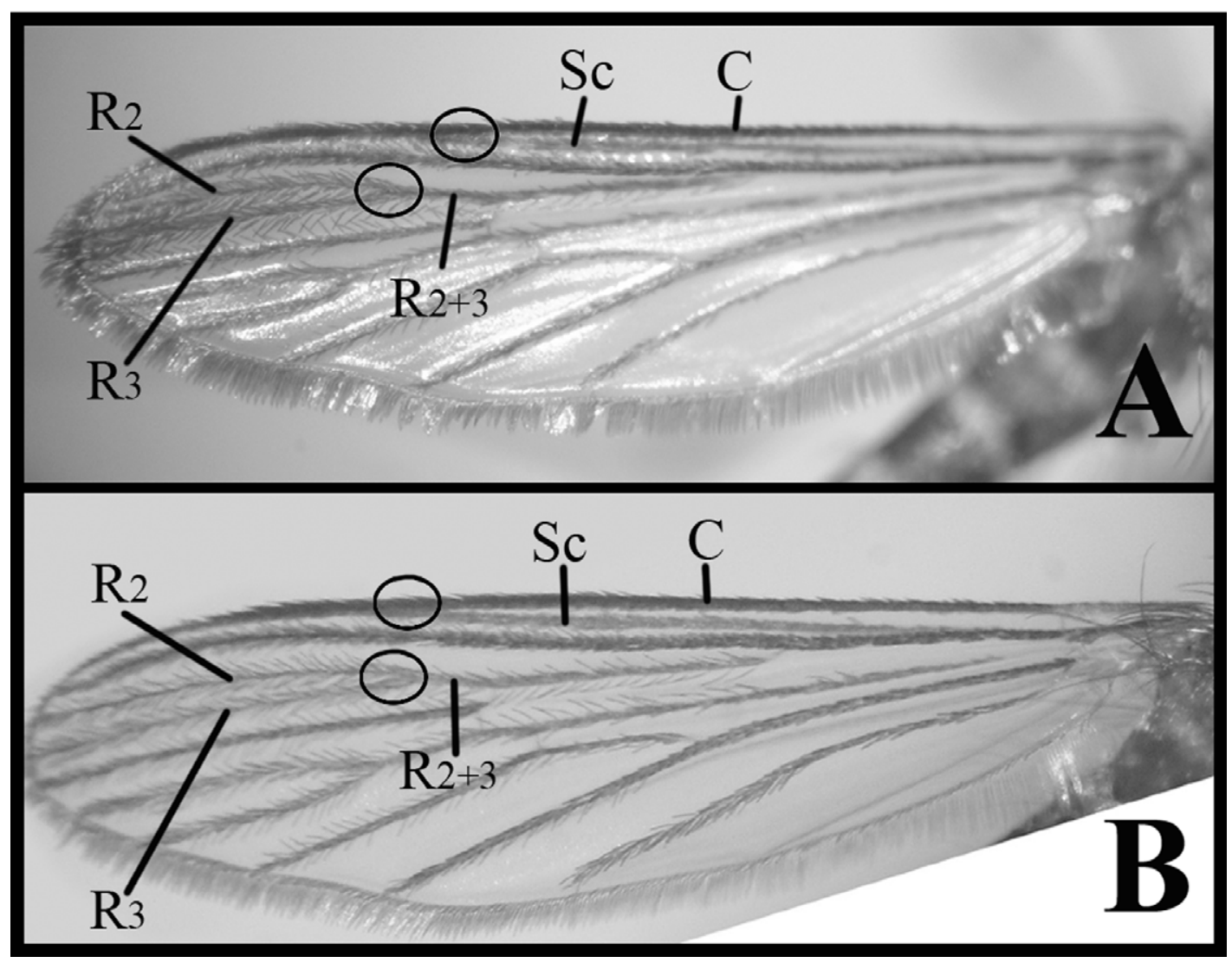

FIGURE 18. Wing veins of adult female mosquitoes. A: Culex (Culex) chidesteri Dyar; B: Culex (Culex) eduardoi Casal \& García. $\mathrm{C}=$ costa vein $; \mathrm{R}_{2}=$ radius-two vein $; \mathrm{R}_{3}=$ radius-three vein; $\mathrm{R}_{2+3}=$ radius-two-plus-three; $\mathrm{Sc}=$ subcosta vein.

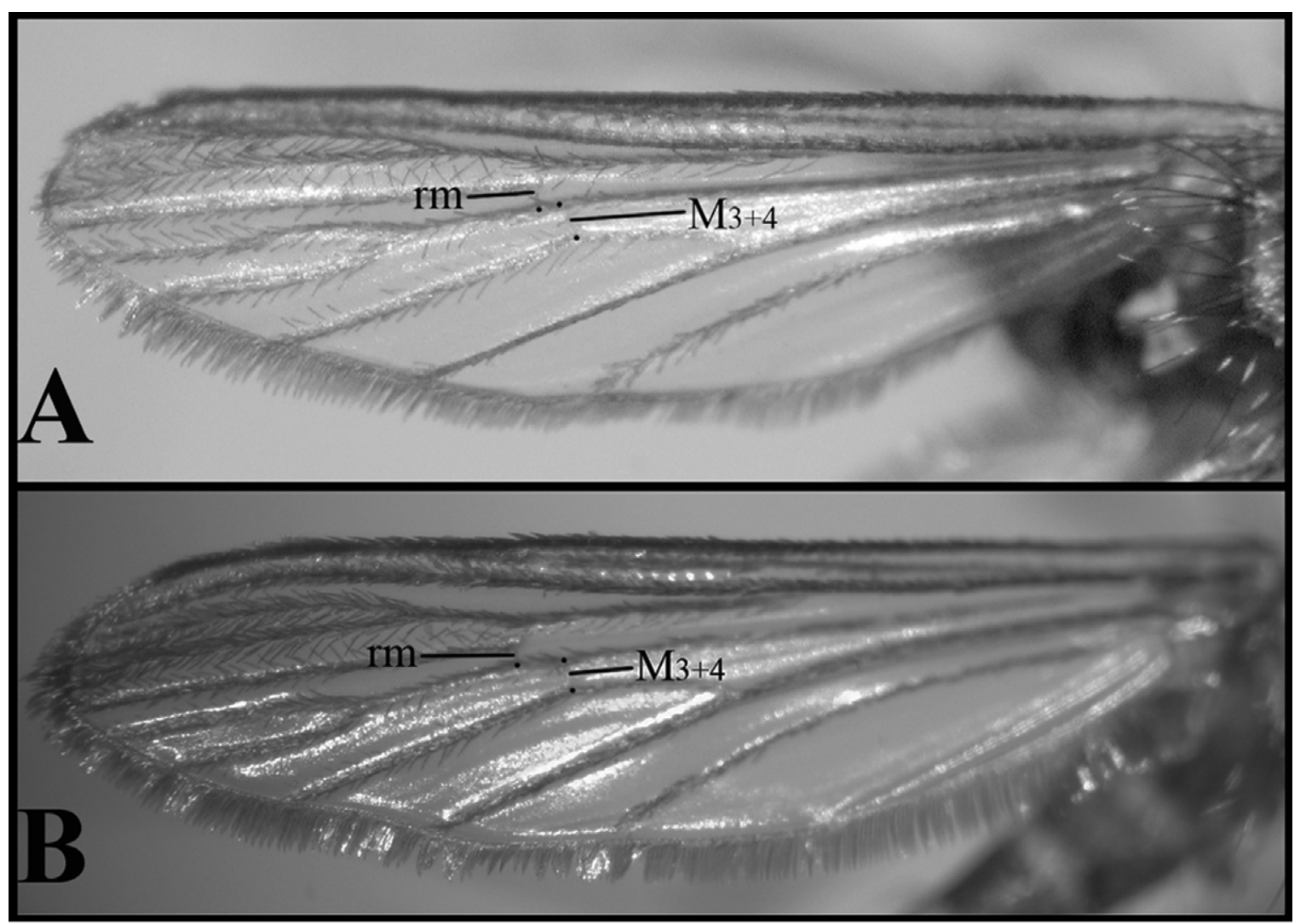

FIGURE 19. Relative length between wing veins of adult female mosquitoes. A: Culex (Culex) saltanensis Dyar; B: Culex (Culex) chidesteri Dyar. $\mathrm{M}_{3+4}=$ media-three-plus-four; $\mathrm{rm}=$ radiomedial crossvein. 


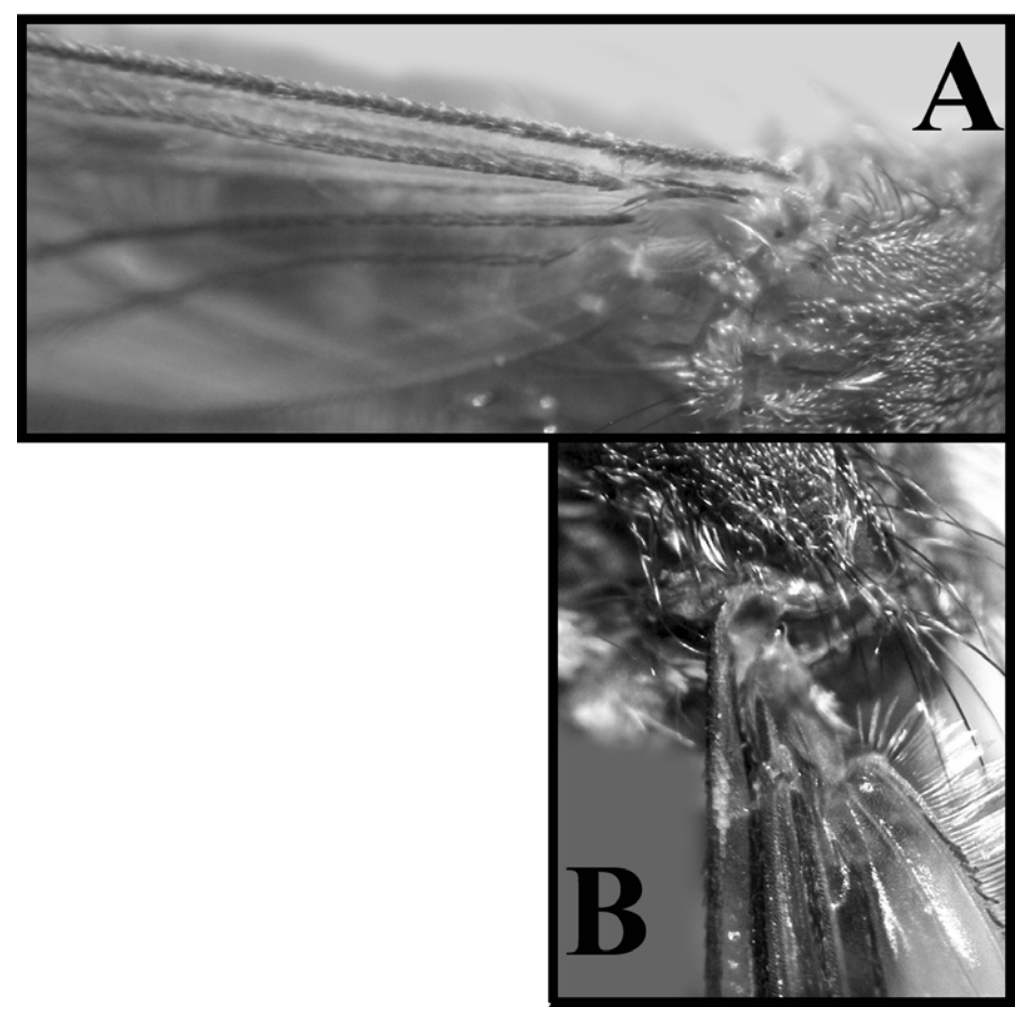

FIGURE 20. Colour of alar scales of adult female mosquitoes. A: Culex (Culex) acharistus Root; B: Culex (Culex) tatoi Casal \& García.

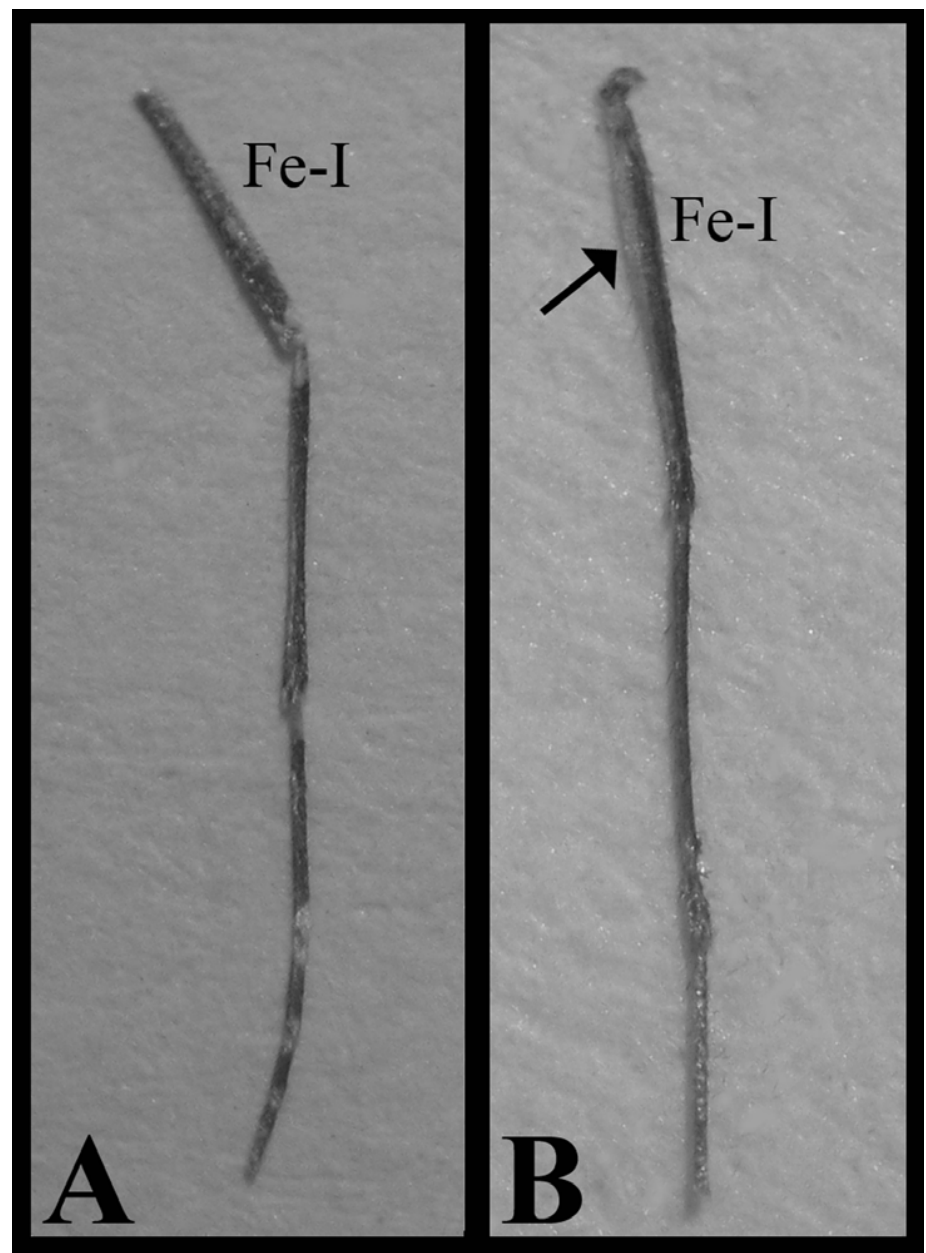

FIGURE 21. Forefemur of adult mosquitoes. A: Lutzia (Lutzia) bigoti (Bellardi); B: Culex (Culex) apicinus Philippi. Fe-I = forefemur. 


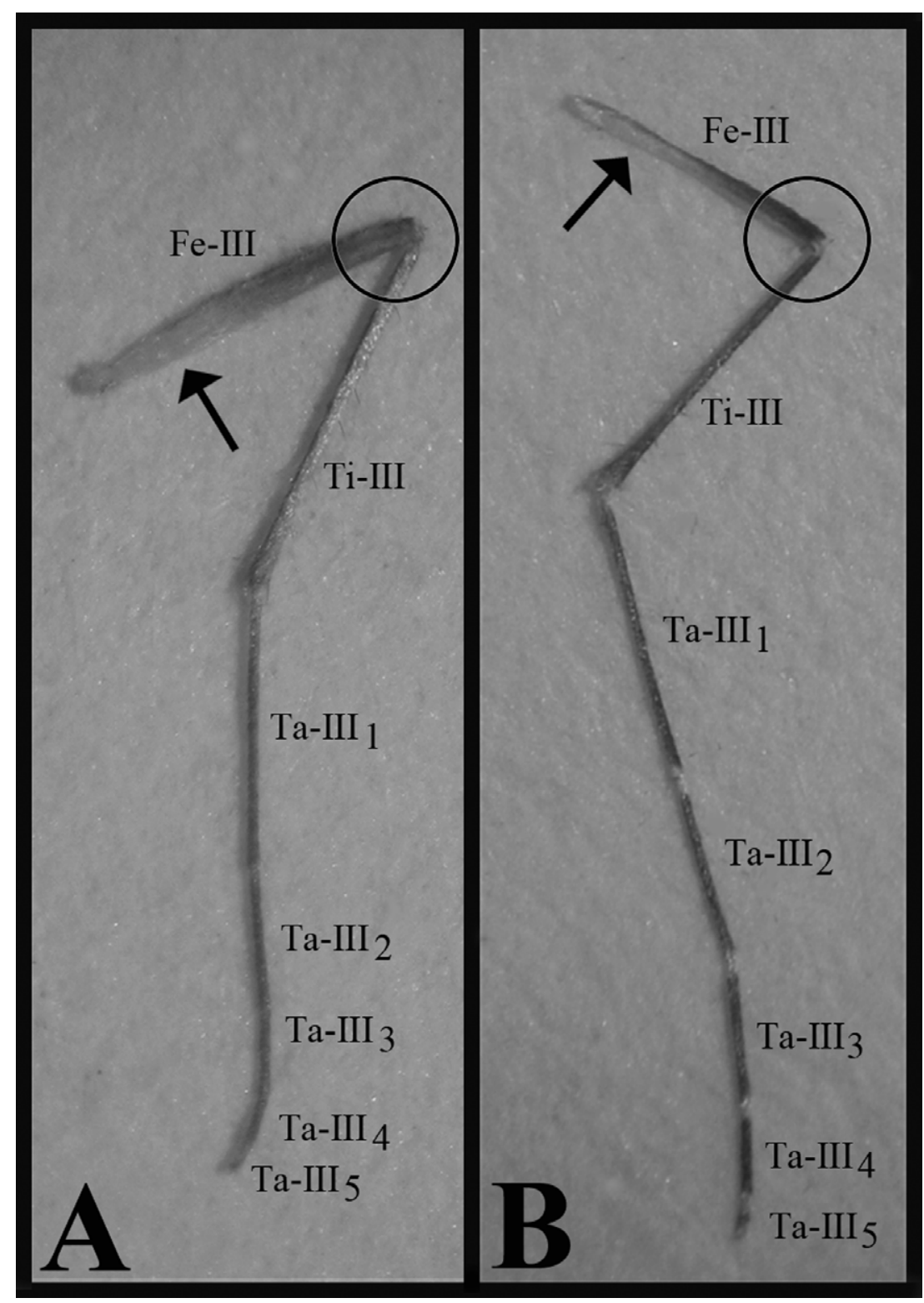

FIGURE 22. Hindleg of adult mosquitoes. A: Culex (Culex) bidens Dyar; B: Culex (Culex) coronator Dyar \& Knab. Fe-III = hindfemur; Ta-III ${ }_{1-5}=$ hindtarsomeres $1-5$; Ti-III = hindtibia.

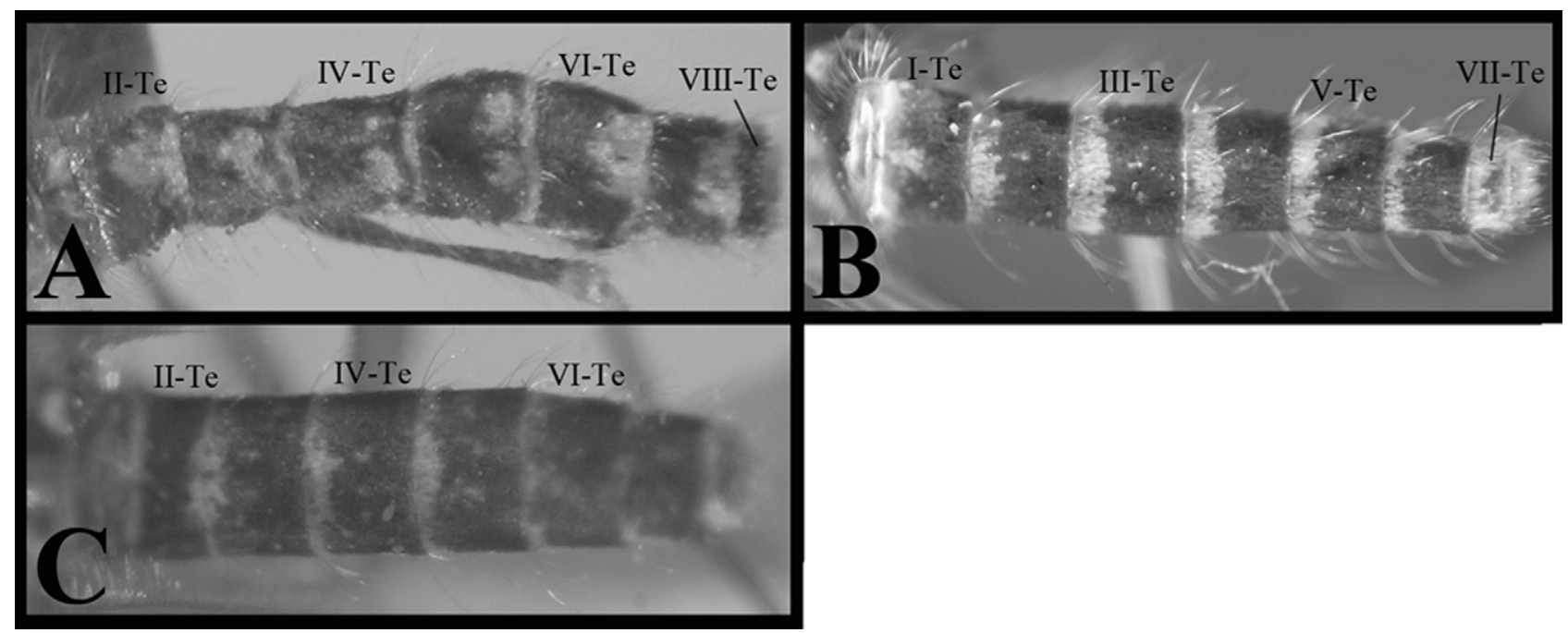

FIGURE 23. Pale scales on terga III-VI of adult mosquitoes. A: Lutzia (Lutzia) bigoti (Bellardi); B: Culex (Culex) chidesteri Dyar; C: Culex (Culex) bidens Dyar. I-VIII-Te = terga I-VIII. 


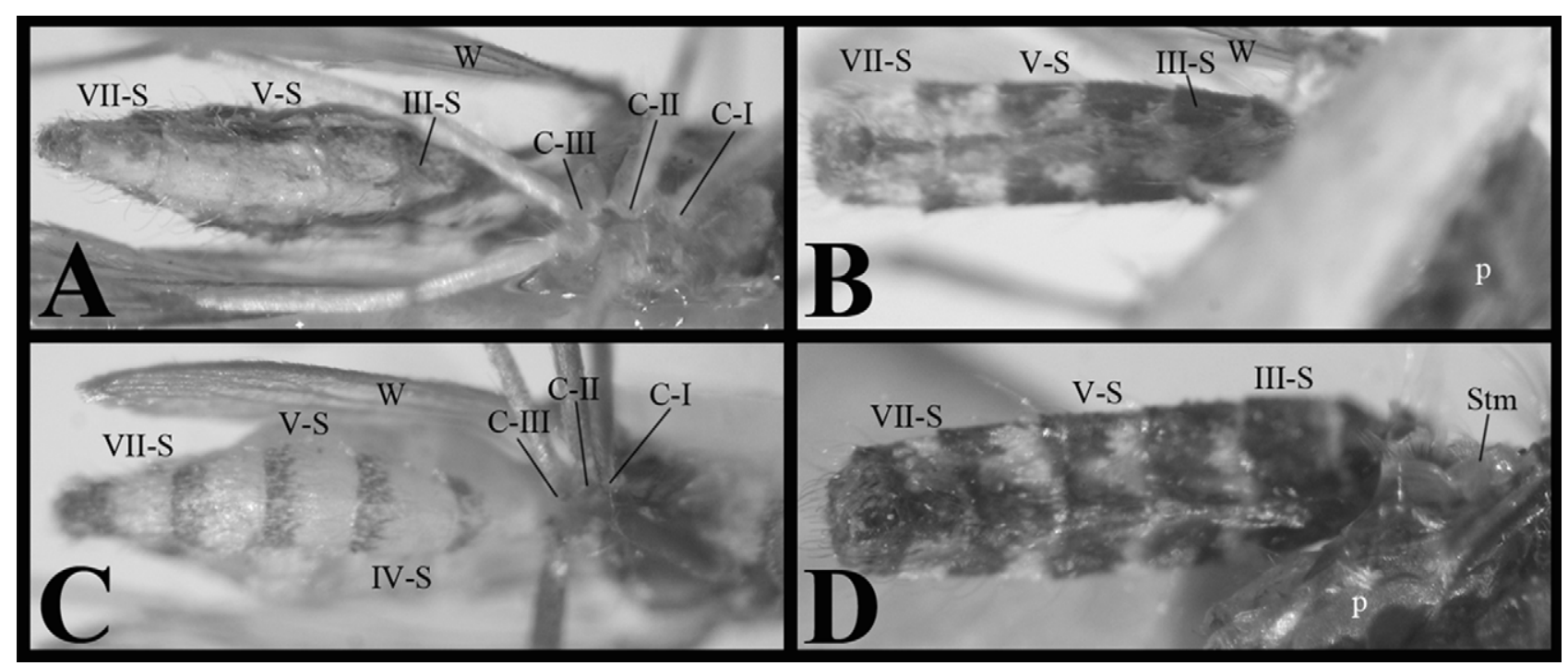

FIGURE 24. Scales on sterna III-VI of adult mosquitoes. A: Culex (Culex) quinquefasciatus Say; B: Culex (Culex) maxi Dyar; C: Culex (Phenacomyia) corniger Theobald; D: Culex (Culex) dolosus (Lynch Arribálzaga). C-I-III = coxae I-III; p = pleuron; $\mathrm{Stm}=$ scutellum; $\mathrm{W}=$ wing; III-VII-S = sterna III-VII.

\section{Male genitalia}

69. Gonocoxite, subapical lobe: (0) undivided (Fig. 25A,B); (1) divided. The subapical lobe is a mesal lobe located near or distal to the middle of the gonocoxite; bearing setae $a-h$. The subapical lobe can be subdivided into two subunits because of a constriction.

70. Gonocoxite, subapical lobe, development: (0) weak (Fig. 25A,B); (1) prominent (Fig. 25C,D). The subapical lobe is considered well developed or prominent when a distinct and round apical bulge can be distinguished.

71. Gonocoxite, subapical lobe, seta $g$ : (0) absent; (1) present (Fig. 25A-D).

72. Gonocoxite, subapical lobe, seta $g$ (if present): (0) filiform; (1) foliform (Fig. 25A-C); (2) cylindrical ending in one or two tips (Fig. 25D). A filiform seta is defined as a thin, thread-shaped seta and a cylindrical seta is a strong rod.

73. Gonocoxite, subapical lobe, seta $h$ : (0) absent; (1) present (Fig. 25A-D).

74. Gonocoxite, subapical lobe, seta $h$ (if present): (0) filiform with straight apex (Fig. 25A); (1) foliform (Fig. 25C,D); (2) filiform with curved apex (Fig. 25B).

75. Gonocoxite, apical setal patch: (0) absent; (1) present (Fig. 26A,B).

76. Gonocoxite, apical setal patch (if present): (0) not reaching midpoint of the gonostylus (Fig. 26A); (1) extending at least to midpoint of the gonostylus (Fig. 26B).

77. Gonostylus, development: (0) not broadened in middle (Fig. 25A,D); (1) broadened in middle (Fig. 25B,C).

78. Gonostylus, apical third: (0) smooth (Fig. 25C); (1) with minute annulations (Fig. 25A,B); (2) rough, with minute striations (Fig. 25D).

79. Phallosome, dorsal arm: (0) absent (Fig. 27A); (1) present (Fig. 27B,C).

80. Phallosome, dorsal arm (if present): (0) weakly developed (shorter or slightly longer than lateral plate, Fig. 27B); (1) well developed (markedly longer than lateral plate, Fig. 27C).

81. Phallosome, ventral arm: (0) straight (Fig. 28A); (1) laterally curved (Fig. 27A-C and Fig. 28B); (2) T-shaped (Fig. 28C).

82. Phallosome, ventral arm, curvature (if present): (0) smooth (Fig. 27A-C); (1) rough (Fig. 28B).

83. Phallosome, apex of ventral arm: (0) pointed (Figs. 27A-C, 28A-C); (1) blunt (see e.g. illustrations in Sirivanakarn (1976), Cx. annulirostris).

84. Phallosome, apical surface of ventral arm: (0) smooth (inconspicuous striations may be present, Figs. 27A-C, 28A-C); (1) serrate (see e.g. illustrations in Sirivanakarn (1976), Cx. annulirostris, and Lane \& Ramalho (1960), Cx. renatoi); (2) spiculated (see e.g. illustrations in Sirivanakarn (1976), Cx. sitiens).

85. Phallosome, lateral arm: (0) absent (Fig. 27A); (1) present (Fig. 29A-E).

86. Phallosome, shape of lateral arm: (0) acute (Fig. 29A-D); (1) blunt (Fig. 29E). 
87. Phallosome, development of tooth (teeth)-shaped lateral arm (if applicable): (0) reduce to denticle(s) (Fig. 29A); (1) one tooth (Fig. 29B); (2) two teeth (Fig. 29C); (3) more than two teeth (Fig. 29D). When the lateral arm is tooth(teeth)-shaped (states 1-3), it may have one or two teeth, or a variable number (if more than three) within the same species.

88. Phallosome, surface of lateral arm: (0) smooth (Fig. 29A-D); (1) denticulate (Fig. 29E).

89. Tergum IX lobes, development: (0) undifferentiated (Fig. 30A); (1) differentiated (Fig. 30B).

90. Proctiger, basolateral arm: (0) absent (see Sirivanakarn, 1976); (1) present (Fig. 31 A-C).

91. Proctiger, basolateral arm, shape (if present): (0) straight (Fig. 31A); (1) bent (Fig. 31B,C).

92. Proctiger, basolateral arm (if present), apex: (0) blunt (Fig. 31A,B); (1) pointed (Fig. 31C).

93. Paraproct, acetabulum (= subbasal process): (0) absent (Fig. 31A,C); (1) present Fig. 31B).

94. Paraproct, crown: (0) with blade-like spicules; (1) with pointed spicules (Fig. 31A,C); (2) with pointed and blade-like spicules (Fig. 31B).

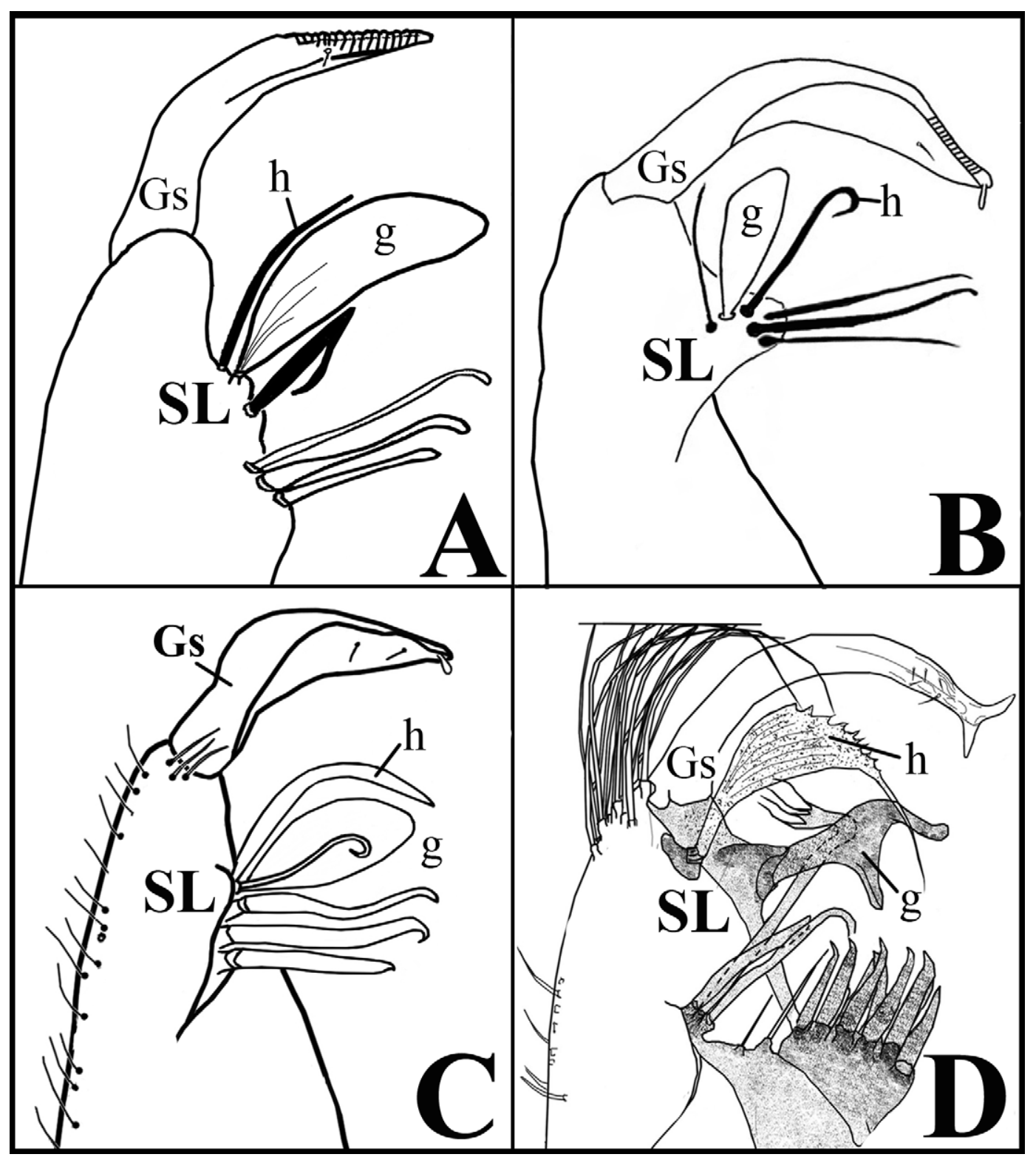

FIGURE 25. Subapical lobe of gonocoxite of male genitalia. A: Culex (Culex) articularis Philippi; B: Culex (Culex) acharistus Root; C: Culex (Culex) lahillei Bachmann \& Casal; D: Culex (Culex) apicinus Philippi. g,h = setae of subpical lobe; Gs = gonostylus; $\mathrm{SL}=$ subapical lobe. 


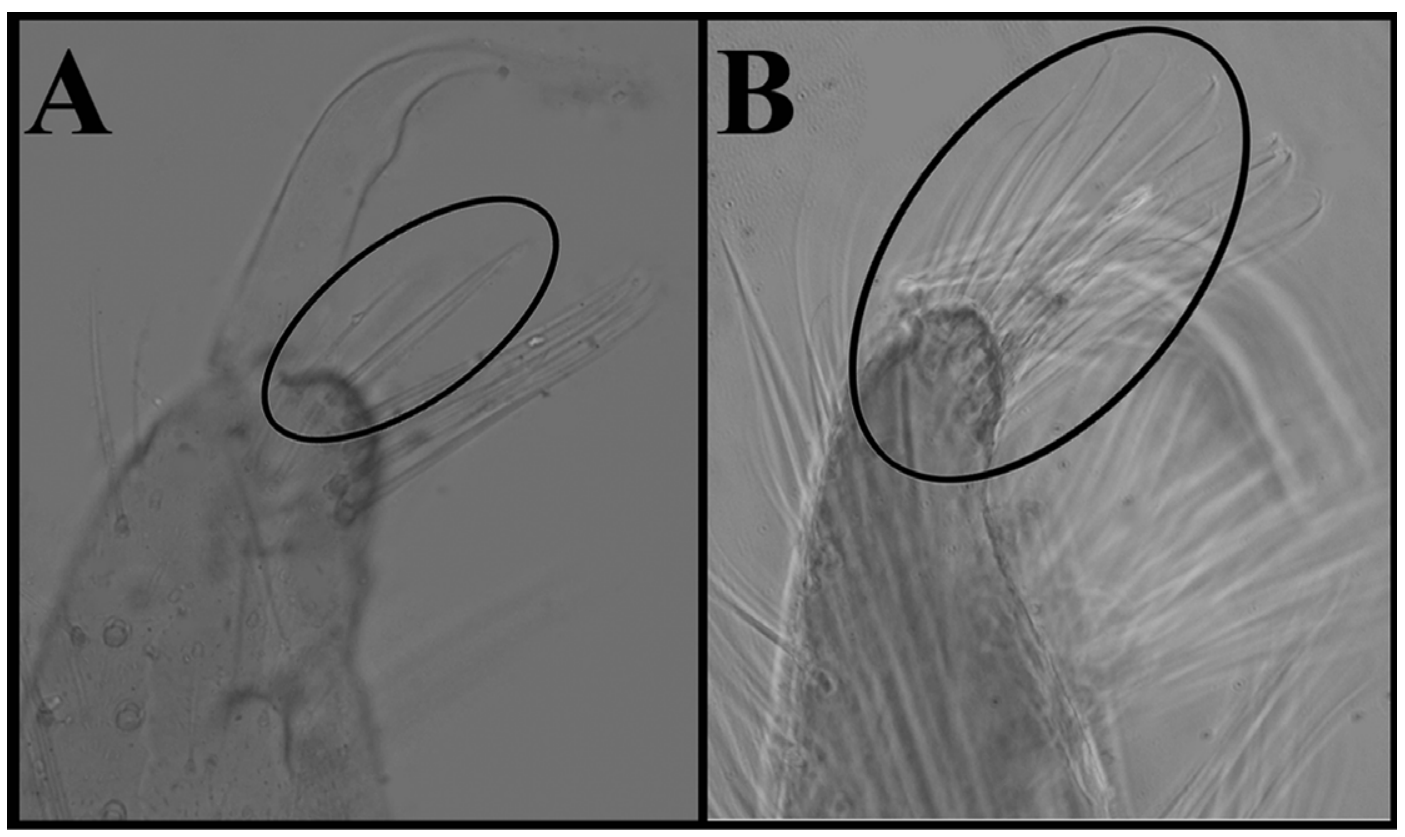

FIGURE 26. Apical setal patch of gonocoxite of male genitalia. A: Culex (Culex) coronator Dyar \& Knab; B: Culex (Culex) usquatissimus Dyar.

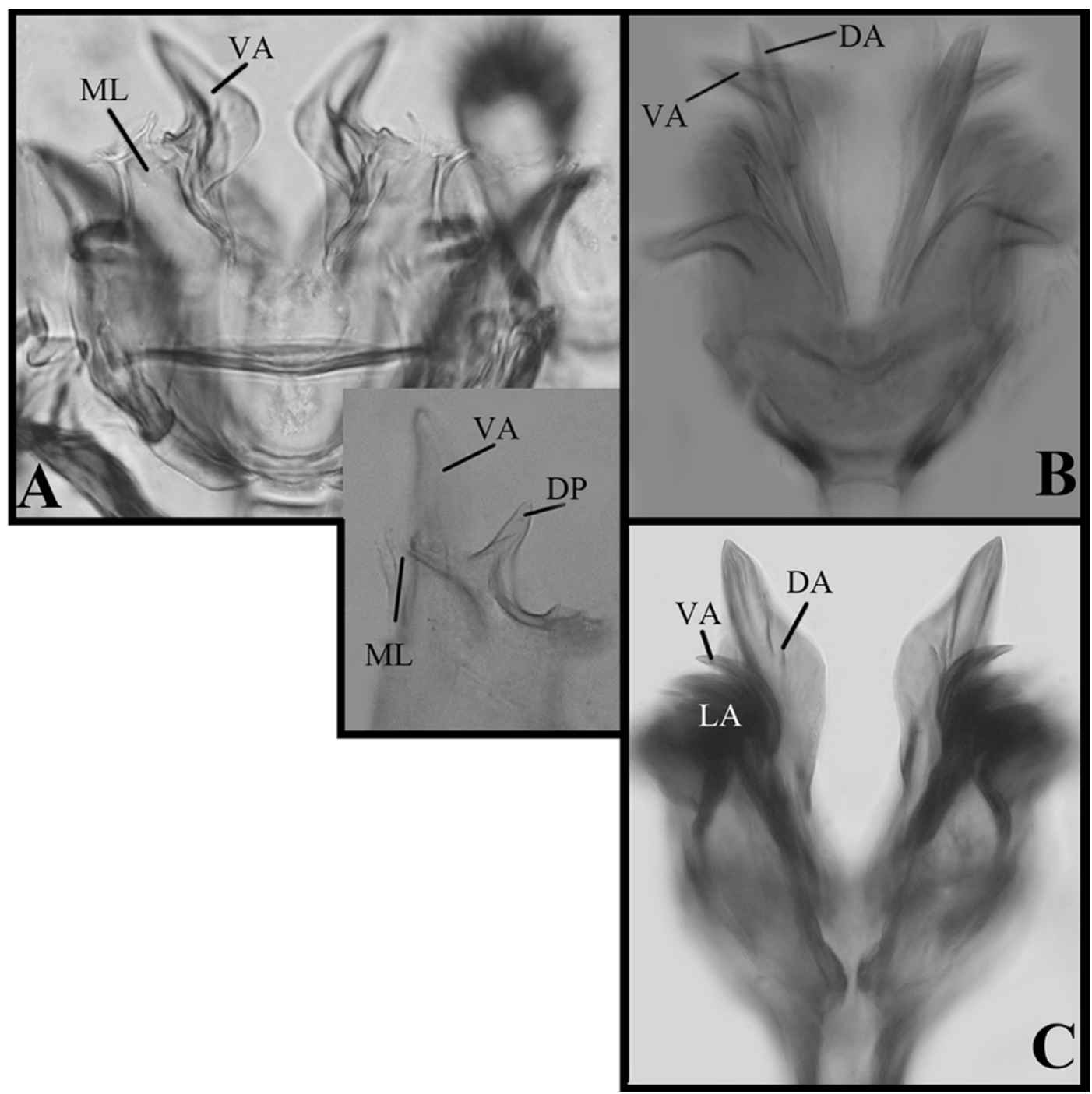

FIGURE 27. Structural features of phallosome of male genitalia. A: Culex (Culex) acharistus Root; B: Culex (Culex) mollis Dyar \& Knab; C: Culex (Culex) lahillei Bachmann \& Casal. DA = dorsal arm; DP = dorsal process; LA = lateral arm; ML = mesal lobe; $\mathrm{VA}=$ ventral arm. 


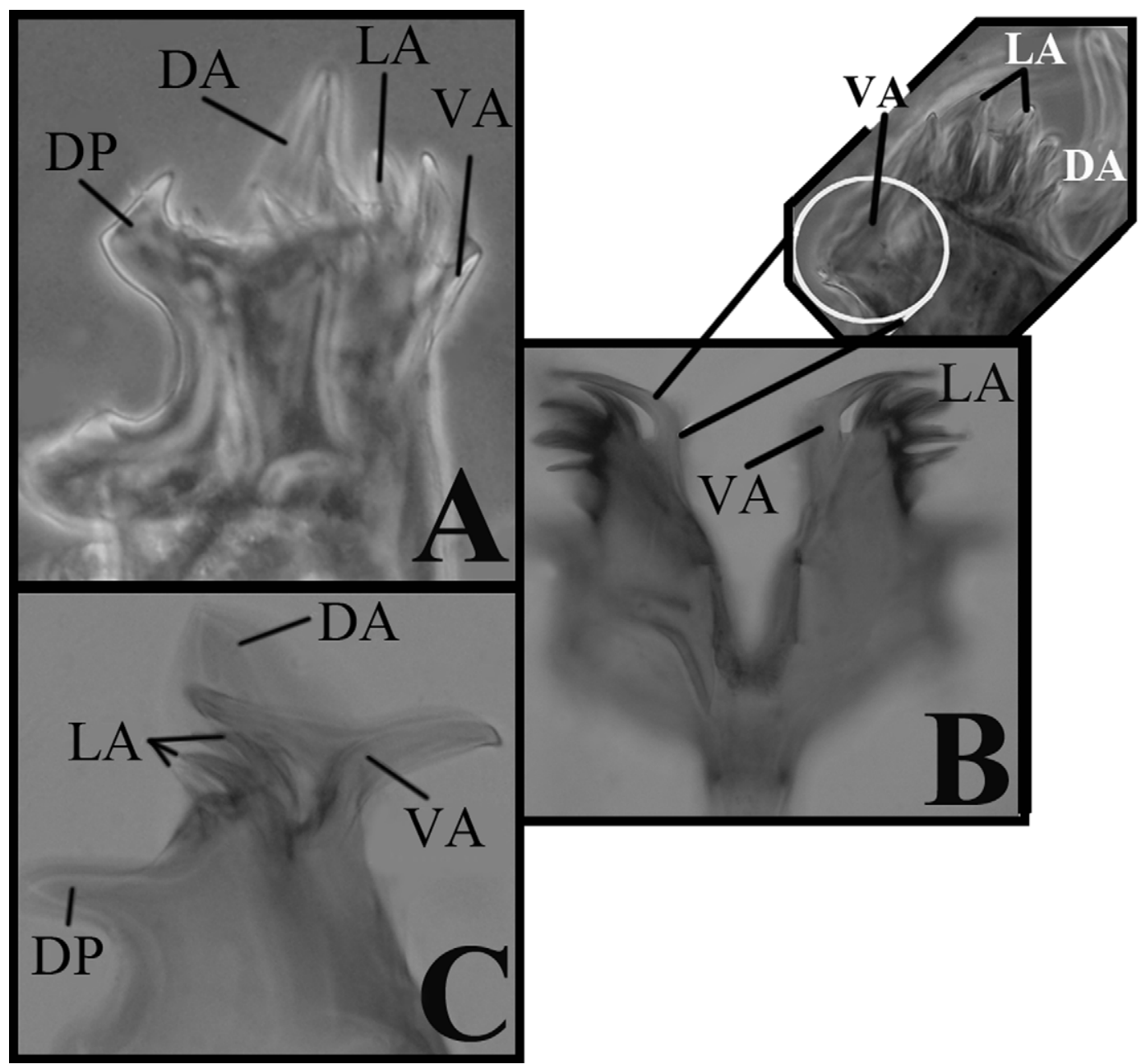

FIGURE 28. Structural features of phallosome of male genitalia. A: Culex (Culex) fernandezi Casal, García \& Cavalieri; B: Culex (Culex) maxi Dyar; C: Culex (Culex) lahillei Bachmann \& Casal. DA = dorsal arm; DP = dorsal process; LA = lateral arm; VA = ventral arm.

Cladistic analysis. The phylogenetic analyses were performed using standard cladistic procedures with the 'Traditional search' option, because of matrix size, in TNT ver. 1.1 (Goloboff et al. 2008a). Implied weighting method was used due to some characters being homoplastic to some degree, showing large numbers of extra steps when fitted onto the optimal cladogram (Goloboff et al. 2008b). A range of $K$ values from 6 to 9 was applied, selected from a wider range, in an attempt not to use an authoritarian criterion. These values were chosen because penalizing more strongly the homoplastic characters $(K<6)$ resulted in many relationships between species that could not be clarified (polytomies), and with values greater than 9 the relationships varied with the value of $K$.

Four series of heuristic searches (one for each concavity value) were performed. The search of the Wagner trees was made using 100 random addition sequences, saving up to 20 trees per replication, collapsing rule 1 (min. length $=0$ ) and TBR as the swapping algorithm followed by a second heuristic search. The strict consensus tree (SCT) was generated for each concavity value, and from the resulting four trees, a general SCT was obtained. Few relationships could be clarified due to a high degree of collapse in some nodes (data not shown). Therefore, a reduced strict consensus tree (RSCT) was performed for each concavity value pruning three unstable taxa $(C x$. bickleyi, Cx. riojanus and $C x$. mauesensis), with the gain of eigth nodes. The unstable taxa behaved in the same way under the four concavity values and the topology of the cladograms was similar. A SCT (Fig. 32) from the four RSCT was elaborated summarizing all the information provided by the data under the four concavity values. The alternative positions of the pruned taxa and the number of nodes are also shown in the SCT (Fig. 32). The character state changes $(K=7)$ common to the RSCTs obtained under different $K$ values are shown in Appendix. 


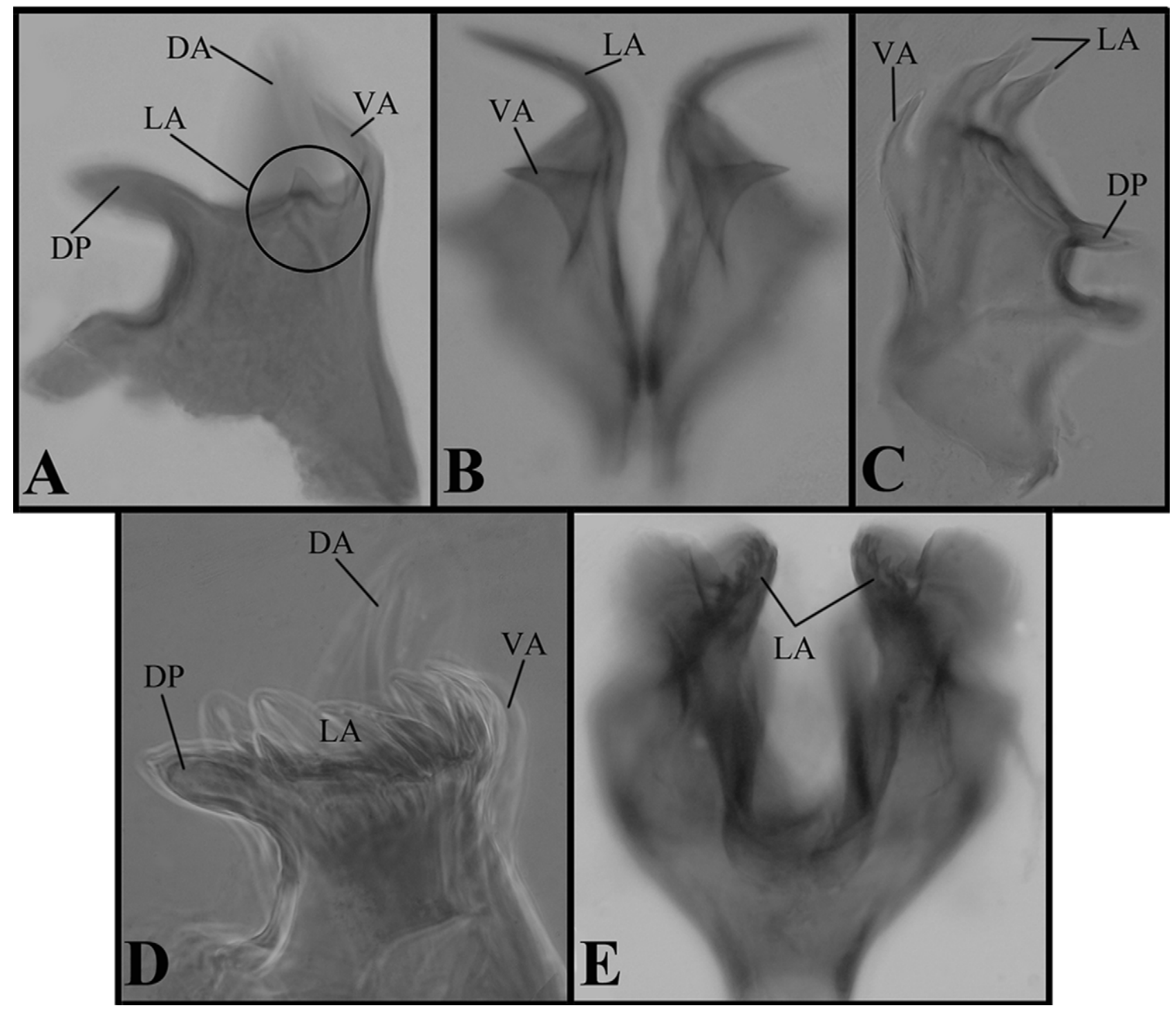

FIGURE 29. Structural features of phallosome of the male genitalia. A: Culex (Culex) brethesi Dyar; B: Culex (Culex) interfor Dyar; C: Culex (Culex) bidens Dyar; D: Culex (Culex) lahillei Bachmann \& Casal; E: Culex (Culex) chidesteri Dyar. DA = dorsal arm; $\mathrm{DP}=$ dorsal process; $\mathrm{LA}=$ lateral arm; $\mathrm{VA}=$ ventral arm.

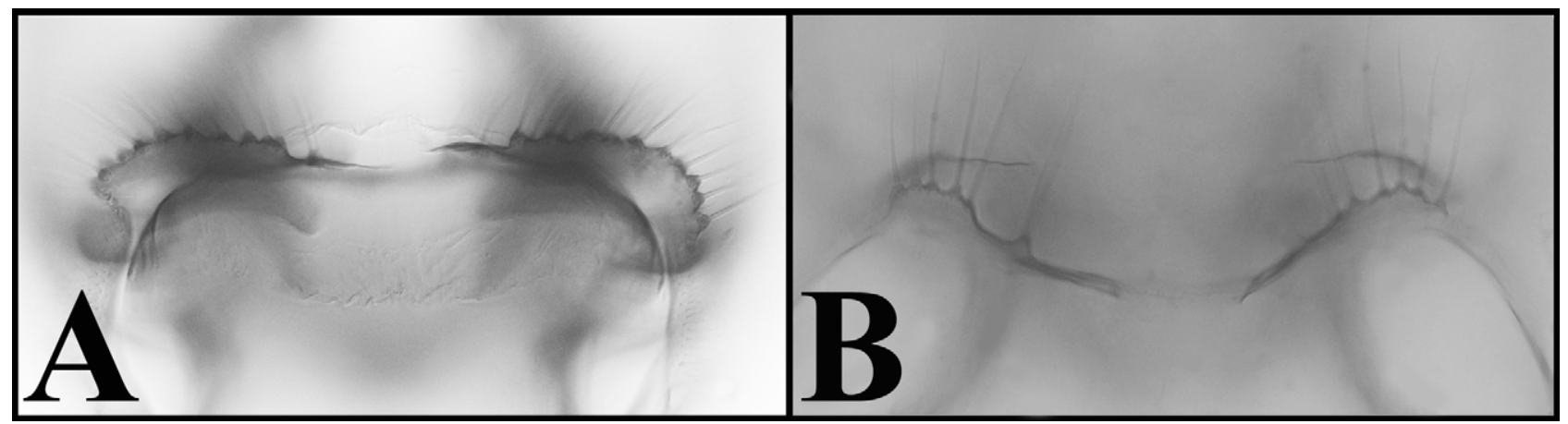

FIGURE 30. Tergum IX of male mosquitoes. A: Culex (Phytotelmatomyia) renatoi Lane \& Ramalho; B: Culex (Culex) quinquefasciatus Say. 


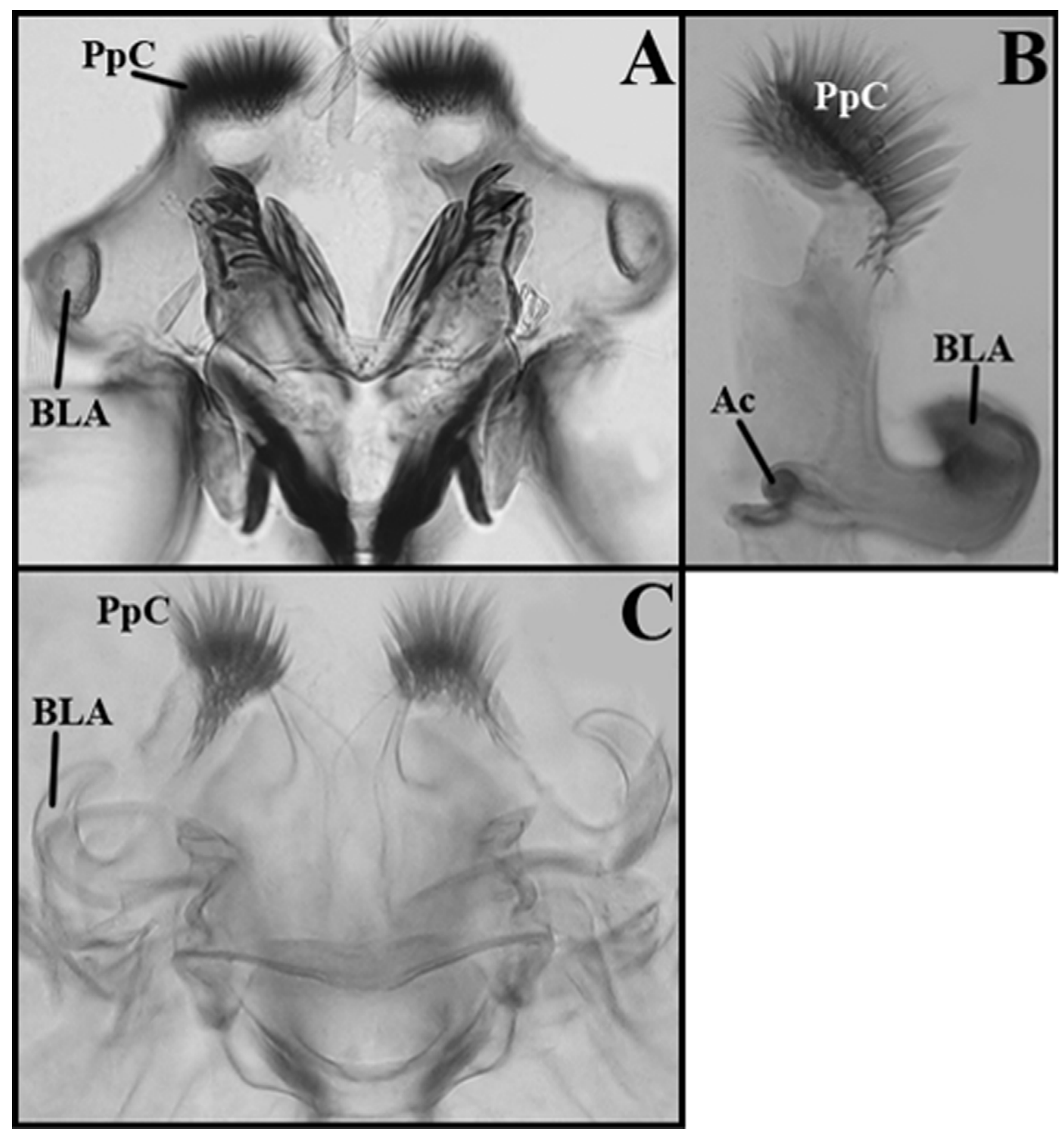

FIGURE 31. Structural features of proctiger of male genitalia. A: Culex (Culex) apicinus Philippi; B: Culex (Culex) lahillei Bachmann \& Casal; C: Culex (Culex) acharistus Root. Ac = acetabulum; BLA = basolateral arm; PpC = paraproct crown.

The support for the groups obtained in the cladistic analysis was calculated using symmetric resampling (SR) (Goloboff et al. 2003) given in frequency differences (GC) and thereby avoids over- or under-estimate clade support due to the differential weighting of the characters. The search was performed using 'Traditional search' option with the following parameters: 5000 replicates, 100 random addition sequences, 10 trees per replication and TBR as swapping algorithm. Only nodes with positive SR values (SRV) can be interpreted as being supported, only these GC values are shown in the SCT $(K=7)$ in Figure 32. The relative Bremer support (RBS) (Goloboff \& Farris 2001) was examined as an alternative means of assessing group support (data not shown). 


\section{Results}

Each series of heuristic searches produced 11900 most parsimonious trees (MPTs), except for $K=9$, where 1700 MPTs were found. The SCTs obtained with the four concavity values were identical, except for a slight difference in the rearrangement of some species of the Coronator Group with $K=9$, and the fits $(26.24134,23.95105$, 22.04779 , and 20.43643 respectively). For the median concavity value, $K=7$, the consistency and retention indices values were 0.31 and 0.54 , respectively. Similar to the results of Reinert et al. (2009) and Harbach et al. (2012), the range of $K=6-9$ represent the stability in which the relationships among the present ingroup species is unaffected by changes in $K$. The best way to summarize all information provided by the data under the four concavity values is the RSCT from the four SCTs (Fig. 32).

\section{Relationships between the subgenera}

According to the SCT of the MPTs shown in the Figure 32, the subgenus Culex is not monophyletic with respect to the subgenus Oculeomyia, which is embedded within the clade that includes all the species of the subgenus Culex (clade 73, Fig. 32). The subgenera Phenacomyia and Phytotelmatomyia are located, as expected, as successive sisters of Culex (Culex), with Phenacomyia closer to the subgenus Culex than to Phytotelmatomyia (Fig. 32).

\section{Internal relationships of Culex (Culex)}

Node 73 (Fig. 32) comprising all sampled species of subgenus Culex and $C x$. (Ocu.) bitaeniorhynchus, is supported by a single synapomorphy and eight homoplastic characters (Appendix). The sole synapomorphy is seta 1-A of the larva possessing more than 5 branches (ch. 2) and the homoplastic characters include characters from all life stages. Those of the fourth-instar larvae include the length of the antenna relative to length of head capsule (ch. 0), branches of the seta 2-C (ch. 5) and length and developement of seta 3-P (ch. 10 and 11). Shared pupal characters include the development of the seta 10-CT (ch. 30), and the adult features, the colour of erect forked scales (ch. 38), the setal development of palpomeres 4 and 5 (ch. 40) and the presence of the apical setal patch on the gonocoxite (ch. 75). One clade to branch from the main stem, node 76, comprises species $(C x$. apicinus $+C x$. scheuberi) which diagnosis does not fully agree with the general pattern of the subgenus like seta $g$ of the subapical lobe ending in one (Cx. scheuberi) or two (Cx. apicinus) tips (synapomorphic character 72). The group, supported with 0.89 of SRV (Fig. 32), also shares other two homoplastic characters from the male genitalia (ch. 69 and 76). According to Rossi et al. (2008), Cx. apicinus does not share many diagnostic characters with the subgenus. Culex scheuberi has $78 \%$ of missing data because only the male genitalia are known for the species.

Node 72 (Fig. 32) is supported with three synapomorphic and seven homoplastic characters. The first ones, related to immature stages include the seta 1-A more than 0.50 relative to the length of the antenna (ch. 3 ) and seta 4-P double, both of the larva, and seta 6-II longer than seta 7-II of the pupa. This node corresponds to a polytomy that includes $C x$. alani and two other nodes (Fig. 32). One node (100) comprises $C x$. articularis $+C x$. acharistus, and is supported by the combination of two homoplastic characters: the insertion of the seta 2-II relative to 3-II of the pupa (ch. 32) and the ornamentation of the apical third of the gonostylus (ch. 78). The other node (71) is supported by a single homoplasy (ch. 22) and includes the clade composed of Cx. dolosus $+C x$. fernandezi (95), which share three homolastic features (Appendix) and the clade 70. One of the two clades of node 70 is the clade 69 that includes species in a sister relationship with a smaller clade comprising $C x$. mollis $+C x$. tatoi (node 105). The species at node 105 ( 0.35 of SRV) share the T-shaped ventral arm of the phallosome (ch. 81).

Node 69 comprises $C x$. ameliae + Cx. eduardoi (96) with 0.07 of SRV (Fig. 32), relationship maintained by the homoplastic characters 29 and 80 (Appendix). The node 68 (Fig. 32) is an unresolved polytomy whose species included therein share the seta 5-IV shorter than the seta 5-V of the larva as synapomorphic character (ch. 34) and other three homoplastic features (ch. 12, 32 and 92; Appendix).

Two branches of the polytomy at node 68 correspond to terminal taxa, with $73 \%$ missing data due to the female, pupal and larval stages being unknown, and the other to resolved or partially resolved relationships. Culex pipiens $+C x$. quinquefasciatus (101), with 0.58 SRV, share four homoplastic features of larva and adults stages (Appendix). The node 102 of the polytomy, Cx. levicastilloi $+C x$. quitensis, is supported with 0.24 of SRV and three homoplastic characters (Appendix). 
The node 99 comprises $C x$. brethesi $+(C x$. interfor $+C x$. bidens $)$, species whose relationships could be explained by the combination of five homoplastic characters (Appendix) and supported with 0.12 of SRV. Culex bidens $+C x$. interfor (104), with 0.93 of SRV, are closely related due to share the homoplastic characters 38, 62,66 and 79 (Appendix).

Node 93 comprises species that share homoplastic features of the larval and adult stages (Appendix). The species included in the node 92 share the pointed and blade-like spicules of the paraproct crown (homoplastic character 94). Species at node 91 share as synapomorphy, the golden scutellar scales of females (ch. 48). Culex nigripalpus is sister to two species at node 90 with 0.06 of SRV support, relationship based on homoplastic features of the adult (Appendix).

Node 67 includes species that share the junction between subcosta and costa veins proximal to the furcation of $\mathrm{R}_{2+3}$ as synapomorphic character (ch. 55) and the homoplastic character 68 . One branch of the clade, node 66, is supported with 0.04 of SRV and includes $C x$. thriambus in a sister-group relationship with the Old World members of Culex included in the analysis (Fig. 32). These Old World species (node 65) share homoplastic features of all life stages except the pupa (Appendix). The group to branch from node 65 comprises the Vishnui Subgroup species (node 75) and the Sitiens Subgroup (node 64) species including Cx. bitaeniorhynchus (Fig. 32). Another branch of the clade 67 is the node 89 which comprises $C x$ lygrus $+C x$. cuyanus (node 97) and the node 88 . Node 87 ( $C x$. diplophyllum $+(C x$. carcinoxenus $+C x$. lahillei $)$, with 0.03 of SRV, is supported by homoplastic characters as in the node 94 (Appendix). Culex chitae (node 98) is sister to node 103 based on the homoplastic character 82. The sister pair at node 103, Cx. guayasi $+C x$. chidesteri, is supported by 0.02 of SRV and shares one synapomorphy in relation to the lateral arm of the phallosome (ch. 88) and other three homoplastic features also of the male genitalia (Appendix).

The species comprising the polytomy of node 84 share the absence of seta $h$ on the subapical lobe of the gonocoxite (ch. 73). Culex declarator and Cx. archegus correspond to terminal taxa of the polytomy (Fig. 32), their relationship with the other species of the clade remain unknown. Node 83 (0.11 of SRV), is supported by the absence of seta $g$ on the subapical lobe (plesiomorphic character 71) and shows $C x$. habilitator as the sister to node 82 which includes $C x$. surinamensis in a sister relationship with the node 81 . The latter, includes species with acetabulum on the male paraproct (homoplastic character 93) and $C x$. bonneae is sister to node 80 . The sister pair $C x$. saltanensis $+C x$. maracayensis (node 86, 0.60 of SRV) is supported by homoplastic characters of larvae (ch. 20) and females (ch. 44). Node 79 includes the Coronator Group species, Cx. brevispinosus, Cx. maxi and $C x$. paramaxi and is supported by homoplastic features of larvae (ch. 12) and the male genitalia (ch. 82). Culex covagarciai is the sister species to node 78 ( 0.10 of SRV), supported by the synapomorphic character 24: presence of subapical spines on the siphon of larvae. Culex maxi is in a sister-group relationship with the polytomy that comprises clade 77, supported by the synapomorphic character 19 which imply spine-like and evenly fringed comb scales of larvae and other two homoplastic characters (Appendix). Four branches of the polytomy correspond to terminal taxa (Fig. 32) and the one comprises another unresolved polytomy, node 85 . Node 85 is supported with 0.28 of SRV and homoplastic features of larvae (ch. 8 and 18) and the male genitalia (ch. 76).

\section{Discussion}

According to Belkin (1962), the affinities of the subgenera of Culex are obscure. Likewise, affinities of the species within the subgenus Culex are also obscure.

Based on morphology, Mallampali (1995) showed the genus Culex formed a paraphyletic clade relative to Deinocerites and Galindomyia. Based on molecular characters, Miller et al. (1996) found that Lutzia was sister to the subgenus Culex and the genus Culex appeared to be paraphyletic. The genus Culex is polyphyletic relative to Deinocerites, according to St. John (2007), and Deinocerites and Galindomyia, according to Harbach et al. (2012), both studies based on morphological characters of adults, pupae and larvae. In contrast to Demari-Silva et al. (2011), Vesgueiro et al. (2011) and Harbach et al. (2012), we did not recover subgenus Phenacomyia within the subgenus Culex. Unlike Harbach et al. (2012), Phytotelmatomyia was not recovered as a terminal taxon within the Pipiens Group, or even within $C x$. (Cux.). However, subgenus Oculeomyia was subsumed within the subgenus Culex in agreement with the results obtained by Harbach et al. (2012). In accordance with Harbach (2011b), our analysis shows that the classification of Culex is based on a subjective interpretation of morphological similarities and consists of unnatural assemblages of species. 


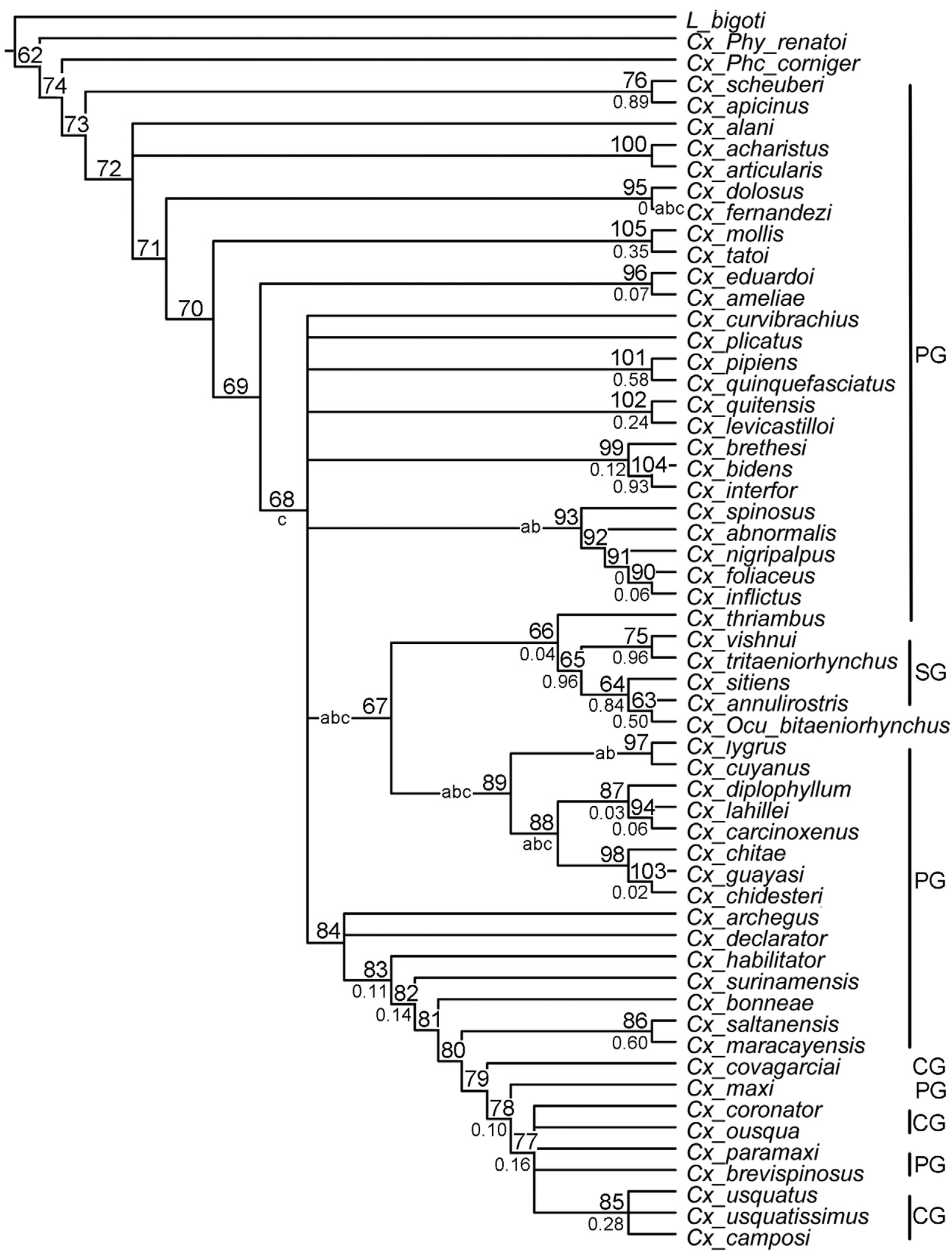

FIGURE 32. Strict consensus tree (SCT) from four reduced strict consensus trees (RSCT) of 11900 MPTs, obtained from the analysis of data (Table 2) using TNT ver. 1.1 and implied weighting method $(\mathrm{K}=6-9)$. The node numbers are indicated above each branch. Only positive symmetric resampling support values (SRV) given in frequency differences (GC) are provided below the corresponding branches. The alternative positions of unstable taxa (Culex bickleyi, Culex riojanus and Culex mauesensis) are indicated with bold letters in the branches. $\mathrm{a}=$ Culex bickleyi $; \mathrm{b}=$ Culex riojanus; $\mathrm{c}=$ Culex mauesensis; $\mathrm{CG}=$ Coronator Group; PG = Pipiens Group; SG = Sitiens Group. 
TABLE 2. Data matrix for 61 species and 95 morphological characters used in the phylogenetic analysis.

\begin{tabular}{|c|c|c|c|c|c|c|c|c|c|c|c|c|c|c|c|c|c|}
\hline & \multirow[t]{2}{*}{$\mathbf{0}$} & \multirow[t]{2}{*}{1} & \multirow[t]{2}{*}{2} & \multirow[t]{2}{*}{3} & \multirow[t]{2}{*}{4} & \multirow[t]{2}{*}{5} & \multirow[t]{2}{*}{6} & \multirow[t]{2}{*}{7} & 8 & 9 & 1 & 1 & 1 & 1 & 1 & 1 & 1 \\
\hline & & & & & & & & & & & 0 & 1 & 2 & 3 & 4 & 5 & 6 \\
\hline Lt. bigoti & 0 & 0 & 0 & 0 & 0 & $?$ & $?$ & 0 & 0 & 1 & 0 & 0 & 1 & 0 & 3 & $?$ & 1 \\
\hline Cx. abnormalis & $?$ & 1 & 1 & $?$ & 2 & $?$ & 1 & $?$ & $?$ & $?$ & $?$ & 0 & $?$ & 1 & 1 & $?$ & $?$ \\
\hline$C x$. acharistus & 1 & 0 & 1 & 1 & 2 & 0 & 0 & 2 & 2 & 0 & 1 & 1 & 1 & 1 & 1 & 1 & 0 \\
\hline Cx. alani & $?$ & $?$ & $?$ & $?$ & $?$ & $?$ & $?$ & $?$ & $?$ & $?$ & $?$ & $?$ & $?$ & $?$ & $?$ & $?$ & $?$ \\
\hline Cx. ameliae & 2 & 1 & 1 & 1 & 2 & 0 & 0 & 0 & 0 & 0 & 1 & 0 & 1 & 1 & 2 & 1 & 0 \\
\hline Cx. annulirostris & 2 & 1 & 1 & 1 & 2 & $?$ & $?$ & 1 & 1 & 0 & 1 & 0 & $?$ & 1 & 2 & 1 & 0 \\
\hline Cx. apicinus & 1 & 1 & 1 & 0 & 1 & 1 & 0 & 1 & 0 & 0 & 1 & 1 & 2 & 2 & 3 & 2 & 1 \\
\hline Cx. archegus & 1 & 1 & 1 & $?$ & $?$ & $?$ & $?$ & $?$ & $?$ & $?$ & $?$ & $?$ & $?$ & $?$ & $?$ & $?$ & $?$ \\
\hline Cx. articularis & 1 & 1 & 1 & 1 & 0 & 1 & 0 & 1 & 1 & 0 & 1 & 0 & 1 & 1 & 1 & 1 & 0 \\
\hline Cx. bickleyi & $?$ & $?$ & $?$ & $?$ & $?$ & $?$ & $?$ & $?$ & $?$ & $?$ & $?$ & $?$ & $?$ & $?$ & $?$ & $?$ & $?$ \\
\hline Cx. bidens & 1 & 1 & 1 & 1 & 0 & 0 & 0 & 1 & 1 & 0 & 1 & 0 & 1 & 1 & 1 & 1 & 0 \\
\hline Cx. bitaeniorhynchus & 2 & 0 & 1 & 1 & 2 & 0 & 0 & 0 & 1 & 0 & 1 & 0 & 1 & 1 & 2 & 1 & 0 \\
\hline Cx. bonneae & $?$ & 1 & 1 & $?$ & 0 & $?$ & $?$ & $?$ & $?$ & $?$ & $?$ & $?$ & $?$ & 1 & $?$ & $?$ & $?$ \\
\hline Cx. brethesi & 1 & 1 & 1 & 1 & 0 & 0 & $\dot{0}$ & $\dot{1}$ & 2 & $\dot{0}$ & 1 & 0 & $\dot{1}$ & 1 & $\dot{1}$ & $\dot{1}$ & 0 \\
\hline Cx. brevispinosus & $?$ & 1 & 1 & $?$ & $?$ & $?$ & $?$ & $?$ & $?$ & $?$ & $?$ & 0 & $?$ & 1 & 2 & $?$ & $?$ \\
\hline Cx. camposi & 1 & 1 & 1 & 1 & 0 & 0 & 0 & 1 & $?$ & 0 & 1 & 0 & 1 & 1 & $?$ & 1 & 0 \\
\hline Cx. carcinoxenus & 1 & 1 & 1 & $?$ & $?$ & $?$ & 0 & 1 & $?$ & $?$ & $?$ & $?$ & $?$ & $?$ & $?$ & $?$ & $?$ \\
\hline Cx. chidesteri & 1 & 1 & 1 & 1 & 0 & 0 & 0 & 1 & 1 & 0 & 1 & 0 & 2 & 1 & 1 & 1 & 0 \\
\hline Cx. chitae & $?$ & $?$ & $?$ & $?$ & $?$ & $?$ & $?$ & $?$ & $?$ & $?$ & $?$ & $?$ & $?$ & $?$ & $?$ & $?$ & $?$ \\
\hline Cx. corniger & 0 & 0 & 0 & 0 & 0 & 0 & 0 & 0 & 1 & 0 & 0 & 2 & 2 & 2 & 1 & 1 & 1 \\
\hline Cx. coronator & 1 & 1 & 1 & 1 & 0 & 0 & 0 & 1 & 1 & 0 & 1 & 0 & 1 & 1 & 2 & 1 & 0 \\
\hline Cx. covagarciai & $?$ & 1 & 1 & $?$ & $?$ & $?$ & $?$ & $?$ & $?$ & $?$ & 1 & 0 & 1 & 1 & 2 & $?$ & $?$ \\
\hline Cx. curvibrachius & $?$ & $?$ & $?$ & $?$ & $?$ & $?$ & $?$ & $?$ & $?$ & $?$ & $?$ & $?$ & $?$ & $?$ & $?$ & ? & $?$ \\
\hline CX. cuyanus & 1 & $\dot{1}$ & 1 & $\dot{1}$ & $\dot{0}$ & 0 & $\dot{0}$ & 2 & $\dot{1}$ & $\dot{1}$ & $\dot{1}$ & $\dot{0}$ & $?$ & 1 & $\dot{1}$ & $\dot{1}$ & $\dot{0}$ \\
\hline Cx. declarator & 2 & 1 & 1 & 1 & 0 & $?$ & 0 & 1 & $?$ & $?$ & 1 & 0 & $?$ & 1 & 1 & $?$ & $?$ \\
\hline Cx. diplophyllum & $?$ & 1 & 1 & $?$ & 0 & $?$ & $?$ & $?$ & $?$ & $?$ & $?$ & 0 & $?$ & $?$ & $?$ & ? & $?$ \\
\hline Cx. dolosus & 2 & 1 & 1 & 1 & 0 & 1 & 0 & $\dot{1}$ & 2 & $\dot{0}$ & 1 & 1 & $i$ & 1 & $\dot{1}$ & 1 & 0 \\
\hline Cx. eduardoi & 2 & 1 & 1 & 1 & 0 & 0 & 0 & 1 & 1 & 0 & 1 & 0 & 1 & 1 & 1 & 1 & 0 \\
\hline$C x$. fernandezi & 1 & 1 & 1 & 1 & 0 & 1 & 1 & 1 & 2 & 0 & 2 & 1 & 3 & 1 & 2 & 1 & 0 \\
\hline Cx. foliaceus & 2 & 1 & 1 & 1 & $?$ & $?$ & 0 & 1 & $?$ & $?$ & $?$ & $?$ & $?$ & $?$ & $?$ & $?$ & $?$ \\
\hline Cx. guayasi & $?$ & $?$ & $?$ & $?$ & $?$ & $?$ & $?$ & $?$ & $?$ & $?$ & $?$ & $?$ & $?$ & $?$ & $?$ & $?$ & $?$ \\
\hline Cx. habilitator & $?$ & 1 & 1 & $?$ & $?$ & $?$ & $\dot{0}$ & $?$ & $?$ & $?$ & $?$ & $\dot{0}$ & $?$ & $\dot{1}$ & $\dot{1}$ & $?$ & $?$ \\
\hline Cx. inflictus & $?$ & 1 & 1 & $?$ & $?$ & $?$ & 0 & $?$ & $?$ & ? & $?$ & $?$ & ? & $?$ & $?$ & ? & $?$ \\
\hline Cx. interfor & 1 & 1 & 1 & 1 & 0 & 0 & 0 & 2 & 2 & 0 & 1 & 0 & 1 & 1 & 1 & 1 & 0 \\
\hline Cx. lahillei & 2 & 1 & 1 & 1 & 2 & 0 & 0 & 1 & 2 & 0 & 1 & 0 & 0 & 1 & 1 & 1 & 0 \\
\hline Cx. levicastilloi & 2 & 1 & 1 & $?$ & $?$ & $?$ & $?$ & $?$ & $?$ & $?$ & 1 & 0 & 2 & 1 & 2 & $?$ & $?$ \\
\hline Cx. lygrus & $?$ & $?$ & ? & $?$ & $?$ & $?$ & $?$ & $?$ & $?$ & $?$ & $?$ & $?$ & $?$ & $?$ & $?$ & ? & $?$ \\
\hline CX. maracayensis & $?$ & $\dot{1}$ & 1 & $?$ & $?$ & $?$ & $\dot{0}$ & $?$ & $?$ & $?$ & $?$ & $\dot{0}$ & $?$ & $\dot{1}$ & 2 & $?$ & $?$ \\
\hline Cx. mauesensis & $?$ & $?$ & $?$ & $?$ & $?$ & $?$ & $?$ & $?$ & $?$ & $?$ & $?$ & $?$ & ? & $?$ & $?$ & ? & $?$ \\
\hline Cx. maxi & 2 & 1 & 1 & 1 & 0 & 0 & 0 & 1 & 2 & 1 & 2 & 0 & 1 & 1 & 2 & 1 & 0 \\
\hline Cx. mollis & 1 & 1 & 1 & 1 & 0 & 1 & 0 & 1 & 1 & 0 & 1 & 0 & 1 & 1 & 1 & 1 & 0 \\
\hline Cx. nigripalpus & 2 & 1 & 1 & 1 & $?$ & 0 & $?$ & 1 & 2 & 0 & $?$ & 0 & $?$ & 1 & 2 & 1 & 0 \\
\hline Cx. ousqua & 1 & 1 & 1 & 1 & 0 & 0 & 0 & 1 & $?$ & 0 & 1 & 0 & 1 & 1 & $?$ & 1 & 0 \\
\hline$C x$ paramaxi & $?$ & $?$ & $?$ & $?$ & $?$ & $?$ & $?$ & $?$ & $?$ & $?$ & $?$ & $?$ & $?$ & $?$ & $?$ & $?$ & $?$ \\
\hline Cx. pipiens & 1 & 1 & 1 & 1 & 0 & 0 & 0 & 1 & 1 & 0 & 1 & 0 & 2 & 1 & 1 & 1 & 0 \\
\hline Cx. plicatus & $?$ & $?$ & $?$ & $?$ & $?$ & $?$ & $?$ & $?$ & $?$ & $?$ & $?$ & $?$ & $?$ & $?$ & $?$ & $?$ & $?$ \\
\hline Cx. quinquefasciatus & 1 & 1 & 1 & 1 & 0 & 0 & 0 & 1 & 1 & 0 & 1 & 0 & 2 & 1 & 1 & 1 & 0 \\
\hline Cx. quitensis & $?$ & $?$ & $?$ & $?$ & $?$ & $?$ & $?$ & $?$ & $?$ & $?$ & $?$ & $?$ & $?$ & $?$ & $?$ & $?$ & $?$ \\
\hline Cx. renatoi & 0 & 1 & 0 & 0 & 1 & 0 & 0 & 1 & 1 & 0 & 0 & 2 & 0 & 2 & 2 & 1 & 0 \\
\hline Cx. riojanus & $?$ & $?$ & $?$ & $?$ & $?$ & $?$ & $?$ & $?$ & $?$ & $?$ & $?$ & $?$ & $?$ & $?$ & $?$ & $?$ & $?$ \\
\hline Cx. saltanensis & 2 & 1 & 1 & $\dot{1}$ & 0 & 0 & 0 & $\dot{1}$ & $\dot{1}$ & $\dot{0}$ & 1 & 0 & 2 & $\dot{1}$ & $\dot{2}$ & 1 & $\dot{0}$ \\
\hline Cx. scheuberi & $?$ & $?$ & $?$ & $?$ & $?$ & $?$ & $?$ & $?$ & $?$ & $?$ & $?$ & $?$ & $?$ & $?$ & $?$ & $?$ & $?$ \\
\hline CX. sitiens & 2 & 1 & 1 & $\dot{1}$ & 3 & 0 & $\dot{0}$ & 1 & 2 & $\dot{0}$ & 1 & 0 & 2 & $\dot{1}$ & 2 & 1 & $\dot{0}$ \\
\hline Cx. spinosus & $?$ & 1 & 1 & $?$ & 2 & $?$ & $?$ & 2 & $?$ & $?$ & $?$ & 0 & $?$ & 1 & 3 & $?$ & $?$ \\
\hline Cx. surinamensis & 3 & 1 & 1 & ? & $?$ & ? & ? & $?$ & $?$ & ? & $?$ & 0 & ? & 1 & 2 & ? & ? \\
\hline Cx. tatoi & 1 & 1 & 1 & 1 & 0 & 1 & 0 & 1 & 1 & 0 & 1 & 0 & 1 & 1 & 1 & $\dot{1}$ & $\dot{0}$ \\
\hline Cx. thriambus & ? & 1 & 1 & ? & 0 & ? & 0 & 1 & 2 & ? & 1 & 0 & 2 & 1 & 1 & 1 & ? \\
\hline Cx. tritaeniorhynchus & 2 & 1 & 1 & 1 & 2 & 0 & $?$ & 1 & 2 & 0 & 1 & 0 & 1 & 1 & 2 & 1 & 0 \\
\hline Cx. usquatissimus & 1 & 1 & 1 & 1 & 0 & 0 & 0 & 1 & 0 & 0 & 1 & 0 & 1 & 1 & 2 & 1 & 0 \\
\hline Cx. usquatus & 1 & 1 & 1 & 1 & 0 & 0 & 0 & 1 & 0 & 0 & 1 & 0 & 1 & 1 & 2 & 1 & 0 \\
\hline Cx. vishnui & 2 & 1 & 1 & $?$ & 2 & 0 & $?$ & 2 & 2 & 0 & 1 & 0 & 2 & 1 & 2 & 1 & 0 \\
\hline
\end{tabular}


TABLE 2. (Continued)

\begin{tabular}{|c|c|c|c|c|c|c|c|c|c|c|c|c|c|c|c|c|c|c|c|c|}
\hline & 1 & 1 & 1 & 2 & 2 & 2 & 2 & 2 & 2 & 2 & 2 & 2 & 2 & 3 & 3 & 3 & 3 & 3 & 3 & 3 \\
\hline & 7 & 8 & 9 & 0 & 1 & 2 & 3 & 4 & 5 & 6 & 7 & 8 & 9 & 0 & 1 & 2 & 3 & 4 & 5 & 6 \\
\hline Lt. bigoti & ? & 1 & 1 & 3 & 1 & 0 & 1 & 0 & - & 2 & 0 & 0 & 0 & 0 & 0 & 0 & 0 & 1 & 0 & 1 \\
\hline Cx. abnormalis & $?$ & 1 & 1 & 2 & 1 & $?$ & 0 & 0 & - & $?$ & $?$ & $?$ & $?$ & $?$ & $?$ & $?$ & $?$ & $?$ & $?$ & $?$ \\
\hline Cx. acharistus & 0 & 1 & 1 & 0 & 1 & 1 & 0 & 0 & - & 1 & 1 & 1 & 1 & 1 & 2 & 0 & 1 & 1 & 01 & 0 \\
\hline$C x$. alani & $?$ & $?$ & $?$ & $?$ & $?$ & $?$ & $?$ & $?$ & $?$ & $?$ & $?$ & $?$ & $?$ & $?$ & $?$ & $?$ & $?$ & $?$ & $?$ & $?$ \\
\hline Cx. ameliae & 1 & 1 & 1 & 1 & 1 & 0 & 0 & 0 & - & 0 & 1 & 1 & 0 & 0 & 2 & 2 & 1 & 1 & 0 & 1 \\
\hline Cx. annulirostris & 0 & 0 & 1 & 3 & 1 & 0 & 0 & 0 & - & 0 & 0 & 1 & 1 & 1 & 2 & 0 & 1 & 0 & 0 & 1 \\
\hline Cx. apicinus & 0 & 1 & 1 & 3 & 1 & 1 & 0 & 0 & - & 2 & 0 & 0 & 1 & 1 & 1 & 2 & 0 & 1 & 1 & 1 \\
\hline Cx. archegus & $?$ & 1 & 1 & 2 & $?$ & $?$ & 0 & 0 & - & 0 & 1 & 1 & $?$ & $?$ & $?$ & $?$ & $?$ & $?$ & 0 & 1 \\
\hline$C x$. articularis & 0 & 1 & 1 & 2 & 1 & 1 & 0 & 0 & - & 0 & 1 & 1 & 0 & 1 & 2 & 0 & 1 & 1 & 0 & 1 \\
\hline Cx. bickleyi & $?$ & $?$ & $?$ & $?$ & $?$ & $?$ & $?$ & $?$ & $?$ & $?$ & $?$ & $?$ & $?$ & $?$ & $?$ & $?$ & $?$ & $?$ & $?$ & $?$ \\
\hline Cx. bidens & 0 & 1 & 1 & 1 & 1 & 0 & 0 & 0 & - & 0 & 1 & 1 & 1 & 1 & 2 & 02 & 1 & 0 & 0 & 1 \\
\hline Cx. bitaeniorhynchus & 1 & 1 & 0 & 3 & 0 & 0 & 0 & 0 & - & 0 & 0 & 0 & 1 & 1 & 2 & 2 & 1 & 0 & 0 & 1 \\
\hline Cx. bonneae & $?$ & $?$ & 1 & 1 & 0 & $?$ & 0 & 0 & - & 2 & 1 & $?$ & $?$ & $?$ & $?$ & $?$ & $?$ & $?$ & $?$ & $?$ \\
\hline CX. brethesi & 0 & 1 & 1 & 1 & 1 & 0 & 0 & 0 & - & 0 & 1 & 1 & 0 & 1 & 2 & 2 & 1 & 0 & 01 & 1 \\
\hline Cx. brevispinosus & $?$ & $?$ & 2 & 2 & 1 & $?$ & $?$ & 1 & 1 & 0 & $?$ & $?$ & $?$ & $?$ & $?$ & $?$ & $?$ & $?$ & $?$ & $?$ \\
\hline Cx. camposi & 0 & $?$ & 2 & $?$ & 1 & 0 & 0 & 1 & 1 & 0 & $?$ & 1 & 1 & 0 & 2 & 0 & 1 & 0 & 0 & 1 \\
\hline Cx. carcinoxenus & $?$ & $?$ & 0 & 2 & $?$ & $?$ & 0 & 0 & - & 0 & $?$ & 1 & $?$ & $?$ & $?$ & $?$ & $?$ & $?$ & 0 & 1 \\
\hline Cx. chidesteri & 0 & 01 & 1 & 3 & 1 & 0 & 0 & 0 & - & 1 & 0 & 1 & 1 & 1 & 2 & 0 & 1 & 0 & 0 & 1 \\
\hline Cx. chitae & $?$ & $?$ & $?$ & $?$ & $?$ & $?$ & $?$ & $?$ & $?$ & $?$ & $?$ & $?$ & $?$ & $?$ & $?$ & $?$ & $?$ & $?$ & $?$ & $?$ \\
\hline CX. corniger & 0 & 0 & 1 & 0 & 1 & 1 & 0 & 0 & - & 2 & 1 & 0 & 1 & 0 & 1 & 2 & 0 & 1 & 0 & 1 \\
\hline Cx. coronator & 0 & 1 & 2 & 2 & 1 & 0 & 0 & 1 & 1 & 0 & 0 & 1 & 1 & 0 & 2 & 0 & 1 & 0 & 0 & 1 \\
\hline Cx. covagarciai & $?$ & $?$ & 1 & $?$ & $?$ & $?$ & 1 & 0 & - & 2 & $?$ & $?$ & $?$ & $?$ & $?$ & $?$ & $?$ & $?$ & $?$ & $?$ \\
\hline Cx. curvibrachius & $?$ & $?$ & $?$ & $?$ & $?$ & $?$ & $?$ & $?$ & $?$ & $?$ & $?$ & $?$ & $?$ & $?$ & $?$ & $?$ & $?$ & $?$ & $?$ & $?$ \\
\hline Cx. cuyanus & 0 & 1 & 1 & 2 & 1 & 0 & 0 & 0 & - & 0 & 0 & 0 & 1 & 1 & 2 & 2 & 1 & 2 & 0 & 1 \\
\hline Cx. declarator & 0 & 1 & 1 & 1 & $?$ & $?$ & 0 & 0 & - & 0 & 1 & $?$ & $?$ & $?$ & $?$ & $?$ & $?$ & $?$ & 0 & 1 \\
\hline Cx. diplophyllum & $?$ & $?$ & 1 & 2 & 1 & $?$ & 0 & 0 & - & 0 & ? & ? & ? & ? & $?$ & ? & $?$ & ? & ? & ? \\
\hline Cx. dolosus & 0 & 1 & 1 & 1 & 1 & 0 & 0 & 0 & - & 1 & 1 & 1 & 1 & 1 & 2 & 2 & 1 & 1 & 0 & 1 \\
\hline Cx. eduardoi & 0 & 1 & 1 & 1 & 1 & 0 & 0 & 0 & - & 0 & 0 & 1 & 0 & 1 & 2 & 2 & 1 & 1 & 0 & 1 \\
\hline$C x$. fernandezi & 0 & 0 & 0 & 3 & 1 & 0 & 0 & 0 & - & 0 & 1 & 1 & 1 & 1 & 2 & 2 & 1 & 1 & 0 & 0 \\
\hline Cx. foliaceus & 0 & 1 & 1 & 0 & 1 & $?$ & 0 & 0 & - & 0 & $?$ & $?$ & $?$ & $?$ & $?$ & $?$ & $?$ & $?$ & $?$ & $?$ \\
\hline$C x$. guayasi & $?$ & $?$ & $?$ & $?$ & $?$ & $?$ & $?$ & $?$ & $?$ & $?$ & $?$ & $?$ & $?$ & $?$ & $?$ & $?$ & $?$ & $?$ & $?$ & $?$ \\
\hline$C x$. habilitator & 0 & 1 & 1 & 2 & $?$ & $?$ & 0 & 0 & - & 0 & $?$ & $?$ & $?$ & $?$ & $?$ & $?$ & $?$ & $?$ & $?$ & $?$ \\
\hline$C x$. inflictus & 0 & 1 & $?$ & 1 & $?$ & $?$ & $?$ & 0 & - & 0 & $?$ & $?$ & $?$ & $?$ & $?$ & $?$ & $?$ & $?$ & $?$ & $?$ \\
\hline Cx. interfor & 0 & 1 & 1 & 1 & 1 & 0 & 0 & 0 & - & 0 & 1 & 1 & 1 & 1 & 2 & 2 & 1 & 0 & 0 & 1 \\
\hline$C x$. lahillei & 0 & 1 & 1 & 2 & 1 & 0 & 0 & 0 & - & 0 & 0 & 1 & 1 & 1 & 2 & 0 & 1 & 0 & 01 & 1 \\
\hline Cx. levicastilloi & 0 & 1 & 1 & 1 & 1 & $?$ & 0 & 0 & - & 0 & $?$ & 1 & 0 & $?$ & 1 & 0 & 1 & 0 & 0 & 1 \\
\hline Cx. lygrus & $?$ & $?$ & $?$ & $?$ & $?$ & $?$ & $?$ & $?$ & $?$ & $?$ & $?$ & $?$ & $?$ & $?$ & $?$ & $?$ & $?$ & $?$ & $?$ & $?$ \\
\hline Cx. maracayensis & $?$ & $?$ & 1 & 3 & 1 & $?$ & 1 & 0 & - & 0 & $?$ & $?$ & $?$ & $?$ & $?$ & $?$ & $?$ & $?$ & $?$ & $?$ \\
\hline$C x$. mauesensis & $?$ & $?$ & $?$ & $?$ & $?$ & $?$ & $?$ & $?$ & $?$ & $?$ & $?$ & $?$ & $?$ & $?$ & $?$ & $?$ & $?$ & $?$ & $?$ & $?$ \\
\hline$C x . \operatorname{maxi}$ & 0 & 1 & 1 & 2 & 1 & 0 & 0 & 1 & 0 & 0 & 0 & 1 & 1 & 1 & 2 & 0 & 1 & 0 & 01 & 1 \\
\hline Cx. mollis & 0 & 1 & 1 & 1 & 1 & 0 & 0 & 0 & - & 0 & 1 & 1 & 1 & 1 & 2 & 2 & 1 & 1 & 0 & 1 \\
\hline$C x$. nigripalpus & 0 & 1 & 1 & 1 & 1 & 0 & 0 & 0 & - & 0 & 1 & $?$ & 1 & 1 & 2 & 2 & 1 & 0 & 0 & 1 \\
\hline Cx. ousqua & 0 & 1 & 2 & $?$ & 1 & 0 & 0 & 1 & 1 & 0 & $?$ & 1 & 1 & 0 & 2 & 0 & 1 & 0 & 0 & 1 \\
\hline$C x$. paramaxi & $?$ & $?$ & $?$ & $?$ & $?$ & $?$ & $?$ & $?$ & $?$ & $?$ & $?$ & $?$ & $?$ & $?$ & $?$ & $?$ & $?$ & $?$ & $?$ & $?$ \\
\hline Cx. pipiens & 0 & 1 & 1 & 1 & 1 & 0 & 0 & 0 & - & 0 & 1 & 1 & 1 & 1 & 2 & 0 & 1 & 0 & 0 & 1 \\
\hline Cx. plicatus & $?$ & $?$ & $?$ & $?$ & $?$ & $?$ & $?$ & $?$ & $?$ & $?$ & $?$ & $?$ & $?$ & $?$ & $?$ & $?$ & $?$ & $?$ & $?$ & $?$ \\
\hline Cx. quinquefasciatus & 0 & 1 & 1 & 1 & 1 & 0 & 0 & 0 & - & 0 & 1 & 1 & 1 & 1 & 2 & 0 & 1 & 0 & 0 & 1 \\
\hline Cx. quitensis & $?$ & $?$ & 1 & 1 & 1 & $?$ & 0 & 0 & - & 0 & $?$ & $?$ & $?$ & $?$ & $?$ & $?$ & $?$ & $?$ & $?$ & $?$ \\
\hline Cx. renatoi & 0 & 0 & 1 & 3 & 1 & 0 & 0 & 0 & - & 0 & 0 & 1 & 1 & 0 & 0 & 2 & 0 & 1 & 0 & 1 \\
\hline Cx. riojanus & $?$ & $?$ & $?$ & $?$ & $?$ & $?$ & $?$ & $?$ & $?$ & $?$ & $?$ & $?$ & $?$ & $?$ & $?$ & $?$ & $?$ & $?$ & $?$ & $?$ \\
\hline Cx. saltanensis & 1 & 0 & 1 & 3 & 1 & 0 & 1 & 0 & - & 0 & 0 & 0 & 1 & $i$ & 2 & 0 & 1 & 0 & 0 & 1 \\
\hline Cx. scheuberi & $?$ & $?$ & $?$ & $?$ & $?$ & $?$ & $?$ & $?$ & $?$ & $?$ & $?$ & $?$ & $?$ & $?$ & $?$ & $?$ & $?$ & $?$ & $?$ & $?$ \\
\hline$C x$. sitiens & 0 & 1 & 1 & 3 & 1 & 0 & 0 & 0 & - & 0 & 1 & 1 & 1 & 1 & 2 & 0 & 1 & 0 & 0 & 1 \\
\hline CX. spinosus & $?$ & $?$ & 1 & 2 & 1 & $?$ & $?$ & 0 & - & 0 & $?$ & $?$ & $?$ & $?$ & $?$ & $?$ & $?$ & $?$ & 0 & $?$ \\
\hline Cx. surinamensis & 0 & 1 & 1 & 2 & 1 & $?$ & $?$ & $?$ & $?$ & 0 & $?$ & $?$ & $?$ & $?$ & $?$ & $?$ & $?$ & $?$ & $?$ & $?$ \\
\hline Cx. tatoi & 0 & 1 & 1 & 1 & 1 & 0 & 0 & 0 & - & 0 & 1 & 1 & 1 & 1 & 2 & 2 & 1 & 1 & 0 & 1 \\
\hline Cx. thriambus & 0 & 1 & 1 & 1 & 0 & $?$ & 0 & 0 & - & 0 & 1 & $?$ & $?$ & $?$ & $?$ & $?$ & $?$ & $?$ & $?$ & $?$ \\
\hline Cx. tritaeniorhynchus & 0 & 1 & 1 & 2 & 1 & 0 & 0 & 0 & - & 0 & 0 & 1 & 1 & 1 & 2 & 0 & 1 & 0 & 0 & 1 \\
\hline Cx. usquatissimus & 0 & 0 & 2 & 2 & 1 & 0 & 0 & 1 & 1 & 0 & 0 & 1 & 1 & 0 & 2 & 0 & 1 & 0 & 0 & 1 \\
\hline Cx. usquatus & 0 & 0 & 2 & 2 & 1 & 0 & 0 & 1 & 1 & 0 & 0 & 1 & 1 & 0 & 2 & 0 & 1 & 0 & 0 & 1 \\
\hline Cx. vishnui & 0 & 1 & 1 & 2 & 1 & 0 & 0 & 0 & - & 0 & 1 & 1 & 1 & 0 & 2 & 0 & 1 & 0 & 0 & 1 \\
\hline
\end{tabular}


TABLE 2. (Continued)

\begin{tabular}{|c|c|c|c|c|c|c|c|c|c|c|c|c|c|c|c|c|c|c|c|c|}
\hline & 3 & 3 & 3 & 4 & 4 & 4 & 4 & 4 & 4 & 4 & 4 & 4 & 4 & 5 & 5 & 5 & 5 & 5 & 5 & 5 \\
\hline & 7 & 8 & 9 & $\mathbf{0}$ & 1 & 2 & 3 & 4 & 5 & 6 & 7 & 8 & 9 & 0 & 1 & 2 & 3 & 4 & 5 & 6 \\
\hline Lt. bigoti & 1 & 1 & 0 & 1 & 1 & 2 & 1 & 1 & 1 & 1 & 1 & 0 & 0 & 1 & 1 & 0 & 1 & 1 & 1 & 0 \\
\hline Cx. abnormalis & $?$ & 3 & $?$ & $?$ & 0 & - & 1 & 1 & 1 & $?$ & $?$ & 0 & $?$ & $?$ & 1 & $?$ & 1 & 0 & ? & $?$ \\
\hline Cx. acharistus & - & 0 & 1 & 0 & 0 & - & 1 & 1 & 1 & 0 & 1 & 0 & 0 & 0 & 1 & 0 & 1 & 0 & 2 & 0 \\
\hline$C x$. alani & $?$ & $?$ & $?$ & $?$ & $?$ & $?$ & $?$ & $?$ & $?$ & $?$ & $?$ & $?$ & $?$ & $?$ & $?$ & $?$ & $?$ & $?$ & ? & $?$ \\
\hline Cx. ameliae & 0 & 0 & 1 & 0 & 0 & - & 1 & 1 & 1 & 0 & 1 & 0 & 0 & 1 & 1 & 1 & 1 & 0 & 2 & 2 \\
\hline Cx. annulirostris & 0 & 0 & 1 & 1 & 1 & 0 & 1 & 0 & 1 & 0 & 1 & 0 & 0 & 0 & 1 & 0 & 0 & - & 0 & 2 \\
\hline Cx. apicinus & 0 & 0 & 1 & 0 & 0 & - & 1 & 1 & 1 & 0 & 1 & 0 & 0 & 0 & 1 & 0 & 1 & 0 & 1 & 2 \\
\hline Cx. archegus & 0 & 1 & $?$ & $?$ & 0 & - & 1 & 1 & 0 & 0 & $?$ & 0 & $?$ & $?$ & $?$ & $?$ & $?$ & $?$ & ? & $?$ \\
\hline Cx. articularis & 0 & 1 & $?$ & 0 & 0 & - & 1 & 1 & 0 & $?$ & $?$ & $?$ & $?$ & $?$ & 1 & 0 & 1 & 0 & ? & $?$ \\
\hline Cx. bickleyi & $?$ & $?$ & $?$ & $?$ & $?$ & $?$ & $?$ & $?$ & $?$ & $?$ & $?$ & $?$ & $?$ & $?$ & $?$ & $?$ & $?$ & $?$ & ? & $?$ \\
\hline Cx. bidens & 0 & 2 & 1 & 1 & 0 & - & 1 & 1 & 0 & 0 & 1 & 0 & 0 & 0 & 1 & 0 & 1 & 0 & 2 & 2 \\
\hline Cx. bitaeniorhynchus & 0 & 0 & 1 & 1 & 1 & 0 & 1 & 0 & 0 & 0 & 1 & 0 & 0 & 1 & 1 & 1 & 0 & - & 0 & 0 \\
\hline Cx. bonneae & $?$ & 0 & 1 & 0 & 0 & - & 0 & - & $?$ & 0 & $?$ & 0 & $?$ & $?$ & $?$ & $?$ & $?$ & $?$ & ? & $?$ \\
\hline Cx. brethesi & 0 & 0 & 1 & 1 & 0 & - & 1 & 1 & 0 & 0 & 1 & 0 & 0 & 0 & 1 & 0 & 1 & 0 & 2 & 2 \\
\hline Cx. brevispinosus & $?$ & 1 & $?$ & $?$ & $?$ & $?$ & 1 & 1 & 1 & $?$ & $?$ & 0 & $?$ & $?$ & 1 & $?$ & 1 & 0 & $?$ & $?$ \\
\hline Cx. camposi & 0 & 2 & 1 & 0 & 0 & - & 1 & 1 & 1 & 1 & 1 & 0 & 0 & 0 & 1 & 0 & 1 & 0 & 2 & $?$ \\
\hline Cx. carcinoxenus & 0 & 2 & 1 & $?$ & 0 & - & 1 & 1 & $?$ & 0 & 1 & 0 & $?$ & $?$ & $?$ & $?$ & 1 & 0 & ? & $?$ \\
\hline Cx. chidesteri & 0 & 0 & 1 & 0 & 0 & - & 1 & 1 & 1 & 0 & 1 & 0 & 1 & 1 & 1 & 1 & 1 & 0 & 0 & 2 \\
\hline Cx. chitae & $?$ & $?$ & $?$ & $?$ & $?$ & $?$ & $?$ & $?$ & $?$ & $?$ & $?$ & $?$ & $?$ & $?$ & $?$ & $?$ & $?$ & $?$ & ? & $?$ \\
\hline Cx. corniger & 0 & 1 & 1 & 1 & 0 & - & 1 & 1 & 1 & 0 & 1 & 0 & 0 & 0 & 1 & 0 & 1 & 0 & 1 & 2 \\
\hline Cx. coronator & 0 & 2 & 1 & 0 & 0 & - & 1 & 1 & 1 & 1 & 1 & 0 & 0 & 0 & 1 & 0 & 1 & 0 & & 2 \\
\hline Cx. covagarciai & $?$ & 2 & 1 & 0 & 0 & - & 1 & 1 & 1 & 1 & 1 & 0 & 0 & 0 & 1 & c & 1 & 0 & & $?$ \\
\hline Cx. curvibrachius & $?$ & $?$ & $?$ & $?$ & $?$ & $?$ & $?$ & $?$ & $?$ & $?$ & $?$ & $?$ & $?$ & $?$ & $?$ & $?$ & $?$ & $?$ & $?$ & $?$ \\
\hline Cx. cuyanus & 0 & 0 & 1 & 0 & 0 & - & 1 & 1 & 0 & 0 & 0 & 0 & 0 & 0 & 0 & 0 & 1 & 0 & 0 & 0 \\
\hline Cx. declarator & 0 & 3 & $?$ & $?$ & 0 & - & 1 & 1 & 1 & 0 & $?$ & 0 & $?$ & $?$ & 1 & $?$ & 1 & 0 & ? & $?$ \\
\hline Cx. diplophyllum & $?$ & 2 & $?$ & 0 & 0 & - & 1 & 1 & 1 & $?$ & $?$ & 0 & $?$ & $?$ & 1 & $?$ & $?$ & $?$ & ? & $?$ \\
\hline Cx. dolosus & 0 & 0 & 1 & 0 & 0 & - & 1 & 0 & 1 & 0 & 1 & 0 & 1 & 0 & 1 & 0 & 1 & 0 & 2 & 2 \\
\hline$C x$. eduardoi & 0 & 0 & 1 & 1 & 1 & 1 & 1 & 1 & 1 & 0 & 1 & 0 & 0 & 0 & 1 & 0 & 1 & 0 & 2 & 2 \\
\hline$C x$. fernandezi & - & 0 & 1 & 1 & 0 & - & 1 & 1 & 1 & 0 & 0 & 0 & 1 & 0 & 1 & 0 & 1 & 0 & 2 & 2 \\
\hline Cx. foliaceus & $?$ & 2 & $?$ & $?$ & 0 & - & 0 & - & $?$ & $?$ & $?$ & $?$ & $?$ & $?$ & $?$ & $?$ & $?$ & $?$ & ? & $?$ \\
\hline Cx. guayasi & $?$ & $?$ & $?$ & $?$ & $?$ & $?$ & 0 & - & $?$ & 0 & $?$ & 0 & $?$ & $?$ & $?$ & $?$ & $?$ & $?$ & ? & $?$ \\
\hline$C x$. habilitator & $?$ & 0 & $?$ & $?$ & 0 & - & 1 & 1 & 1 & $?$ & $?$ & 0 & $?$ & $?$ & $?$ & $?$ & 1 & 0 & $?$ & $?$ \\
\hline$C x$. inflictus & $?$ & 2 & 1 & $?$ & 0 & - & 0 & - & $?$ & 0 & $?$ & 2 & $?$ & $?$ & $?$ & $?$ & 1 & 0 & $?$ & $?$ \\
\hline Cx. interfor & 0 & 2 & 1 & 1 & 0 & - & 1 & 1 & 0 & 0 & 1 & 0 & 0 & 0 & 1 & 0 & 1 & 0 & 2 & 2 \\
\hline Cx. lahillei & 0 & 2 & 1 & 0 & 1 & 1 & 1 & 1 & 1 & 0 & 0 & 0 & 1 & 1 & 1 & 0 & 1 & 0 & 0 & 2 \\
\hline Cx. levicastilloi & 0 & 0 & 1 & $?$ & 1 & 2 & 0 & - & 1 & 0 & $?$ & 0 & $?$ & $?$ & 1 & 0 & 1 & 0 & ? & $?$ \\
\hline Cx. lygrus & $?$ & 0 & $?$ & $?$ & 0 & - & 1 & 1 & 0 & 0 & $?$ & 0 & $?$ & $?$ & 1 & $?$ & 1 & 0 & ? & $?$ \\
\hline Cx. maracayensis & $?$ & 0 & $?$ & $?$ & 0 & - & 1 & 0 & 1 & $?$ & $?$ & 0 & $?$ & $?$ & $?$ & $?$ & $?$ & $?$ & $?$ & $?$ \\
\hline CX. mauesensis & $?$ & 0 & $?$ & $?$ & 0 & - & 1 & 1 & 1 & $?$ & $?$ & 0 & $?$ & $?$ & $?$ & $?$ & 1 & 0 & ? & $?$ \\
\hline$C x . \operatorname{maxi}$ & 0 & 0 & 1 & 0 & 0 & - & 1 & 1 & 1 & 0 & 1 & 0 & 0 & 0 & 1 & 0 & 1 & 0 & 2 & 2 \\
\hline Cx. mollis & 0 & 0 & 1 & 0 & 0 & - & 1 & 1 & 1 & 0 & 1 & 0 & 0 & 0 & 1 & 0 & 1 & 0 & 2 & 2 \\
\hline$C x$. nigripalpus & 0 & 0 & $?$ & $?$ & 0 & - & 1 & 1 & 0 & 0 & 1 & 2 & 0 & 1 & 0 & 0 & 1 & 0 & 2 & $?$ \\
\hline Cx. ousqua & 0 & 2 & 1 & 0 & 0 & - & 1 & 1 & 1 & 1 & 1 & 0 & 0 & 0 & 1 & 0 & 1 & 0 & 2 & $?$ \\
\hline$C x$. paramaxi & $?$ & $?$ & $?$ & $?$ & $?$ & $?$ & $?$ & $?$ & $?$ & $?$ & $?$ & $?$ & $?$ & $?$ & $?$ & $?$ & $?$ & $?$ & $?$ & $?$ \\
\hline Cx.pipiens & 0 & 1 & 1 & 0 & 1 & 1 & 1 & 1 & 1 & 0 & 1 & 0 & 0 & 0 & 1 & 0 & 1 & 0 & 2 & 2 \\
\hline Cx. plicatus & $?$ & $?$ & $?$ & $?$ & $?$ & $?$ & $?$ & $?$ & $?$ & $?$ & $?$ & $?$ & $?$ & $?$ & $?$ & $?$ & $?$ & $?$ & $?$ & $?$ \\
\hline Cx. quinquefasciatus & 0 & 1 & 1 & 0 & 1 & 1 & 1 & 1 & 1 & 0 & 1 & 0 & 0 & 0 & 1 & 0 & 1 & 0 & 2 & 2 \\
\hline Cx. quitensis & $?$ & 1 & $?$ & $?$ & 1 & 1 & 0 & - & 1 & $?$ & $?$ & 0 & $?$ & $?$ & $?$ & $?$ & $?$ & $?$ & ? & $?$ \\
\hline Cx. renatoi & 0 & 1 & 1 & 1 & 1 & 1 & 1 & 0 & 1 & 0 & 1 & 0 & 0 & 0 & 1 & 0 & 1 & 0 & 1 & 2 \\
\hline Cx. riojanus & $?$ & $?$ & $?$ & $?$ & $?$ & $?$ & $?$ & $?$ & $?$ & $?$ & $?$ & $?$ & $?$ & $?$ & $?$ & $?$ & $?$ & $?$ & ? & $?$ \\
\hline Cx. saltanensis & 0 & 0 & 1 & 0 & 0 & - & 1 & 0 & 1 & 1 & 1 & 0 & 0 & 0 & 1 & 0 & 1 & 0 & & 0 \\
\hline Cx. scheuberi & $?$ & $?$ & $?$ & $?$ & $?$ & $?$ & $?$ & $?$ & $?$ & $?$ & $?$ & $?$ & $?$ & $?$ & $?$ & $?$ & $?$ & $?$ & ? & $?$ \\
\hline$C x$. sitiens & 0 & 0 & 1 & 1 & 1 & 0 & 1 & 0 & 1 & 0 & 1 & 0 & 0 & 0 & 1 & 0 & 0 & - & 0 & 2 \\
\hline CX. spinosus & $?$ & 0 & 1 & 1 & 0 & - & 1 & 1 & 1 & 0 & 1 & 0 & 0 & 1 & 1 & 0 & 1 & 0 & 2 & 1 \\
\hline Cx. surinamensis & $?$ & 3 & $?$ & $?$ & 0 & - & 1 & 1 & 1 & 0 & $?$ & 0 & $?$ & $?$ & 1 & 0 & 1 & 0 & $?$ & $?$ \\
\hline Cx. tatoi & 0 & 0 & 1 & 0 & 0 & - & 1 & 1 & 1 & 0 & 1 & 0 & 0 & 0 & 1 & 0 & 1 & 0 & 2 & 2 \\
\hline$C x$. thriambus & $?$ & 0 & $?$ & $?$ & 0 & - & 1 & 1 & $?$ & 0 & 1 & 0 & $?$ & $?$ & $?$ & $?$ & $?$ & $?$ & $?$ & $?$ \\
\hline Cx. tritaeniorhynchus & 0 & 0 & 0 & 1 & 1 & 0 & 1 & 0 & 1 & 0 & 1 & 1 & 0 & 0 & 0 & 0 & 0 & - & 0 & 0 \\
\hline Cx. usquatissimus & 0 & 2 & 1 & 0 & 0 & - & 1 & 1 & 1 & 1 & 1 & 0 & 0 & 0 & 1 & 0 & 1 & 0 & 2 & 2 \\
\hline Cx. usquatus & 0 & 2 & 1 & 0 & 0 & - & 1 & 1 & 1 & 1 & 1 & 0 & 0 & 0 & 1 & 0 & 1 & 0 & 2 & 2 \\
\hline Cx. vishnui & 0 & 0 & 0 & 1 & 1 & 0 & 1 & 0 & 1 & 0 & 1 & 1 & 0 & 0 & 1 & 0 & 0 & - & 0 & 2 \\
\hline
\end{tabular}


TABLE 2. (Continued)

\begin{tabular}{|c|c|c|c|c|c|c|c|c|c|c|c|c|c|c|c|c|c|c|c|c|c|}
\hline & 5 & 5 & 5 & 6 & 6 & 6 & 6 & 6 & 6 & 6 & 6 & 6 & 6 & 7 & 7 & 7 & 7 & 7 & 7 & 7 & 7 \\
\hline & 7 & 8 & 9 & 0 & 1 & 2 & 3 & 4 & 5 & 6 & 7 & 8 & 9 & 0 & 1 & 2 & 3 & 4 & 5 & 6 & 7 \\
\hline Lt. bigoti & 1 & 0 & - & 1 & 0 & 1 & 0 & 0 & 0 & - & 1 & 1 & 0 & 0 & 0 & - & 0 & - & 0 & - & 0 \\
\hline Cx. abnormalis & $?$ & 0 & - & 1 & 0 & 1 & $?$ & 2 & 1 & 2 & 0 & $?$ & 0 & 0 & 1 & 1 & 1 & 0 & 1 & 0 & 0 \\
\hline Cx. acharistus & 0 & 1 & 0 & 1 & 0 & 1 & 0 & 12 & 1 & 0 & 0 & 1 & 0 & 1 & 1 & 1 & 1 & 2 & 1 & 0 & 1 \\
\hline Cx. alani & $?$ & $?$ & $?$ & $?$ & $?$ & $?$ & $?$ & $?$ & $?$ & $?$ & $?$ & $?$ & 0 & 0 & 1 & 1 & 1 & 2 & 1 & 1 & 0 \\
\hline Cx. ameliae & 1 & 1 & 0 & 1 & 0 & 1 & 0 & 0 & 1 & 0 & 0 & 0 & 0 & 1 & 1 & 1 & 1 & 0 & 1 & 0 & 0 \\
\hline CX. annulirostris & 1 & 1 & 1 & 1 & 1 & 0 & 1 & 0 & 1 & 0 & 0 & 2 & 0 & 1 & 1 & 1 & 1 & 0 & 0 & - & 0 \\
\hline$C x$. apicinus & 1 & 1 & 0 & 1 & 0 & 1 & 0 & 2 & 1 & 0 & 0 & 2 & 1 & 1 & 1 & 2 & 1 & 1 & 1 & 1 & 0 \\
\hline Cx. archegus & 0 & $?$ & $?$ & $?$ & $?$ & 1 & $?$ & 0 & 1 & 0 & 0 & 1 & 0 & 0 & 1 & 0 & 0 & - & 1 & 0 & 0 \\
\hline$C x$. articularis & 0 & 1 & 0 & 1 & 0 & 1 & $?$ & 0 & 1 & 0 & 0 & $?$ & 0 & 0 & 1 & 1 & 1 & 0 & 1 & 0 & 0 \\
\hline Cx. bickleyi & $?$ & $?$ & $?$ & $?$ & $?$ & $?$ & $?$ & $?$ & $?$ & $?$ & $?$ & $?$ & 0 & 1 & 1 & 1 & 1 & 0 & 1 & 0 & 0 \\
\hline Cx. bidens & 1 & 1 & 0 & 1 & 0 & 0 & 0 & 2 & 1 & 1 & 0 & 0 & 0 & 1 & 1 & 1 & 1 & 0 & 1 & 0 & 0 \\
\hline Cx. bitaeniorhynchus & 1 & 1 & 1 & 1 & 1 & 0 & 1 & 0 & 1 & 2 & 1 & 2 & 0 & 1 & 1 & 1 & 1 & 0 & 0 & - & 0 \\
\hline$C x$. bonneae & $?$ & 1 & 0 & 1 & 0 & 1 & $?$ & 2 & 1 & 2 & 0 & $?$ & 0 & 1 & 0 & - & 0 & - & $?$ & $?$ & 0 \\
\hline Cx. brethesi & 1 & 1 & 0 & 1 & 0 & 1 & 0 & 2 & 1 & 0 & 0 & 1 & 0 & 1 & 1 & 1 & 1 & 2 & 1 & 0 & 0 \\
\hline Cx. brevispinosus & $?$ & 1 & 0 & 1 & 0 & 1 & ? & 2 & 1 & 2 & 0 & 2 & 0 & 0 & 0 & - & 0 & - & 1 & 0 & 0 \\
\hline Cx. camposi & 1 & 1 & 0 & 1 & 0 & 1 & 0 & 0 & 1 & 0 & 0 & 0 & 0 & 1 & 0 & - & 0 & - & 1 & 1 & 0 \\
\hline Cx. carcinoxenus & $?$ & 1 & 0 & 1 & 0 & 1 & $?$ & 2 & 1 & 0 & 0 & 2 & 0 & 1 & 1 & 1 & 1 & 1 & 1 & 0 & 1 \\
\hline Cx. chidesteri & 1 & 1 & 0 & 1 & 0 & 1 & 0 & 0 & 1 & 0 & 0 & 0 & 0 & 1 & 1 & 1 & 1 & 0 & 1 & 0 & 0 \\
\hline Cx. chitae & $?$ & $?$ & $?$ & $?$ & $?$ & $?$ & $?$ & $?$ & $?$ & $?$ & $?$ & $?$ & 0 & 1 & 1 & 1 & 1 & 0 & 1 & 0 & 0 \\
\hline$C x$. corniger & 0 & 1 & 0 & 1 & 0 & 1 & 1 & 0 & 1 & 0 & 0 & 2 & 0 & 1 & 1 & 1 & 1 & 0 & & - & 0 \\
\hline$C x$. & 1 & 1 & 0 & 1 & 0 & 1 & 0 & 0 & 1 & 0 & 0 & 0 & 0 & 1 & 0 & - & 0 & & & 0 & 0 \\
\hline$C x . c$ & 1 & 1 & 0 & 1 & 0 & 1 & 2 & 0 & 1 & 0 & 0 & 0 & 0 & 1 & 0 & - & 0 & - & & 0 & 0 \\
\hline Cx. curvibrachius & $?$ & $?$ & $?$ & $?$ & $?$ & $?$ & $?$ & $?$ & $?$ & $?$ & $?$ & $?$ & 0 & 1 & 1 & 1 & 1 & 2 & & 0 & 0 \\
\hline Cx. cuyanus & 1 & 1 & 0 & 1 & 0 & 1 & 0 & 2 & 1 & 0 & 0 & 2 & 0 & 1 & 1 & 1 & 1 & 0 & & 0 & 0 \\
\hline Cx. declarator & 0 & 1 & 0 & 1 & 0 & 1 & $?$ & 0 & 1 & 0 & 0 & 0 & 0 & 1 & 1 & 0 & 0 & - & $?$ & $?$ & 0 \\
\hline Cx. diplophyllum & 1 & 1 & 0 & 1 & 0 & 1 & $?$ & 2 & 1 & 0 & 0 & 4 & 0 & 1 & 1 & 1 & 1 & 1 & 1 & 0 & 1 \\
\hline Cx. dolosus & 1 & 1 & 0 & 1 & 0 & 1 & 1 & 0 & 1 & 0 & 0 & 4 & 0 & 1 & 1 & 1 & 1 & 0 & 1 & 0 & 0 \\
\hline Cx. eduardoi & 1 & 1 & 0 & 1 & 0 & 1 & 0 & 0 & 1 & 0 & 0 & 1 & 0 & 1 & 1 & 1 & 1 & 1 & 1 & 0 & 0 \\
\hline$C x$. fernandezi & 1 & 1 & 0 & 1 & 0 & 1 & 0 & 2 & 1 & 0 & 0 & 1 & 0 & 1 & 1 & 1 & 1 & 0 & 1 & 0 & 0 \\
\hline Cx. foliaceus & $?$ & 1 & 0 & 1 & 0 & 1 & ? & 2 & 1 & 0 & 0 & 2 & 0 & 1 & 1 & 1 & 1 & 1 & 1 & 0 & 0 \\
\hline Cx. guayasi & $?$ & 0 & - & 0 & - & 1 & $?$ & 0 & 0 & - & 1 & 4 & 0 & 1 & 1 & 1 & 1 & 0 & 1 & 0 & 0 \\
\hline$C x$. habilitator & $?$ & 1 & 0 & 1 & 0 & $?$ & $?$ & 0 & 1 & 0 & 0 & 0 & 0 & 1 & 0 & - & 0 & - & 1 & 0 & 1 \\
\hline$C x$. inflictus & $?$ & 1 & 0 & 1 & 0 & 1 & $?$ & 2 & 1 & 2 & 0 & 2 & 1 & 1 & 1 & 1 & 1 & 1 & 1 & 0 & 0 \\
\hline Cx. interfor & 1 & 1 & 0 & 1 & 0 & 0 & 0 & 2 & 1 & 1 & 0 & 0 & 0 & 1 & 1 & & 1 & 0 & & 0 & 0 \\
\hline Cx. lahillei & 1 & 1 & 0 & 1 & 0 & 1 & 1 & 2 & 1 & 0 & 0 & 1 & 0 & 1 & 1 & 1 & 1 & & & 0 & 1 \\
\hline Cx. levi & 0 & 1 & 0 & 1 & 0 & $?$ & ? & c & 1 & 0 & 0 & 2 & 0 & 1 & 1 & 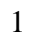 & 1 & & & 0 & 0 \\
\hline Cx. lygru & 1 & 1 & 0 & 1 & 0 & 1 & $?$ & 0 & 1 & 0 & 0 & $?$ & 0 & 1 & 1 & 1 & 1 & 0 & & 0 & 0 \\
\hline Cx. marac & $?$ & 1 & 0 & 1 & 0 & 1 & $?$ & 0 & 1 & 0 & 0 & 0 & 0 & 1 & 0 & - & 0 & - & 1 & 0 & 0 \\
\hline$C x . n$ & $?$ & 1 & 0 & 1 & 0 & 1 & $?$ & 0 & 1 & 0 & 0 & $?$ & 0 & 1 & 1 & 1 & 1 & 0 & 1 & 0 & 0 \\
\hline$C x . \operatorname{maxi}$ & 1 & 1 & 0 & 1 & 0 & 1 & 0 & 0 & 1 & 1 & 0 & 1 & 0 & 1 & 0 & - & 0 & - & 1 & 0 & 0 \\
\hline Cx. mollis & 0 & 1 & 0 & 1 & 0 & 1 & 0 & 2 & 1 & 0 & 0 & 0 & 0 & 1 & 1 & 1 & 1 & 0 & 1 & 0 & 0 \\
\hline Cx. nigripalpus & 0 & 1 & 0 & 1 & 0 & 1 & 1 & 2 & 1 & 3 & 0 & 0 & 0 & 1 & 1 & 1 & 1 & 0 & 1 & 0 & 0 \\
\hline Сx. ousqua & 1 & 1 & 0 & 1 & 0 & 1 & 0 & 0 & 1 & 0 & 0 & 0 & 1 & 1 & 0 & - & 0 & - & 1 & 0 & 0 \\
\hline Cx. paramaxi & $?$ & $?$ & $?$ & $?$ & $?$ & $?$ & $?$ & $?$ & $?$ & $?$ & $?$ & $?$ & 1 & 0 & 0 & - & 0 & - & 1 & 0 & 0 \\
\hline$C x$. pipiens & 0 & 1 & 0 & 1 & 0 & 1 & 0 & 2 & 1 & 0 & 0 & 0 & 0 & 1 & 1 & 1 & 1 & 0 & 1 & 0 & 0 \\
\hline Cx.plicatus & $?$ & $?$ & $?$ & $?$ & $?$ & $?$ & $?$ & $?$ & $?$ & $?$ & $?$ & $?$ & 0 & 1 & 1 & 1 & 1 & 2 & 1 & 0 & 0 \\
\hline Cx. quinquefasciatus & 0 & 1 & 0 & 1 & 0 & 1 & 0 & 2 & 1 & 0 & 0 & 0 & 0 & 1 & 1 & 1 & 1 & 0 & 1 & 0 & 0 \\
\hline Cx. quitensis & 0 & 1 & 0 & 1 & 0 & 1 & $?$ & $?$ & 1 & 0 & 0 & 1 & 0 & 1 & 1 & 1 & 1 & 0 & 1 & 0 & 0 \\
\hline$C x . r$ & 1 & 1 & 0 & 1 & 0 & 1 & 1 & 0 & 1 & 1 & 0 & 1 & 0 & 1 & 1 & 1 & 1 & 0 & 0 & - & 0 \\
\hline$C x . r$ & $?$ & $?$ & $?$ & $?$ & $?$ & $?$ & $?$ & $?$ & $?$ & $?$ & $?$ & $?$ & 0 & 1 & 1 & 1 & 1 & 0 & 1 & 0 & 0 \\
\hline Cx. saltanensis & 1 & 1 & 0 & 1 & 0 & 1 & 0 & 0 & 1 & 0 & 0 & 1 & 0 & 1 & 0 & - & 0 & - & 1 & 0 & 0 \\
\hline Cx. scheuberi & $?$ & $?$ & $?$ & $?$ & $?$ & $?$ & $?$ & $?$ & $?$ & $?$ & $?$ & $?$ & 1 & 1 & 1 & 2 & 1 & 0 & 1 & 1 & 0 \\
\hline$C x$. sitiens & 1 & 1 & 1 & 1 & 1 & 0 & 1 & 0 & 1 & 0 & 0 & 2 & 0 & 1 & 1 & 1 & 1 & 0 & 0 & - & 0 \\
\hline Cx. spinosus & 1 & 1 & 0 & 1 & 0 & 1 & 1 & 2 & 1 & 2 & 0 & 0 & 0 & 1 & 1 & 1 & 1 & 0 & 1 & 0 & 0 \\
\hline Cx. surinamensis & $?$ & 1 & 0 & 1 & 0 & 1 & $?$ & 0 & 1 & 0 & 0 & 2 & 0 & 0 & 0 & - & 0 & - & 1 & 0 & 0 \\
\hline Cx. tatoi & 0 & 1 & 0 & 1 & 0 & 1 & 0 & 2 & 1 & 0 & 0 & 0 & 0 & 1 & 1 & 1 & 1 & 0 & 1 & 1 & 0 \\
\hline Cx. thriambus & 0 & 1 & 0 & 1 & 0 & 1 & $?$ & 0 & 1 & 0 & 0 & 3 & 0 & 1 & 1 & 1 & 1 & 0 & 1 & 0 & 0 \\
\hline Cx. tritaeniorhynchus & 1 & 0 & - & 1 & 0 & 0 & 1 & 0 & 1 & 0 & 0 & 2 & 0 & 1 & 1 & 1 & 1 & 0 & 0 & - & 0 \\
\hline Cx. usquatissimus & 1 & 1 & 0 & 1 & 0 & 1 & 0 & 0 & 1 & 0 & 0 & 0 & 1 & 1 & 0 & - & 0 & - & 1 & 1 & 0 \\
\hline Cx. usquatus & 1 & 1 & 0 & 1 & 0 & 1 & 0 & 0 & 1 & 0 & 0 & 0 & 0 & 1 & 0 & - & 0 & - & 1 & 1 & 0 \\
\hline Cx. vishnui & 1 & 0 & - & 1 & 0 & 0 & 1 & 0 & 1 & 0 & 0 & 2 & 0 & 1 & 1 & 1 & 1 & 0 & 0 & - & 0 \\
\hline
\end{tabular}


TABLE 2. (Continued)

\begin{tabular}{|c|c|c|c|c|c|c|c|c|c|c|c|c|c|c|c|c|c|}
\hline & 7 & 7 & 8 & 8 & 8 & 8 & 8 & 8 & 8 & 8 & 8 & 8 & 9 & 9 & 9 & 9 & 9 \\
\hline & 8 & 9 & 0 & 1 & 2 & 3 & 4 & 5 & 6 & 7 & 8 & 9 & 0 & 1 & 2 & 3 & 4 \\
\hline Lt. bigoti & 0 & 0 & - & 0 & - & 0 & 0 & 0 & - & - & - & 0 & 0 & - & - & 0 & 0 \\
\hline Cx. abnormalis & 0 & 1 & 1 & 1 & 0 & 0 & 0 & 1 & 0 & 3 & 0 & 1 & 1 & 1 & 0 & 0 & 2 \\
\hline Cx. acharistus & 1 & 0 & - & 1 & 0 & 0 & 0 & 0 & - & - & - & 1 & 1 & 1 & 1 & 0 & 1 \\
\hline Cx. alani & 0 & 1 & 0 & 1 & 0 & 0 & 0 & 1 & 0 & 3 & 0 & 1 & 1 & 1 & 1 & 0 & 1 \\
\hline$C x$. ameliae & 0 & 1 & 1 & 1 & 0 & 0 & 0 & 1 & 0 & 3 & 0 & 1 & 1 & 1 & $?$ & 0 & 1 \\
\hline$C x$. annulirostris & 0 & 1 & 0 & 0 & - & 1 & 1 & 0 & - & - & - & 0 & 0 & - & - & 1 & 1 \\
\hline$C x$. apicinus & 2 & 1 & 0 & 1 & 0 & 0 & 0 & 1 & 0 & 3 & 0 & 1 & 1 & 0 & 0 & 0 & 1 \\
\hline$C x$. archegus & 0 & 1 & 1 & 1 & 0 & 0 & 0 & 1 & 0 & 3 & 0 & 1 & 1 & 1 & 0 & 0 & 1 \\
\hline$C x$. articularis & 1 & 1 & 0 & 1 & 0 & 0 & 0 & 1 & 0 & 3 & 0 & 1 & 1 & 1 & 0 & 0 & 1 \\
\hline Cx. bickleyi & 0 & 1 & 1 & 1 & 0 & 0 & 0 & 1 & 0 & 3 & 0 & 1 & 1 & 1 & 0 & 0 & 1 \\
\hline$C x$. bidens & 0 & 0 & - & 1 & 0 & 0 & 0 & 1 & 0 & 2 & 0 & 1 & 1 & 1 & 0 & 1 & 1 \\
\hline Cx. bitaeniorhynchus & 0 & 1 & 0 & 0 & - & 1 & 2 & 1 & 1 & - & 0 & 0 & 1 & 0 & 0 & 1 & 2 \\
\hline Cx. bonneae & 0 & 1 & 1 & 1 & 0 & 0 & 0 & 1 & 0 & 3 & 0 & 1 & 1 & 1 & 1 & 1 & 1 \\
\hline Cx. brethesi & 0 & 1 & 0 & 1 & 0 & 0 & 0 & 1 & 0 & 0 & 0 & 1 & 1 & 1 & 0 & 1 & 1 \\
\hline Cx. brevispinosus & 0 & 1 & 0 & 2 & - & 0 & 0 & 1 & 0 & 3 & 0 & 1 & 1 & 1 & 1 & 0 & 1 \\
\hline Cx. camposi & 0 & 1 & 0 & 1 & 1 & 0 & 0 & 1 & 0 & 3 & 0 & 1 & 1 & 1 & 0 & 1 & 1 \\
\hline Cx. carcinoxenus & 0 & 1 & 0 & 1 & 0 & 0 & 0 & 1 & 0 & 3 & 0 & 1 & 1 & 1 & 0 & 0 & 2 \\
\hline Cx. chidesteri & 0 & 1 & 0 & 0 & - & 1 & 1 & 1 & 1 & - & 1 & 1 & 1 & 1 & 1 & 0 & 2 \\
\hline Cx. chitae & 0 & 1 & 1 & 1 & 1 & 0 & 0 & 1 & 0 & 3 & 0 & 1 & 1 & 0 & 0 & 0 & 1 \\
\hline CX. corniger & 0 & 1 & 0 & 1 & 0 & 0 & 0 & 1 & 0 & 3 & 0 & 1 & 1 & 0 & 0 & 0 & 1 \\
\hline Cx. coronator & 0 & 1 & 0 & 1 & 1 & 0 & 0 & 1 & 0 & 3 & 0 & 1 & 1 & 1 & 0 & 1 & 1 \\
\hline Cx. covagarciai & 0 & 1 & 0 & 1 & 1 & 0 & 0 & 1 & 0 & 3 & 0 & 1 & 1 & 1 & 0 & $?$ & 1 \\
\hline Cx. curvibrachius & 0 & 1 & 0 & 1 & 0 & 0 & 0 & 1 & 0 & 0 & 0 & 1 & 1 & 1 & 1 & 0 & 1 \\
\hline Cx. cuyanus & 0 & 1 & 1 & 1 & 0 & 0 & 0 & 1 & 0 & 3 & 0 & 1 & 1 & 0 & 01 & 0 & 1 \\
\hline Cx. declarator & 0 & 1 & 0 & 1 & 0 & 0 & 0 & 1 & 0 & 1 & 0 & 1 & 1 & 1 & 0 & 0 & 1 \\
\hline Cx. diplophyllum & 1 & 1 & 1 & 1 & 0 & 0 & 0 & 1 & 0 & 3 & 0 & 1 & 1 & 1 & 1 & $?$ & 1 \\
\hline Cx. dolosus & 0 & 1 & 1 & 1 & 0 & 0 & 0 & 1 & 0 & 3 & 0 & 1 & 1 & 1 & 1 & 0 & 1 \\
\hline Cx. eduardoi & 0 & 1 & 1 & 1 & 0 & 0 & 0 & 1 & 0 & 3 & 0 & 1 & 1 & 1 & 1 & 0 & 1 \\
\hline$C x$. fernandezi & 0 & 1 & 1 & 0 & - & 0 & 0 & 1 & 0 & 3 & 0 & 1 & 1 & 1 & 0 & 0 & 1 \\
\hline Cx. foliaceus & 0 & 1 & 1 & 1 & 0 & 0 & 0 & 1 & 0 & 3 & 0 & 1 & 1 & 1 & 0 & 0 & 1 \\
\hline Cx. guayasi & 0 & 1 & 0 & 1 & 1 & 0 & 0 & 1 & 1 & - & 1 & 1 & 1 & 0 & 1 & 0 & 1 \\
\hline$C x$. habilitator & 0 & 1 & 0 & $?$ & $?$ & $?$ & $?$ & 1 & 0 & 0 & 0 & 1 & 1 & 0 & 0 & 0 & 2 \\
\hline$C x$. inflictus & 0 & 1 & 1 & 1 & 0 & 0 & 0 & 1 & 0 & 3 & 0 & 1 & 1 & 1 & 0 & 0 & 2 \\
\hline$C x$. interfor & 0 & 0 & - & 0 & - & 0 & 0 & 1 & 0 & 1 & 0 & 1 & 1 & 1 & 0 & 1 & 1 \\
\hline Cx. lahillei & 0 & 1 & 1 & 1 & 0 & 0 & 0 & 1 & 0 & 3 & 0 & 1 & 1 & 1 & 0 & 1 & 2 \\
\hline Cx. levicastilloi & 0 & 1 & 0 & 1 & 0 & 0 & 0 & 1 & 0 & 3 & 0 & 1 & 1 & 1 & 1 & 0 & 1 \\
\hline Cx. lygrus & 0 & 1 & 1 & 1 & 0 & 0 & 0 & 1 & 0 & 3 & 0 & 1 & 1 & 1 & 0 & 0 & 1 \\
\hline Cx. maracayensis & 0 & 1 & 1 & 0 & - & 1 & 1 & 1 & 0 & 3 & 0 & 1 & 1 & 1 & 1 & 1 & 1 \\
\hline Cx. mauesensis & 0 & 0 & - & 1 & 0 & 0 & 0 & 1 & 0 & 3 & 0 & 1 & 1 & 1 & 0 & 0 & 1 \\
\hline$C x \cdot \operatorname{maxi}$ & 0 & 1 & 0 & 1 & 1 & 0 & 0 & 1 & 0 & 3 & 0 & 1 & 1 & 1 & 1 & 1 & 1 \\
\hline Cx. mollis & 0 & 1 & 0 & 2 & - & 0 & 0 & 1 & 0 & 3 & 0 & 1 & 1 & 1 & 1 & 0 & 1 \\
\hline$C x$. nigripalpus & 0 & 1 & 0 & 1 & 0 & 0 & 0 & 1 & 0 & 3 & 0 & 1 & 1 & 1 & 0 & 0 & 2 \\
\hline Cx. ousqua & 0 & 1 & 0 & 1 & 1 & 0 & 0 & 1 & 0 & 3 & 0 & 1 & 1 & 1 & 0 & 1 & 1 \\
\hline Cx. paramaxi & 0 & 1 & 0 & 1 & 1 & 0 & 0 & 1 & 0 & 3 & 0 & 1 & 1 & 1 & 1 & 1 & 1 \\
\hline Cx. pipiens & 0 & 1 & 0 & 1 & 0 & 0 & 0 & 1 & 0 & 0 & 0 & 1 & 1 & 1 & 0 & 0 & 1 \\
\hline Cx. plicatus & 2 & 1 & 0 & 1 & 0 & 0 & 0 & 1 & 0 & 0 & 0 & 1 & 1 & 1 & 0 & 0 & 1 \\
\hline Cx. quinquefasciatus & 0 & 1 & 0 & 1 & 0 & 0 & 0 & 1 & 0 & 0 & 0 & 1 & 1 & 1 & 0 & 0 & 1 \\
\hline Cx. quitensis & 0 & 0 & - & 1 & 0 & 0 & 0 & 1 & 0 & 3 & 0 & 1 & 1 & 1 & 1 & 0 & 1 \\
\hline Cx. renatoi & 0 & 1 & 0 & 1 & 0 & 0 & 1 & 1 & 0 & 3 & 0 & 0 & 1 & 0 & 0 & 0 & 1 \\
\hline Cx. riojanus & 0 & 1 & 1 & 1 & 0 & 0 & 0 & 1 & 0 & 3 & 0 & 1 & 1 & 1 & 0 & 0 & 1 \\
\hline Cx. saltanensis & 0 & 1 & 1 & 1 & 0 & 0 & 0 & 1 & 0 & 3 & 0 & 1 & 1 & 1 & 1 & 1 & 1 \\
\hline Cx. scheuberi & 0 & 1 & 0 & 1 & 0 & 0 & 0 & 1 & 0 & 3 & 0 & 1 & 1 & 0 & 0 & 0 & 1 \\
\hline$C x$. sitiens & 2 & 0 & - & 0 & - & 1 & 2 & 1 & 1 & - & 0 & 0 & 1 & 1 & 0 & 1 & 2 \\
\hline Cx. spinosus & 0 & 1 & 1 & 1 & 0 & 0 & 0 & 1 & 0 & 3 & 0 & 1 & 1 & 1 & 0 & 0 & 1 \\
\hline$C x$. surinamensis & 0 & 1 & 0 & 1 & 0 & 0 & 0 & 1 & 0 & 3 & 0 & 1 & 1 & 1 & 1 & 0 & 1 \\
\hline Cx. tatoi & 1 & 1 & 0 & 2 & - & 0 & 0 & 1 & 0 & 3 & 0 & 1 & 1 & 1 & 1 & 0 & 1 \\
\hline Cx. thriambus & 0 & 1 & 0 & 0 & - & 1 & 2 & 1 & 0 & 3 & 0 & 1 & 1 & 1 & 0 & 0 & 1 \\
\hline Cx. tritaeniorhynchus & 0 & 1 & 0 & 0 & - & 1 & 2 & 1 & 0 & 3 & 0 & 1 & 1 & 1 & 1 & 0 & 2 \\
\hline Cx. usquatissimus & 0 & 1 & 0 & 1 & 1 & 0 & 0 & 1 & 0 & 3 & 0 & 1 & 1 & 1 & 0 & 1 & 1 \\
\hline CX. usquatus & 0 & 1 & 0 & 1 & 1 & 0 & 0 & 1 & 0 & 3 & 0 & 1 & 1 & 1 & 0 & 1 & 1 \\
\hline Cx. vishnui & 1 & 1 & 0 & 0 & - & 1 & 2 & 1 & 0 & 3 & 0 & 1 & 1 & 1 & 0 & 0 & 2 \\
\hline
\end{tabular}


Regarding the internal relationships of the subgenus Culex, the polyphyly described above is consistent with the studies of other authors. Miller et al. (1996) discussed the evolutionary relationships of species of the subgenus Culex and noted that the Pipiens Group appears to be polyphyletic, suggesting that the Sitiens Group (Old World) is more closely related to New World members of the Pipiens Group than to Old World members. The nonmonophyly of the subgenus was found also by St. John (2007), who found that the subgenus Culex is paraphyletic and the relationships between the Decens, Pipiens and Sitiens Subgroups, relative to the subgenera Oculeomyia and Kitzmilleria Danilov, were poorly resolved.

According to our results, in agreement with Harbach (2011b), the internal classification of the subgenus Culex is in a chaotic condition. The Pipiens Group is polyphyletic relative to the Sitiens and Coronator Groups and the Coronator Group is polyphyletic relative to the Pipiens Group (Fig. 32). In disagreement with our study, the Pipiens Group did appear as monophyletic in the phylogeny of Harbach et al. (2012), but, unfortunately, no species of the Coronator Group were included in their analysis.

Because of the unknown life stages for many species and the amount of missing data, it is premature to propose nomenclatural changes. The fact that some characters were coded as '?' may explain the unresolved topology, even though just three were unstable taxa and nine were coded as '?' in many characters. Like other phylogenetic studies of mosquitoes based on morphological data our data set shows a high degree of homoplasy. Monophyly of some groups is supported by a combination of homoplastic characters, as was the subgenus Phytotelmatomyia in Rossi and Harbach (2008); however, in the present study there was not a unique combination of characters supporting the subgenus Culex as a distinct lineage.

The non-monophyly of the subgenus Culex means that phylogenetically unrelated groups are included. Much remains to be learned about species of the subgenus Culex, especially in relation to unknown life stages. Like any large group, the subgenus includes several polymorphic features and exceptional forms (Harbach 2007), and females are very similar. The subgenus has been retained solely as a 'taxon of convenience' (Harbach et al. 2012). When a group is recognized as non-monophyletic, it is in general justifiable to reclassify it in order to ensure their natural affinities in the classification. To obtain a better understanding of the phylogenetic relationships of the subgenus Culex, analyses of molecular characters may be necessary. Description of unknown life stages of $C x$. scheuberi is also needed to evaluate if the phylogenetic signal from these life stages is congruent with that from the male genitalia, and differing from the pattern in the subgenus Culex. If so, $C x$. apicinus and $C x$. scheuberi should be included in the subgenus Phalangomyia Dyar \& Knab, which must be resurrected from synonymy with the genus Culex. Phalangomyia was proposed as a subgenus by Dyar (1928) to group Cx. apicinus, Cx. debilis Dyar \& Knab and $C x$. escomeli Brèthes. Furthermore, deciphering the relationships between $C x$. maxi, $C x$. paramaxi and $C x$. brevispinosus of the Coronator group will require description of the unknown life stages of $C x$. paramaxi and the addition of missing data for $C x$. brevispinosus and $C x$. covagarciai.

In the absence of attendant DNA sequence data and because much remains to be learned about species of the subgenus, we recommend against any proposed formal changes to the classification of Culex (Culex).

\section{Acknowledgements}

We are indebted to the following institutions, and their curators, for generously providing specimens or photographs: Centro de Investigaciones Entomológicas (S.I. Molina), the Administración Nacional de Laboratorios e Instituto de Salud 'Dr. Carlos G. Malbrán' (F. Crespo), Centro de Estudios Parasitológicos y de Vectores (G.C. Rossi), Fundación e Instituto Miguel Lillo (G.L. Claps), Departamento de Epidemiología, Faculdade de Saúde Pública (M.A. Mureb Sallum) and National Museum of Natural History (R.C. Wilkerson). We thank G.C. Rossi for providing the photographs included in the Figures 3,13B, 14, 15, 17, 20B, 27A, 30A and 31A. This study was partially funded by grants from FONCYT (BID 1728/OC-AR PICT 38060) and CONICET (PIP 2010-2012). The authors are members of CONICET.

\section{References}

Belkin, J.N. (1962) The Mosquitoes of the South Pacific (Diptera, Culicidae). California University Press, Berkeley and Los Angeles, 608pp. 
Bram, R.A. (1967) Classification of Culex subgenus Culex in the New World (Diptera: Culicidae). Proceedings of the United States National Museum, Washington, $122 \mathrm{pp}$.

Darsie, R.F. Jr. (1985) The mosquitoes of Argentina: Part I. Keys for identification of adult females and fourth stage larvae in English and Spanish (Diptera: Culicidae). Mosquito Systematics, 17, 153-253.

Demari-Silva, B., Tavares Vesgueiro, F., Mureb Sallum, M.A. \& Toledo Marrelli, M. (2011) Taxonomic and phylogenetic relationships between species of the genus Culex (Diptera: Culicidae) from Brazil inferred from the cytochrome $c$ oxidase I mitochondrial gene. Journal of Medical Entomology, 48, 272-279. http://dx.doi.org/10.1603/me09293

Dyar, H.G. (1928) The Mosquitoes of the Americas. Carnegie Institute Washington Publishing, Washington D.C., 616 pp.

Forattini, O.P. (2002) Culicidologia Médica. Editora da Universidad de São Paulo, São Paulo, 860 pp.

Goloboff, P. \& Farris, J.S. (2001) Methods for quick consensus estimation. Cladistics 17, 26-34. http://dx.doi.org/10.1111/j.1096-0031.2001.tb00102.x

Goloboff, P., Farris, J., Källersjö, M., Oxelmann, B., Ramírez, M. \& Szumik, C. (2003) Improvements to resampling measures of group support. Cladistics, 19, 324-332. http://dx.doi.org/10.1111/j.1096-0031.2003.tb00376.x

Goloboff, P., Farris, J. \& Nixon, K. (2008a) Tree Analysis Using New Technology. 1.1. Available from http://www.zmuc.dk/ public/phylogeny/tnt (July 2012).

Goloboff, P., Carpenter J.C., Arías J.S. \& Miranda Esquivel, D.R. (2008 b) Weighting against homoplasy improves phylogenetic analysis of morphological datasets. Cladistics, 24, 758-773.

Harbach, R.E. (1988) The mosquitoes of the subgenus Culex in southwestern Asia and Egypt (Diptera: Culicidae). Contributions of the American Entomological Institute, 24, 6-240.

Harbach, R.E. (2007) The Culicidae (Diptera): a review of taxonomy clasification and phylogeny. Zootaxa, 1668, 591-638.

Harbach, R.E. (2011a) Mosquito Taxonomic Inventory, Available from: http://mosquito-taxonomic-inventory.info/ (Accessed 1 January 2012).

Harbach, R.E. (2011b) Classification within the cosmopolitan genus Culex (Diptera: Culicidae): The foundation for molecular systematics and phylogenetic research. Acta Tropica, 120, 1-14. http://dx.doi.org/10.1016/j.actatropica.2011.06.005

Harbach, R.E. \& Kitching, I.J. (1998) Phylogeny and classification of the Culicidae (Diptera). Systematic Entomology, 23, 327-370. http://dx.doi.org/10.1046/j.1365-3113.1998.00072.x

Harbach, R.E. \& Peyton, E.L. (1992) A new subgenus of Culex in the Neotropical Region (Diptera: Culicidae). Mosquito Systematics, 24, 242-252.

Harbach, R.E., Peyton, E.L. \& Harrison, B.A. (1984) A New Species of Culex (Melanoconion) from Southern South America (Diptera: Culicidae). Mosquito Systematics, 16, 185-200.

Harbach, R.E, Kitching, I.J., Culverwell, L.C., Dubois, J. \& Linton, Y.M. (2012) Phylogeny of mosquitoes of tribe Culicini (Diptera: Culicidae) based on morphological diversity. Zoologica Scripta, 41, 499-514. http://dx.doi.org/10.1111/j.1463-6409.2012.00546.x

Isoe, J. (2000) Chapter 6: Phylogenetic relationships of mosquitoes based on vitellogenin gene sequence analysis. In: Comparative Analysis of the Vitellogenin Genes of the Culicidae. PhD Thesis, Faculty of the Interdisciplinary Program in Insect Science, The University of Arizona.

Lane, J. \& Ramalho, G.R. (1960) A new neotropical Culex. Revista brasileira de Entomología, 9, 173-176.

Laurito, M., Almirón, W.R. \& Rossi, G.C. (2009) Morphological redescription of the immature and adult stages of Culex (Culex) acharistus Root (Diptera: Culicidae). Zootaxa, 2263, 21-30.

Laurito, M., Almirón, W.R. \& Rossi, G.C. (2011) Description of the immature stages and redescription of the adults of Culex (Culex) lahillei Bachmann \& Casal (Diptera: Culicidae). Zootaxa, 2915, 29-38.

Maddison, W.P \& Maddison, D.R. (2010) Mesquite 2.75. Available from http://mesquiteproject.org. (January 2012)

Mallampalli, V.L. (1995) Phylogenetics relationships among taxa in the genus Culex, and the phylogenetics relationships of vectors of New World alphaviruses in the subgenus Melanoconion (Diptera: Culicidae). Ph. thesis, University of Maryland, $500 \mathrm{pp}$.

Miller, B., Crabtree, M. \& Savage, H. (1996) Phylogenetic relationships of the Culicomorpha inferred from $18 \mathrm{~S}$ and 5.8S ribosomal DNA sequences (Diptera: Nematocera). Insect Molecular Biology, 6, 105-114. http://dx.doi.org/10.1111/j.1365-2583.1997.tb00078.x

Navarro, J.C. \& Liria, J. (2000) Phylogenetic relationships among eighteen Neotropical Culicini species. Journal of the American Mosquito Control Association, 16, 75-85.

Reinert, J.F., Harbach, R.E. \& Kitching, I.J. (2004) Phylogeny and classification of Aedini (Diptera: Culicidae), based on morphological characters of all life stages. Zoological Journal of the Linnean Society, 142, 289-368. http://dx.doi.org/10.1111/j.1096-3642.2004.00144.x

Reinert, J.F., Harbach, R.E. \& Kitching, I.J. (2008) Phylogeny and classification of Ochlerotatus and allied taxa (Diptera: Culicidae: Aedini) based on morphological data from all life stages. Zoological Journal of the Linnean Society, 153, 29114. http://dx.doi.org/10.1111/j.1096-3642.2008.00382.x 
Reinert, J.F., Harbach, R.E. \& Kitching, I.J. (2009) Phylogeny and classification of tribe Aedini (Diptera: Culicidae). Zoological Journal of the Linnean Society, 157, 700-794. http://dx.doi.org/10.1111/j.1096-3642.2009.00570.x

Rossi, G.C. \& Harbach, R.E. (2008) Phytotelmatomyia, a new Neoropical subgenus of Culex (Diptera: Culicidae). Zootaxa, $1879,1-17$.

Rossi, G.C., Laurito, M. \& Almirón, W.R. (2008) Morphological description of the pupa and redescription of the adults and larva of Culex (Culex) apicinus Philippi (Diptera: Culicidae). Zootaxa, 1941, 31-42.

Rossi, G.C., Scheibler, E. \& Dominguez, M.C. (2006) Morphological descriptions of the female, pupa, and larva of Culex (Culex) cuyanus Duret (Diptera: Culicidae). Zootaxa, 1165, 47-55.

Sirivanakarn, S. (1976) Medical entomology studies - III. A revision of the subgenus Culex in the Oriental Region (Diptera: Culicidae). Contributions of the American Entomological Institute, 12, 1-272.

St. John, O. (2007) Phylogeny of the genus Culex (Diptera: Culicidae). MRes thesis, Imperial College, London.

Vesgueiro, F.T., Demari-Silva, B., dos Santos Malafronte, R., Mureb Sallum, M.A. \& Toledo Marrelli, M. (2011) Intragenomic variation in the second internal transcribed spacer of the ribosomal DNA of species of the genera Culex and Lutzia (Diptera: Culicidae). Memórias do Instituto Oswaldo Cruz, 106, 1-8.

http://dx.doi.org/10.1590/S0074-02762011000100001 
APPENDIX. Character state changes $(K=7)$ common to the RSCT obtained with $\mathrm{K}=6-9$. The node numbers correspond to those in Figure 32. Character changes are not listed for terminal taxa.

\begin{tabular}{|c|c|c|c|}
\hline Node 63 & Ch. 28: $0 \rightarrow 1$ & Node 83 & Node 95 \\
\hline Ch. $8: 2 \rightarrow 1$ & Ch. $31: 1 \rightarrow 2$ & Ch. 71: $1 \rightarrow 0$ & Ch. $8: 1 \rightarrow 2$ \\
\hline \multirow[t]{2}{*}{ Ch. 27: $1 \rightarrow 0$} & Ch. 33: $0 \rightarrow 1$ & & Ch. 49: $0 \rightarrow 1$ \\
\hline & Ch. 55: $1 \rightarrow 2$ & Node 84 & Ch. $80: 0 \rightarrow 1$ \\
\hline Node 64 & Ch. 91: $0 \rightarrow 1$ & Ch. $72: 1 \rightarrow 0$ & \\
\hline Ch. 61: $0 \rightarrow 1$ & Ch. 92: $0 \rightarrow 1$ & Ch. 73: $1 \rightarrow 0$ & Node 96 \\
\hline Ch. 86: $0 \rightarrow 1$ & & & Ch. 29: $1 \rightarrow 0$ \\
\hline Ch. 89: $1 \rightarrow 0$ & Node 73 & Node 85 & \\
\hline \multirow[t]{2}{*}{ Ch. 93: $0 \rightarrow 1$} & Ch. $0: 0 \rightarrow 1$ & Ch. $8: 1 \rightarrow 0$ & Ch. $80: 0 \rightarrow 1$ \\
\hline & Ch. $2: 0 \rightarrow 1$ & Ch. 18: $1 \rightarrow 0$ & \\
\hline Node 65 & Ch. 5: $0 \rightarrow 1$ & Ch. 76: $0 \rightarrow 1$ & Node 97 \\
\hline Ch. 4: $0 \rightarrow 2$ & Ch. 10: $0 \rightarrow 1$ & & Ch. $45: 1 \rightarrow 0$ \\
\hline Ch. 14: $1 \rightarrow 2$ & Ch. $11: 3 \rightarrow 1$ & Node 86 & Node 98 \\
\hline Ch. $41: 0 \rightarrow 1$ & Ch. $30: 0 \rightarrow 1$ & Ch. 20: $2 \rightarrow 3$ & Ch. $82: 0 \rightarrow 1$ \\
\hline Ch. $44: 1 \rightarrow 0$ & Ch. 38: $1 \rightarrow 0$ & Ch. 44: $1 \rightarrow 0$ & \\
\hline Ch. 62: $1 \rightarrow 0$ & Ch. 40: $1 \rightarrow 0$ & & Node 99 \\
\hline Ch. $75: 1 \rightarrow 0$ & Ch. $75: 0 \rightarrow 1$ & Node 87 & Ch. $0: 2 \rightarrow 1$ \\
\hline \multirow[t]{2}{*}{ Ch. 94: $1 \rightarrow 2$} & & Ch. 38: $0 \rightarrow 2$ & Ch. $12: 2 \rightarrow 1$ \\
\hline & Node 75 & Ch. 74: $0 \rightarrow 1$ & Ch. 32: $0 \rightarrow 2$ \\
\hline Node 66 & Ch. 39: $1 \rightarrow 0$ & Ch. 77: $0 \longrightarrow 1$ & Ch. $40: 0 \rightarrow 1$ \\
\hline Ch. 8: $1 \rightarrow 2$ & Ch. $48: 0 \rightarrow 1$ & & Ch. $45: 1 \rightarrow 0$ \\
\hline Ch. 81: $1 \rightarrow 0$ & Ch. 58: $1 \rightarrow 0$ & Node 88 & Ch. 93: $0 \rightarrow 1$ \\
\hline Ch. 83: $0 \rightarrow 1$ & & Ch. 49: $0 \rightarrow 1$ & \\
\hline \multirow[t]{2}{*}{ Ch. 84: $0 \rightarrow 2$} & Node 76 & Ch. 50: $0 \rightarrow 1$ & Node 100 \\
\hline & Ch. 69: $0 \rightarrow 1$ & & Ch. 32: $2 \rightarrow 0$ \\
\hline Node 67 & Ch. $72: 1 \rightarrow 2$ & Node 89 & Ch. $78: 0 \rightarrow 1$ \\
\hline Ch. 55: $2 \rightarrow 0$ & Ch. 76: $0 \rightarrow 1$ & Ch. 0: $2 \rightarrow 1$ & \\
\hline \multirow{2}{*}{ Ch. 68: $0 \rightarrow 2$} & & Ch. 27: $1 \rightarrow 0$ & Node 101 \\
\hline & Node 77 & Ch. $80: 0 \rightarrow 1$ & Ch. 0: $2 \rightarrow 1$ \\
\hline Node 68 & Ch. $0: 2 \rightarrow 1$ & & Ch. 38: $0 \rightarrow 1$ \\
\hline Ch. 12: $1 \rightarrow 2$ & Ch. 19: $1 \rightarrow 2$ & Node 90 & Ch. $41: 0 \rightarrow 1$ \\
\hline Ch. 32: $2 \rightarrow 0$ & Ch. $30: 1 \rightarrow 0$ & Ch. 38: $0 \rightarrow 2$ & Ch. $87: 3 \rightarrow 0$ \\
\hline Ch. 34: $1 \rightarrow 0$ & & Ch. 43: $1 \rightarrow 0$ & \\
\hline \multirow[t]{2}{*}{ Ch. 92: $1 \rightarrow 0$} & Node 78 & Ch. 68: $0 \rightarrow 2$ & Node 102 \\
\hline & Ch. $24: 0 \rightarrow 1$ & Ch. 74: $0 \rightarrow 1$ & Ch. $41: 0 \rightarrow 1$ \\
\hline Node 69 & & & Ch. $43: 1 \rightarrow 0$ \\
\hline Ch. $0: 1 \rightarrow 2$ & Node 79 & Node 91 & Ch. $92: 0 \rightarrow 1$ \\
\hline \multirow[t]{2}{*}{ Ch. $5: 1 \rightarrow 0$} & Ch. $12: 2 \rightarrow 1$ & Ch. 48: $0 \rightarrow 2$ & \\
\hline & Ch. $82: 0 \rightarrow 1$ & & Node 103 \\
\hline Node 70 & & Node 92 & Ch. $80: 1 \rightarrow 0$ \\
\hline Ch. 11: $1 \rightarrow 0$ & & Ch. 94: $1 \rightarrow 2$ & Ch. $86: 0 \rightarrow 1$ \\
\hline \multirow[t]{2}{*}{ Ch. 68: $1 \rightarrow 0$} & Node 80 & & Ch. $88: 0 \rightarrow 1$ \\
\hline & Ch. 27: $1 \rightarrow 0$ & Node 93 & Ch. $92: 0 \rightarrow 1$ \\
\hline Node 71 & Ch. 46: $0 \rightarrow 1$ & Ch. $4: 0 \rightarrow 2$ & \\
\hline \multirow[t]{2}{*}{ Ch. 22: $1 \rightarrow 0$} & & Ch. 50: $0 \rightarrow 1$ & Node 104 \\
\hline & Node 81 & Ch. 63: $0 \rightarrow 1$ & Ch. 38: $0 \rightarrow 2$ \\
\hline Node 72 & Ch. 93: $0 \rightarrow 1$ & Ch. 66: $0 \rightarrow 2$ & Ch. $62: 1 \rightarrow 0$ \\
\hline Ch. 3: $0 \rightarrow 1$ & & Ch. 80: $0 \rightarrow 1$ & Ch. 66: $0 \rightarrow 1$ \\
\hline Ch. 13: $2 \rightarrow 1$ & Node 82 & & Ch. $79: 1 \rightarrow 0$ \\
\hline Ch. 16: $1 \rightarrow 0$ & Ch. 14: $1 \rightarrow 2$ & Node 94 & \\
\hline Ch. 26: $2 \rightarrow 0$ & Ch. 92: $0 \rightarrow 1$ & Ch. $94: 1 \rightarrow 2$ & Node 105 \\
\hline
\end{tabular}

